\title{
Drift Scale Modeling: Study of Unsaturated Flow into a Drift using a Stochastic Continuum Model
}

\author{
J.T. Birkholzer, C.F. Tsang, Y.W. Tsang, J.S.W. Wang
}

\author{
Earth Sciences Division \\ Ernest Orlando Lawrence Berkeley National Laboratory \\ University of California \\ Berkeley, CA 94720
}

September 1996

This work was prepared for the Office of Civilian Radioactive Waste Management, Yucca Mountain Project, through U.S. Department of Energy Contract Number DE-AC03-76SF00098. 


\section{DISCLAIMER}

This report was prepared as an account of work sponsored by an agency of the United States Government. Neither the United States Government nor any agency thereof, nor any of their employees, make any warranty, express or implied, or assumes any legal liability or responsibility for the accuracy, completeness, or usefulness of any information, apparatus, product, or process disclosed, or represents that its use would not infringe privately owned rights. Reference herein to any specific commercial product, process, or service by trade name, trademark, manufacturer, or otherwise does not necessarily constitute or imply its endorsement, recommendation, or favoring by the United States Government or any agency thereof. The views and opinions of authors expressed herein do not necessarily state or reflect those of the United States Government or any agency thereof. 


\section{DISCLAIMER}

Portions of this document may be illegible in electronic image products. Images are produced from the best available original document. 


\title{
Drift Scale Modeling: \\ Study of Unsaturated Flow into a Drift using a Stochastic Continuum Model
}

\author{
J. T. Birkholzer, C. F. Tsang, Y.W. Tsang, and J.S.W. Wang \\ $L B N L / E S D$
}

\begin{abstract}
Unsaturated flow in heterogeneous fractured porous rock was simulated using a stochastic continuum model (SCM). In this model, both the more conductive fractures and the less permeable matrix are generated within the framework of a single continuum stochastic approach, based on non-parametric indicator statistics. High-permeable fracture zones are distinguished from lowpermeable matrix zones in that they have assigned a long range correlation structure in prescribed directions. The SCM was applied to study small-scale flow in the vicinity of an access tunnel, which is currently being drilled in the unsaturated fractured tuff formations at Yucca Mountain, Nevada. Extensive underground testing is underway in this tunnel to investigate the suitability of Yucca Mountain as an underground nuclear waste repository. Different flow scenarios were studied in the present paper, considering the flow conditions before and after the tunnel emplacement, and assuming steady-state net infiltration as well as episodic pulse infiltration. Although the capability of the stochastic continuum model has not yet been fully explored, it has been demonstrated that the SCM is a good alternative model feasible of describing heterogeneous flow processes in unsaturated fractured tuff at Yucca Mountain.
\end{abstract}

\section{Introduction}

Recent interest in the emplacement of a potential nuclear waste repository in unsaturated fractured rock has stimulated a number of studies of flow and transport in unsaturated media. The U.S. Department of Energy is currently performing detailed investigations in the thick tuff formations at Yucca Mountain, Nevada, which are located approximately $200 \mathrm{~m}$ above the water table in partially saturated rock. Though the matrix permeability is very low, it is intensely fractured at the potential repository horizon in the Topopah Spring unit, and the fracture permeability is several orders of magnitude higher than the matrix permeability. Very strong capillary forces hold the water in the matrix pores while the fractures are essentially drained. Therefore, the large permeability of the fractures is available for liquid flow only in case of episodic infiltration pulses.

Many of the numerical studies performed to study flow and transport at Yucca Mountain are based on the Equivalent Continuum Model (ECM), which assumes a local equilibrium between 
fractures and matrix at any time (e.g. Pruess et al., 1990; Bodvarsson \& Bandurraga, 1996). However, the method is capable of taking into account the different hydraulic behavior in fractures and matrix by assigning different material properties to and calculating different flow rates for the two components. Other studies make use of the Double Porosity/Permeability Model (DKM), which assumes the coexistence of the fractures and the matrix media at every spatial location, with a flux transfer term connecting the two governing flow equations in the two overlapping continua representing the fractures and matrix blocks, respectively (e.g., Gerke \& van Genuchten, 1993). Both ECM and DKM are approximate methods based on the assumption of a continuous flow field. On a small scale, however, the assumption of continuity might be violated, and the discrete nature of fracture and matrix flow may become significant.

The present paper employs the so-called Stochastic Continuum Model (SCM), which is essentially a single continuum model with a wide variation in permeability (Tsang et al., in print). It allows for the generation of a heterogeneous permeability field in which large permeability areas are assigned large correlation lengths in prescribed orientations, while the remaining low permeability areas may have smaller correlation lengths. Thus, fracture zones can be made distinct from the matrix by imposing a long range correlation structure for a small fraction of the permeability in the preferred planes of fractures. With this method, the discrete nature of fracture and matrix flow is accounted for, while all portions of the fractured porous rock are described with the same generation approach for the entire heterogeneous field. The SCM conceptually differs from previous discrete models of fractured media (e.g. Endo et al., 1984; Schwartz \& Smith, 1988) in that the previous models consider only the fracture permeability, while the present model includes permeability contributions from both the fractures and the matrix in one single model.

We use the SCM to study unsaturated flow in a heterogeneous fractured porous medium around an underground tunnel, which is currently being drilled at the potential repository level at Yucca Mountain. The spatial scale of our model ("drift scale") lies between mountain scale and laboratory scale studies. While study at the laboratory scale is focused on the effect of fracture-matrix interchange, study at the mountain scale accounts for the effects of layering and faulting, which potentially give rise to lateral flow, fast flow through large features and interlayer ponding. A drift scale study, on the other hand, brings out the importance of heterogeneous features on the scale of meters in the Topopah Spring welded tuff formation, through which a drift has been constructed. The main interest is to calculate the flow velocities and their variations through the unsaturated fractured welded tuff into the drift for the evaluation of the waste canister environment. The temporal and spatial variation of these inflow fluxes are useful input for the performance assessment (PA) of the potential nuclear waste repository .

The numerical simulations are performed with the multi-component, multi-phase code TOUGH2 (Pruess, 1987, 1991). We activate one phase (liquid) and one component (water) flow under isothermal conditions, which means that Richards' equation is used for fluid flow with gas as bystander. Water saturation is variable in the medium and is related to the capillary pressure and relative permeability as given by the van Genuchten relationships (1980).

In the next two sections we shall describe the conceptual model used in this drift scale study, and explain how the field data from recent field tests and observations at Yucca Mountain were used 
in the construction of the model. Then calculations of spatial and temporal fluxes in the vicinity of and into the drift are presented for different simulation scenarios. A discussion of various issues based on these results concludes the paper.

\section{Conceptual Model}

The SCM is a single continuum model which is able to account for the discrete nature of flow in fracture/matrix systems. The permeability field is stochastically generated using a prescribed probability density function, with the permeability value in each model grid block representing either a high permeability fracture zone or a low permeability matrix zone. We followed the approach of Tsang et al. (in print) in which both the more conductive fractures and the less permeable matrix are generated within the framework of a single-continuum stochastic model based on non-parametric geostatistics (Gomez-Hernandez \& Srivastava, 1990). This approach differs from the parametric geostatistics in that it allows permeability distributions of any form, and can take different correlation structures for different intervals of permeability values.

A specific field site is being addressed to demonstrate the practical use of the method; it is the potential repository horizon in the Topopah Spring unit at Yucca Mountain, Nevada. In a previous study (Tsang et al., in print), the SCM has been successfully applied to the saturated fractured granit rock of Äspö Island, the site of the SKB (Swedish Nuclear Fuel and Waste Management Company) Hard Rock Laboratory in Sweden. However, the hydrogeological situation at Yucca Mountain is very different in that the potential repository horizon is located above the water table, in unsaturated rock. For the fractured porous tuff at Yucca Mountain, we hypothesize that the permeability probability distribution takes on two peaks separated by five or six orders of magnitude (see Section 3). The lower peak includes typical matrix permeability values, and the higher peak encompasses the typical fracture permeability values (see an example in Figure 1). The fractures are further distinguished from the matrix in that they have different correlation structures. One would assign a small isotropic'correlation length to the permeability values around the low permeability peak, and anisotropic correlation lengths to the values around the large fracture permeability values. The anisotropic correlation lengths would be large in prescribed directions, and small in the direction normal to it, where the prescribed directions are chosen according to the directions of fracture planes observed in the field. Generating the stochastic medium with these inputs yields a pattern of a heterogeneous distribution of permeabilities in the domain with a number of larger permeability values aligned in the fracture plane orientations. An example in $2 \mathrm{D}$ is shown in Figure 2. 


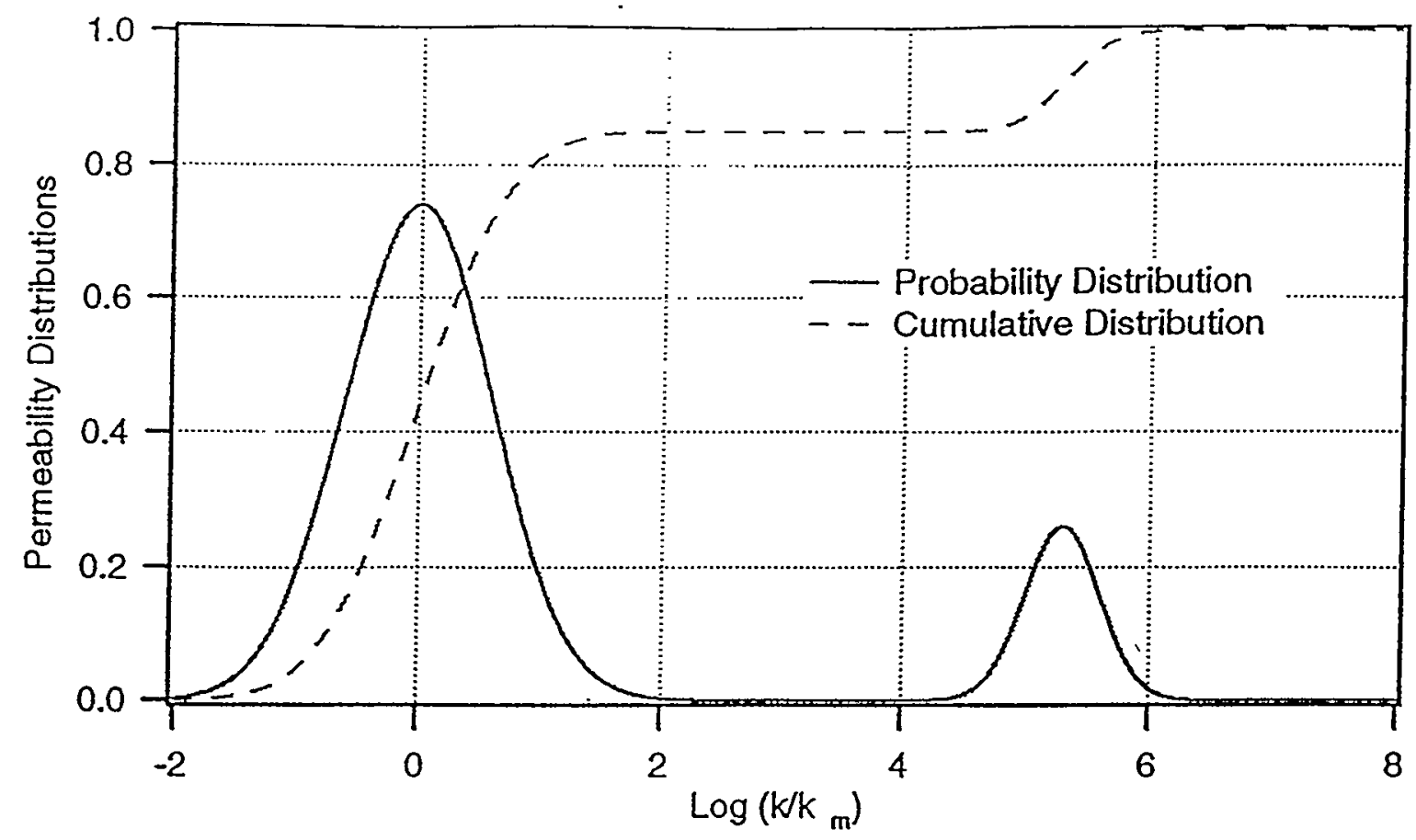

Figure 1 Example of a permeability probability distribution for a fractured porous medium (with $\mathrm{k}_{\mathrm{m}}$ : geometric mean of the matrix permeability values)

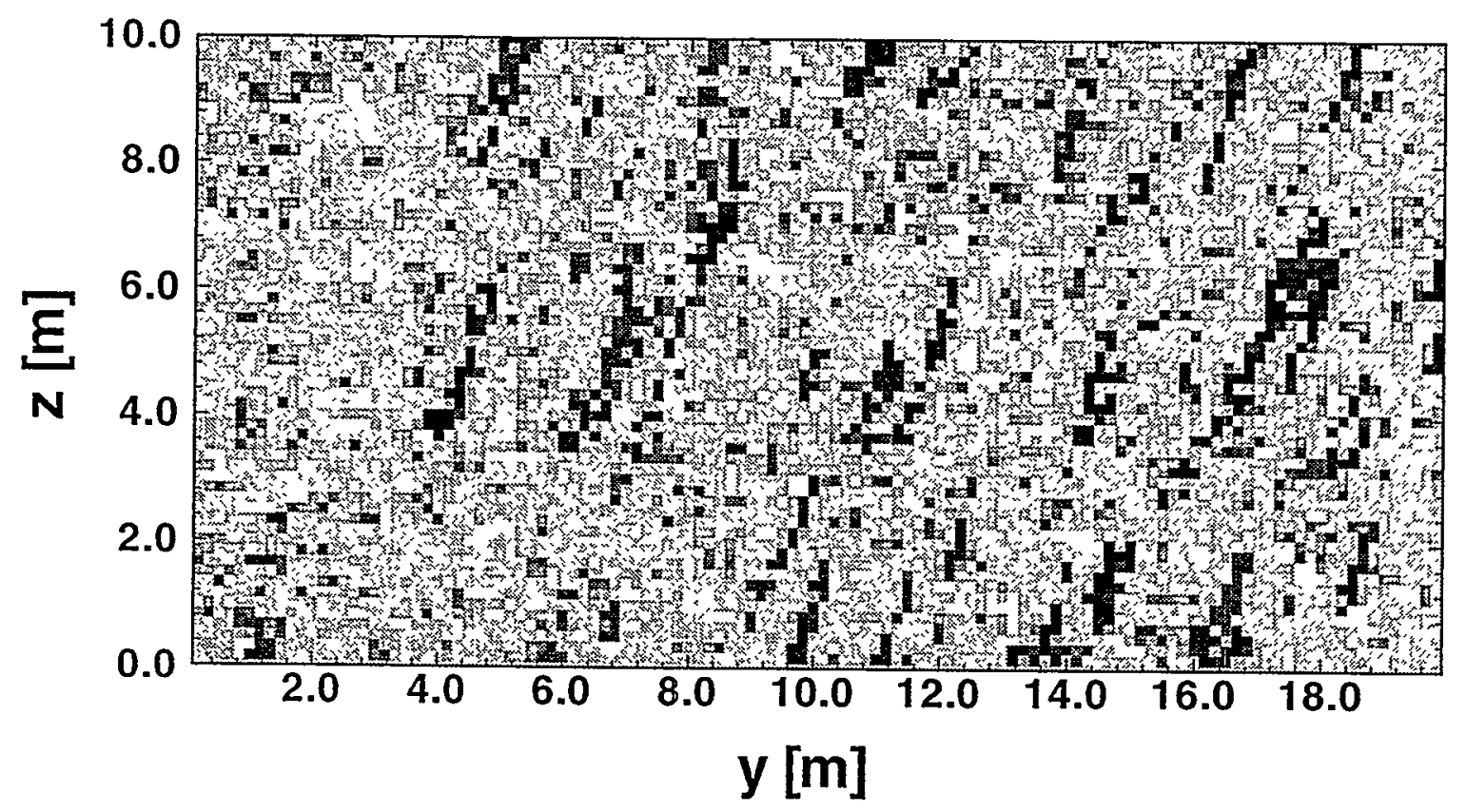

Figure $22 \mathrm{D}$ example of a permeability distribution of a fractured porous medium, based on the Stochastic Continuum Model (dark shading: high permeability, light shading: low permeability). The high permeability features are oriented at approximately $60^{\circ}$ to the $y$ - axis. 
The values for the parameters used in our modeling studies are chosen based on a careful review of recent experiments and modeling results at Yucca Mountain, namely:

1) Observation in the ESF near the Thermal Test Alcove

2) Observation in the Thermal Test Alcove

3) Air Injection Tests of May, 1996

4) LBNL/ÚSGSS Site-Scale Model

The fracture maps of the main ESF drift at the $2820 \mathrm{~m}$ to $2840 \mathrm{~m}$ section were reviewed. One notes the presence of dense, short fractures of lengths up to $3 \mathrm{~m}$ and spacing 2-3 $\mathrm{m}$ between fractures. Large fractures of lengths $7-8 \mathrm{~m}$ with $\sim 10 \mathrm{~m}$ spacing are also observed. Both sets are approximately east-west trending and have dip angles of $70^{\circ}-80^{\circ}$.

In the Thermal Test Alcove, the tunnel boring has exposed three surfaces of a block approximately $15 \mathrm{~m}$ wide. Twenty seven instrument boreholes were drilled into the block for thermal testing (Tsang et al., 1996). Video pictures of the borehole walls and fracture maps of the three surfaces of the block show two sub-vertical fracture sets, one at NS direction with approximately $90^{\circ}$ dip angle and the other at E20 $\mathrm{N}$ direction with approximately $70^{\circ}$ dip angle (Mitchell, 1996). A series of air injection tests were carried out in the boreholes in the Thermal Test Alcove (Tsang et al., 1996). These involved setting packers in each of the boreholes and observing pressure responses in them when one of the boreholes was pressurized. The derived permeabilities from these tests range from $5.2 \times 10^{-12} \mathrm{~m}^{2}$ to $5 \times 10^{-15} \mathrm{~m}^{2}$. The former number is probably associated with fractures which dominate flow in that particular borehole and the latter may reflect a combination of matrix permeability and permeability of smaller fractures. It is also noted that strong variations in permeability occur between two boreholes separated by only $1 \mathrm{~m}$, suggesting that the correlation length of the permeability may be of that order.

Based on the above information, we decided to set the mean permeability value for the fracture peak, $\mathrm{k}_{\mathrm{f}}$, to be $10^{-12} \mathrm{~m}^{2}$. The permeability values around this fracture peak have an exponential correlation structure with a correlation parameter of $4 \mathrm{~m}$ prescribed for two orientations, NS vertically (i.e. $90^{\circ} \mathrm{dip}$ ) and $\mathrm{E} 20^{\circ} \mathrm{N}$ with $70^{\circ} \mathrm{dip}$, respectively. (Note that, for an exponential correlation structure, the range of correlation can be as large as three times the correlation parameter.) For the low permeability matrix blocks, the correlation structure is spherical with a correlation length of $1 \mathrm{~m}$. The mean matrix permeability, $\mathrm{k}_{\mathrm{m}}$, was taken to be the same as given by the 1995 Site-Scale Model report (Wittwer et al., 1995: Model Sub-Layer 3.4), which is $5 \mathrm{x}$ $10^{-18} \mathrm{~m}^{2}$. This is to be compared with $2 \times 10^{-18} \mathrm{~m}^{2}$ used in the recent TSPA work (Wilson et al., 1994). We have kept in contact with the Site-Scale Modeling Group at LBNL and received input from them on the most up-to-date parameter values based on calibration against data. However, since recent changes have not yet been incorporated in a citable reference, we have stayed with the values given by Wittwer et al. (1995). We have done a preliminary sensitivity study of the results on alternative permeability values, which will be presented in Section 6.1. We also follow Wittwer et al. (1995) in assuming the average matrix porosity, $\theta_{\mathrm{m}}$, of the Topopah Spring unit to 
be $14 \%$. The porosity of the fracture areas, $\theta_{\mathrm{f}}$, is set to $0.1 \%$. Parameters used are shown in Table 1. We plan continuing work to be based on the new Site-Scale Model being developed (Bodvarsson \& Bandurraga, in progress), together with insights from other related studies.

In our model, we also need the percentage of values under the respective fracture and matrix peaks in the permeability probability function. Furthermore, the spread of values around the mean permeabilities is needed. No hard data are available for these quantities. Since we expect the fractures to take up a smaller fraction of the rock volume, we attribute about $23 \%$ of the grid blocks to have the larger permeabilities, while the majority (77\%) of the permeability values is assigned to the low permeability matrix peak. Then, with the porosity of the fracture areas set to $0.1 \%$, the total continuum porosity of the fractures amounts to $0.023 \%$. The standard deviations in $\log _{10}$ of permeability, $\sigma$, are assumed to be 0.6 and 0.3 for the matrix peak and the fracture peak, respectively.

Additional parameters required for the calculations are the van Genuchten parameters that correlate saturation with the capillary pressure and the relative permeability. The relevant equations (van Genuchten, 1980) are:

$$
\begin{gathered}
\mathrm{P}_{\text {cap }}=-1 / \alpha\left\{\left(\mathrm{S}_{\mathrm{e}}\right)^{-\frac{1}{\mathrm{~m}}}-1\right\}^{\frac{1}{\beta}} \\
\mathrm{k}_{\mathrm{r}}=\left(\mathrm{S}_{\mathrm{e}}\right)^{\frac{1}{2}}\left\{1-\left(1-\left(\mathrm{S}_{e}\right)^{\frac{1}{m}}\right)^{\mathrm{m}}\right\}^{2}
\end{gathered}
$$

with

$\begin{array}{lll}\mathrm{P}_{\text {cap }}= & \text { capillary pressure } \\ \mathrm{k}_{\mathrm{r}}= & \text { relative permeability } \\ \mathrm{S}_{\mathrm{e}}= & \left(\mathrm{S}-\mathrm{S}_{\mathrm{r}}\right) /\left(1-\mathrm{S}_{\mathrm{r}}\right)=\text { effective saturation } \\ \mathrm{S}_{\mathrm{r}}= & \text { residual saturation } \\ 1 / \alpha= & \text { capillary scaling factor } \\ \beta & =\text { pore size distribution coefficient } \\ \mathrm{m} & =(1-1 / \beta) \text { (after Mualem, 1978) }\end{array}$

A different capillary curve is assigned to each permeability value in the heterogeneous continuum through the multiplicative capillary scaling factor, $1 / \alpha$, in equation (1). This capillary scaling factor is assumed to be inversely proportional to the square root of the local absolute permeability (Leverett, 1941), with the reference values given in Table 1. Hence, high-permeable areas ("fracture peak") are associated with low capillary suction, while low permeable areas ("matrix peak") are associated with strong capillary suction.

The values for $\beta$ and $m$ of the matrix peak are taken from the Site-Scale Model (Wittwer et al., 1995) as shown in Table 1 . The $\beta$ and $\mathrm{m}$ parameters for the fractures are assumed to be the same as in the matrix, which coincides with newest calibration results from the Site-Scale Model. Residual saturation in the matrix, $\mathrm{S}_{\mathrm{r}, \mathrm{m}}$, was estimated as 0.2 , which is also in the range of recent 
Site-Scale Model calibration results. The fracture residual saturation, $S_{\mathrm{r}, \mathrm{f}}$, was arbitrarily set to the same value as in the matrix.

For illustration, the van Genuchten relationships with these parameters are shown in Figure 3 and Figure 4.

Table 1: Material properties

\begin{tabular}{|c|c|c|c|c|}
\hline \multirow{2}{*}{\multicolumn{5}{|c|}{$\begin{array}{l}\text { Material Properties } \\
\text { Matrix Peak ( } 77 \% \text { of all permeability values) }\end{array}$}} \\
\hline & & & & \\
\hline \multirow[t]{2}{*}{$\mathrm{k}_{\mathrm{m}}$} & $=$ & $5 \times 10^{-18} \mathrm{~m}^{2}$ (geom. Mean) & $\Rightarrow$ & Site-Scale Model, Sub- Layer 3.4 \\
\hline & & & & (Wittwer et al., 1995) \\
\hline$\sigma_{\mathrm{k}, \mathrm{m}}$ & $=$ & 0.6 & $\Rightarrow$ & (assumed) \\
\hline$\theta_{\mathrm{m}}$ & $=$ & $14 \%$ & $\Rightarrow$ & $\begin{array}{l}\text { Site-Scale Model, Sub- Layer } 3.4 \\
\text { (Wittwer et al., 1995) }\end{array}$ \\
\hline \multicolumn{5}{|c|}{ Fracture Peak ( $23 \%$ of all permeability values) } \\
\hline $\mathrm{k}_{\mathrm{f}}$ & $=$ & $10^{-12} \mathrm{~m}^{2}$ (geom. Mean) & \multicolumn{2}{|c|}{$\begin{array}{r}\text { ESF - Air Permeability Tests } \\
\text { (Tsang et al., 1996) }\end{array}$} \\
\hline$\sigma_{k, f}$ & $=$ & 0.3 & $\Rightarrow$ & (assumed) \\
\hline$\theta_{\mathrm{f}}$ & $=$ & $0.1 \%$ & $\Rightarrow$ & (assumed) \\
\hline \multicolumn{5}{|c|}{ Parameters for van Genuchten functions } \\
\hline \multicolumn{5}{|c|}{ Matrix Peak } \\
\hline $1 / \alpha_{m}$ & $=$ & $752 \mathrm{KPa}$ & $\Rightarrow$ & $\begin{array}{l}\text { Site-Scale Model, Sub-Layer } 3.4 \\
\text { (Wittwer et al., 1995) }\end{array}$ \\
\hline$\beta_{m}$ & $=$ & 1.33 & $\Rightarrow$ & $\begin{array}{l}\text { Site-Scale Model, Sub-Layer } 3.4 \\
\text { (Wittwer et al., 1995) }\end{array}$ \\
\hline$S_{r, m}$ & $=$ & 0.2 & $\Rightarrow$ & (assumed) \\
\hline \multicolumn{5}{|c|}{ Fracture Peak } \\
\hline $1 / \alpha_{f}$ & $=$ & $1.68 \mathrm{KPa}$ & $\Rightarrow$ & from: $\cdot \cdot_{1} / \bullet_{2}=\left(\mathrm{k}_{1} / \mathrm{k}_{2}\right)^{0.5}$ \\
\hline$\beta_{f}$ & $=$ & 1.33 & $\Rightarrow$ & (assumed) \\
\hline$S_{r, f}$ & $=$ & 0.2 & $\Rightarrow$ & (assumed) \\
\hline Note: & \multicolumn{4}{|c|}{$\begin{array}{l}\mathrm{k} \text { denotes the saturated permeability, and } \sigma_{\mathrm{k}} \text { denotes the standard deviation in } \log 10 \text { of the saturated } \\
\text { permeability. } \theta \text { denotes porosity. The subscripts } \mathrm{m} \text { and } \mathrm{f} \text { indicate matrix and fracture properties, respec- } \\
\text { tively. The reference air entry values } 1 / \alpha \text { listed here are associated with the geometric mean of the per- } \\
\text { meability values of the fracture and matrix ensembles, respectively. All other air entry values are cal- } \\
\text { culated from the scaling law, with the matrix parameters as reference values. The van Genuchten } \\
\text { parameter } \mathrm{m} \text { is calculated from equation: } \mathrm{m}=(1-1 / \beta) \text {. }\end{array}$} \\
\hline
\end{tabular}




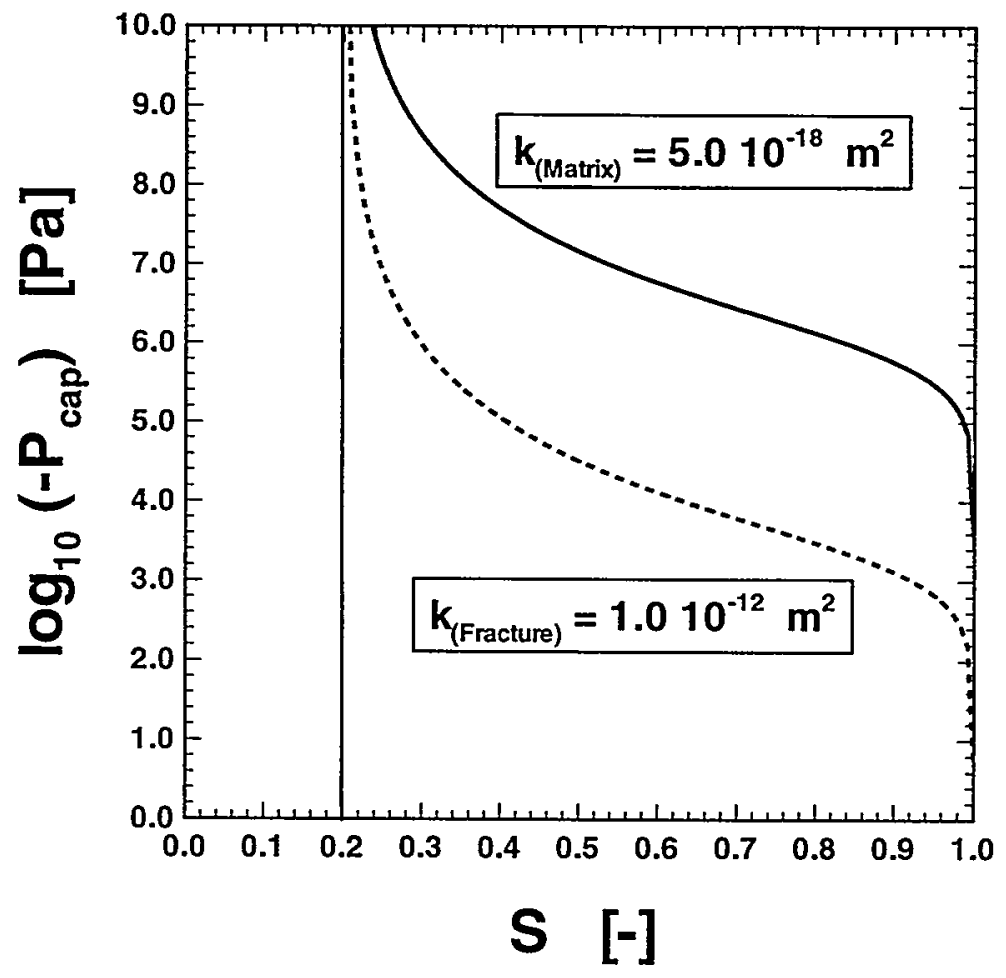

Figure 3 Capillary pressure function for average matrix and fracture permeability

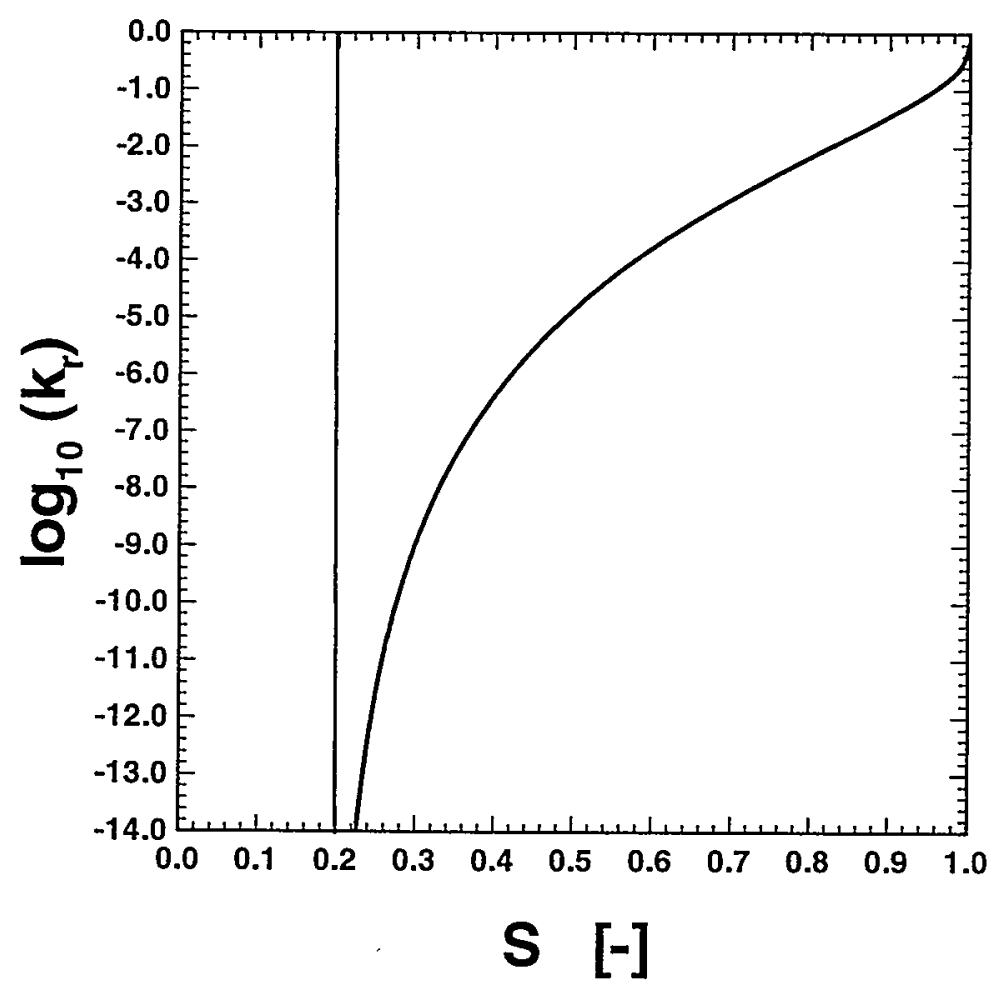

Figure $4 \quad$ Relative permeability function 
Based on the SCM introduced in Section 2 and parameters extracted from field observations, testing and modeling results described in Section 3, a three-dimensional block of heterogeneous permeability distribution was generated using the sequential indicator code SISIM of the geostatistical library GSLIB (Deutsch \& Journel, 1992). Figure 5 presents the one realization that was used for the current study. One notes from the figure that though the generated SCM honors all the input, it does not display a continuous high permeability feature that cuts through the entire block. Such a feature would be found if the correlation length assumed was larger, or if the model were conditioned to particular fracture data. In the current preliminary study, we have not attempted to do either.

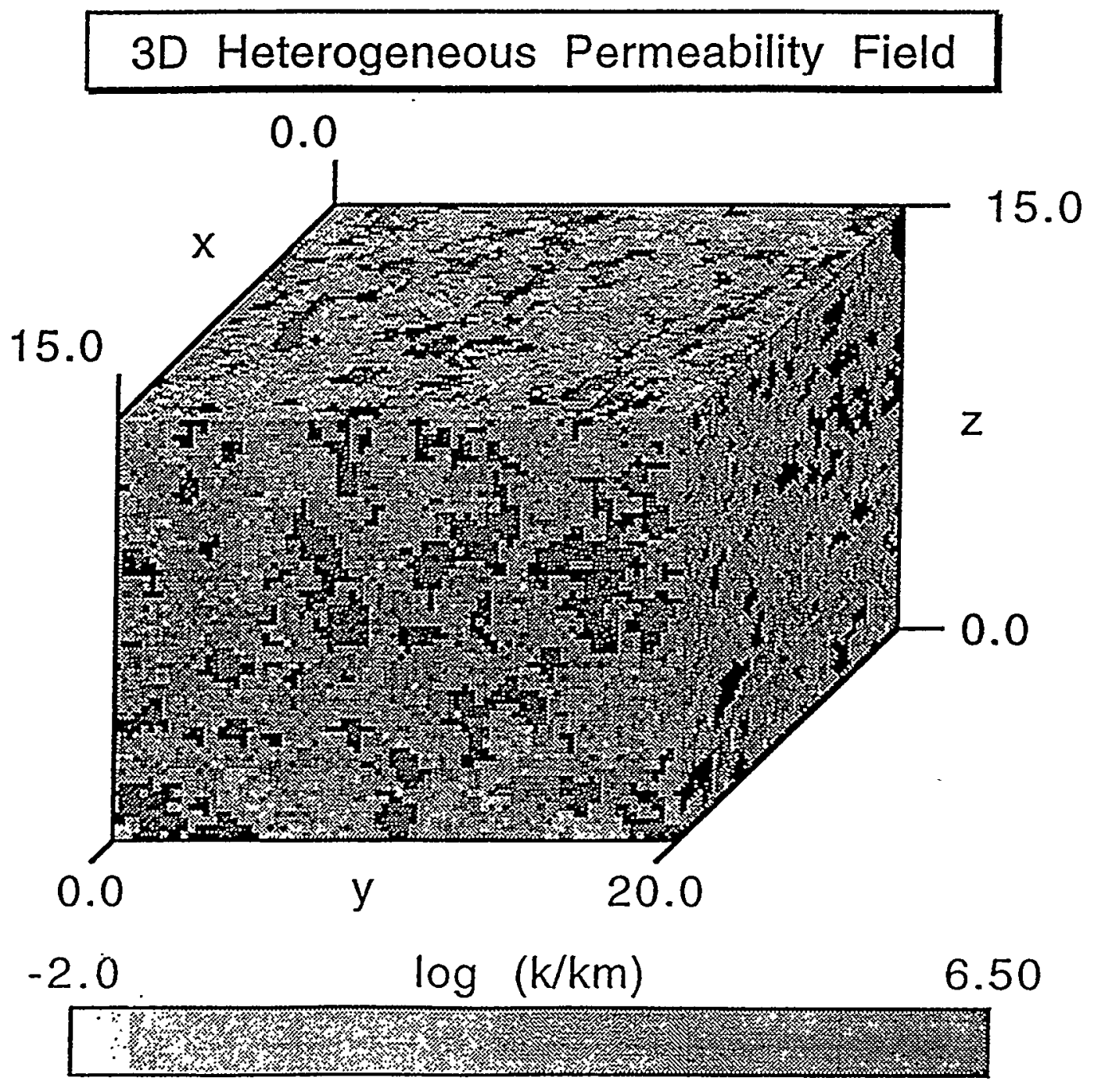

Figure 5 The realization of the three-dimensional permeability field used for the present study (with $\mathrm{k}_{\mathrm{m}}$ : geometric mean of the matrix permeability values). The dimensions are given in meters. 
A large number of two-dimensional simulations were performed on three different vertical cross sections of the three-dimensional permeability field. Figure 6 illustrates how the two-dimensional cross sections are arranged in space. Cross section $\mathrm{YZ}$ is a vertical plane parallel to the drift ( $Y Z$ - plane), the two other cross sections are vertical planes perpendicular to the drift (XZ plane). As already mentioned, one of the main fracture sets found in the Thermal Test Alcove is oriented vertically in NS direction (i.e. in the $\mathrm{XZ}$ - plane). Thus, the $\mathrm{YZ}$ plane is perpendicular to this fracture set and the other cross sections are parallel to it.
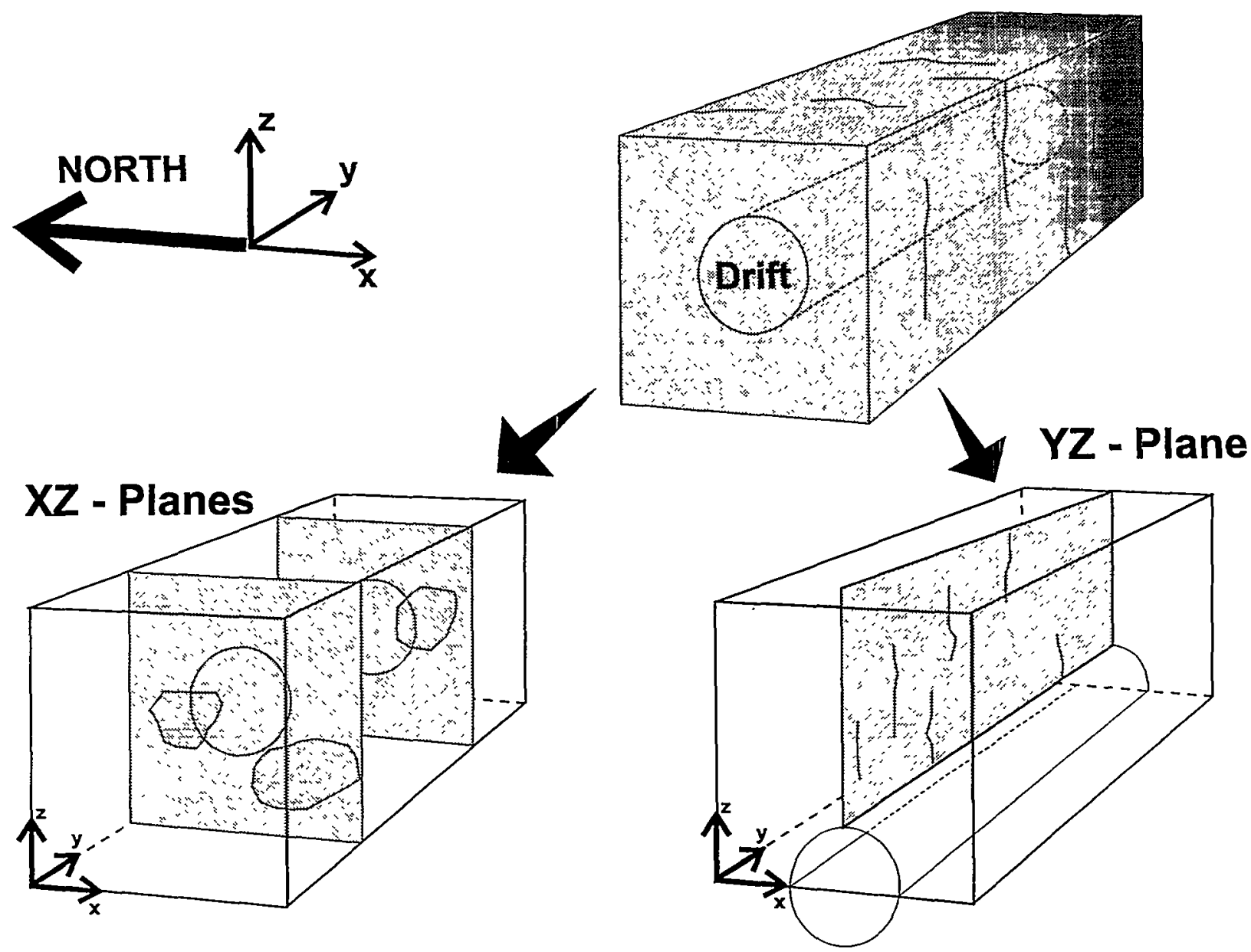

Figure 6 Schematic illustration of the cross sections chosen for the simulations runs

Prior to the simulation runs, a statistical analysis was done to estimate the permeability distributions of all three cross sections and calculate the percentage of low/high permeable values in the domain. The $Y Z$ plane used in the simulation runs was chosen to represent average properties of all $\mathrm{YZ}$ planes. The two $\mathrm{XZ}$ planes were chosen to represent extreme cases with respect to the percentage of fracture permeabilities in the domain. Cross section XZ_1 incorporates a higher proportion of fracture areas, i.e. it has a higher than average permeability. Cross section XZ_2 incorporates fewer fracture areas, i.e. it has a lower than average permeability. See Table 2 for a summary. 
Table 2: Properties of the simulated cross sections

\begin{tabular}{|c|c|c|c|}
\hline $\begin{array}{c}\text { Cross } \\
\text { Section }\end{array}$ & $\begin{array}{l}\text { Mean } \\
\text { Permeability } \\
\left(\mathrm{m}^{2}\right)^{\prime}\end{array}$ & $\begin{array}{l}\text { Percentage } \\
\mathbf{k}<10^{-14} \mathrm{~m}^{2} \\
\text { (\%) }\end{array}$ & $\begin{array}{l}\text { Percentage } \\
\mathbf{k} \geq \mathbf{1 0}^{\mathbf{1 4}} \mathrm{m}^{2} \\
\quad(\%)\end{array}$ \\
\hline $\mathrm{XZ}$ & $0.58 \times 10^{-16}$ & 79 & 21 \\
\hline$X Z_{-} \mathbf{I}$ & $0.14 \times 10^{-15}$ & 72 & 28 \\
\hline$X_{2}$ & $0.41 \times 10^{-16}$ & 82 & 18 \\
\hline 3D-Field & $0.72 \times 10^{-16}$ & 77 & 23 \\
\hline
\end{tabular}

Figure 7 shows the spatial distribution of the absolute permeabilities in the $\mathrm{YZ}$ plane. The model area extends $20 \mathrm{~m}$ in the horizontal and $10 \mathrm{~m}$ in the vertical direction. The domain is divided into $80 \times 40$ square cells, with each of those cells having different material properties. Figure 8 and 9 show the XZ planes which cover a $15 \mathrm{mx} 15 \mathrm{~m}$ area, divided into $60 \times 60$ square cells. The black line in the center of the latter figures indicates the location of the drift, which has a radius of 2.5 $\mathrm{m}$. In all figures, the flow domain is characterized by a strong separation of low permeability areas ("matrix" areas) and high permeability areas ("fracture" areas). Additionally, there is a smaller spatial variation within each of the two separate ensembles.
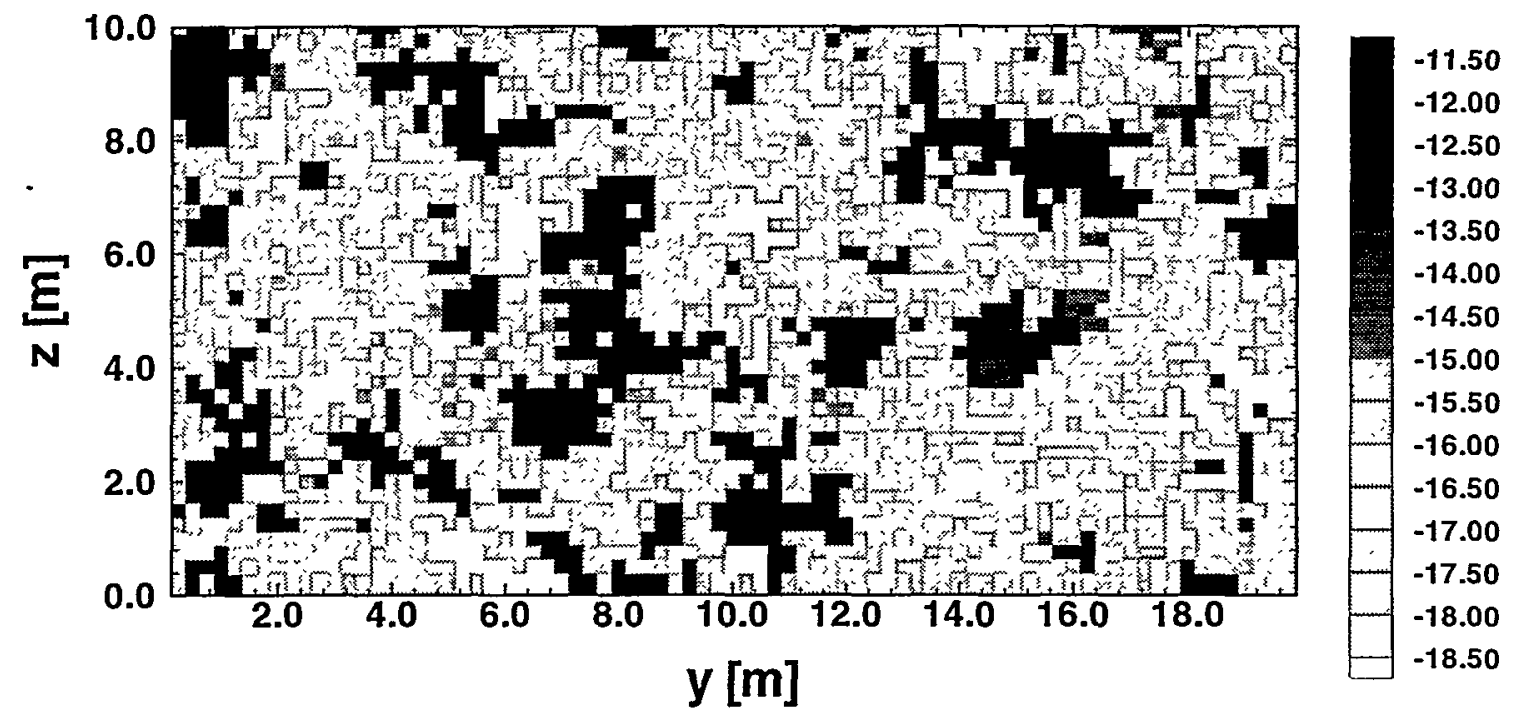

Figure 7 Saturated permeability distribution in the YZ plane (in $\log _{10} \mathrm{~m}^{2}$ ) 


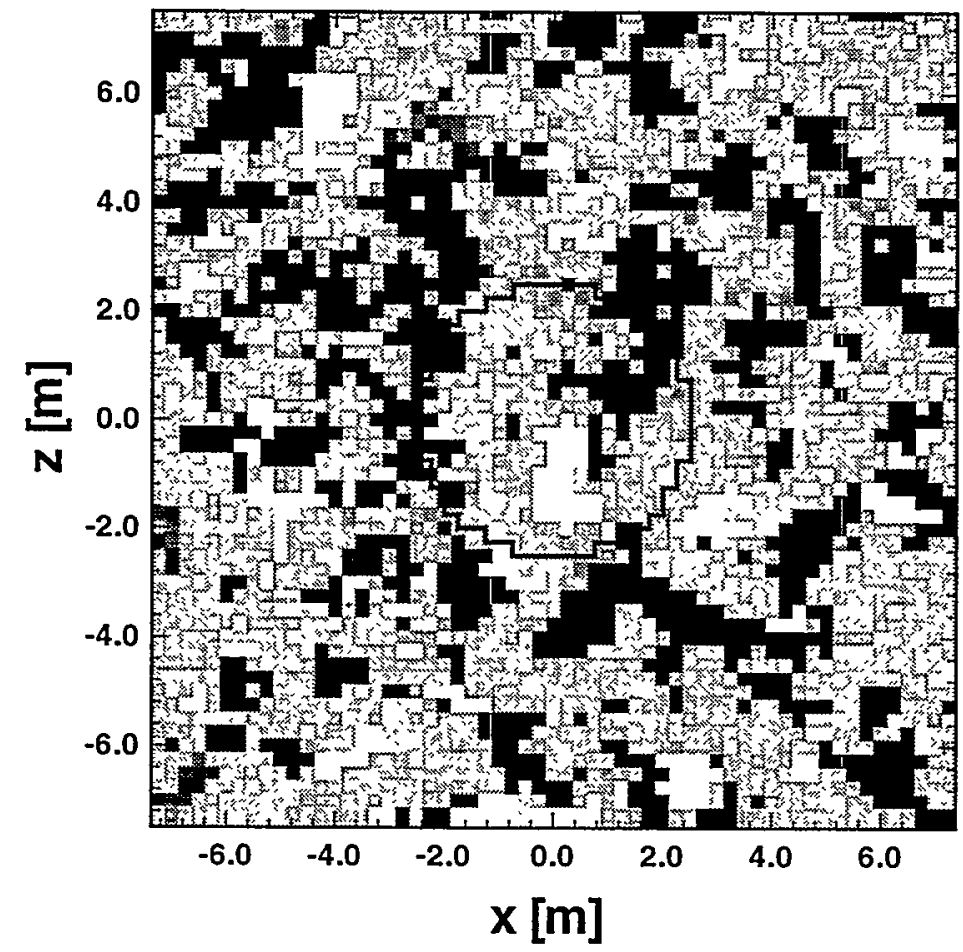

$-11.50$

$-12.00$

$-12.50$

$-13.00$

$-13.50$

$-14.00$

$-14.50$

$-15.00$

$-15.50$

$-16.00$

$-16.50$

$-17.00$

$-17.50$

$-18.00$

$-18.50$

Figure 8 Saturated permeability distribution in the $\mathrm{XZ} \_1$ plane(in $\log _{10} \mathrm{~m}^{2}$ )

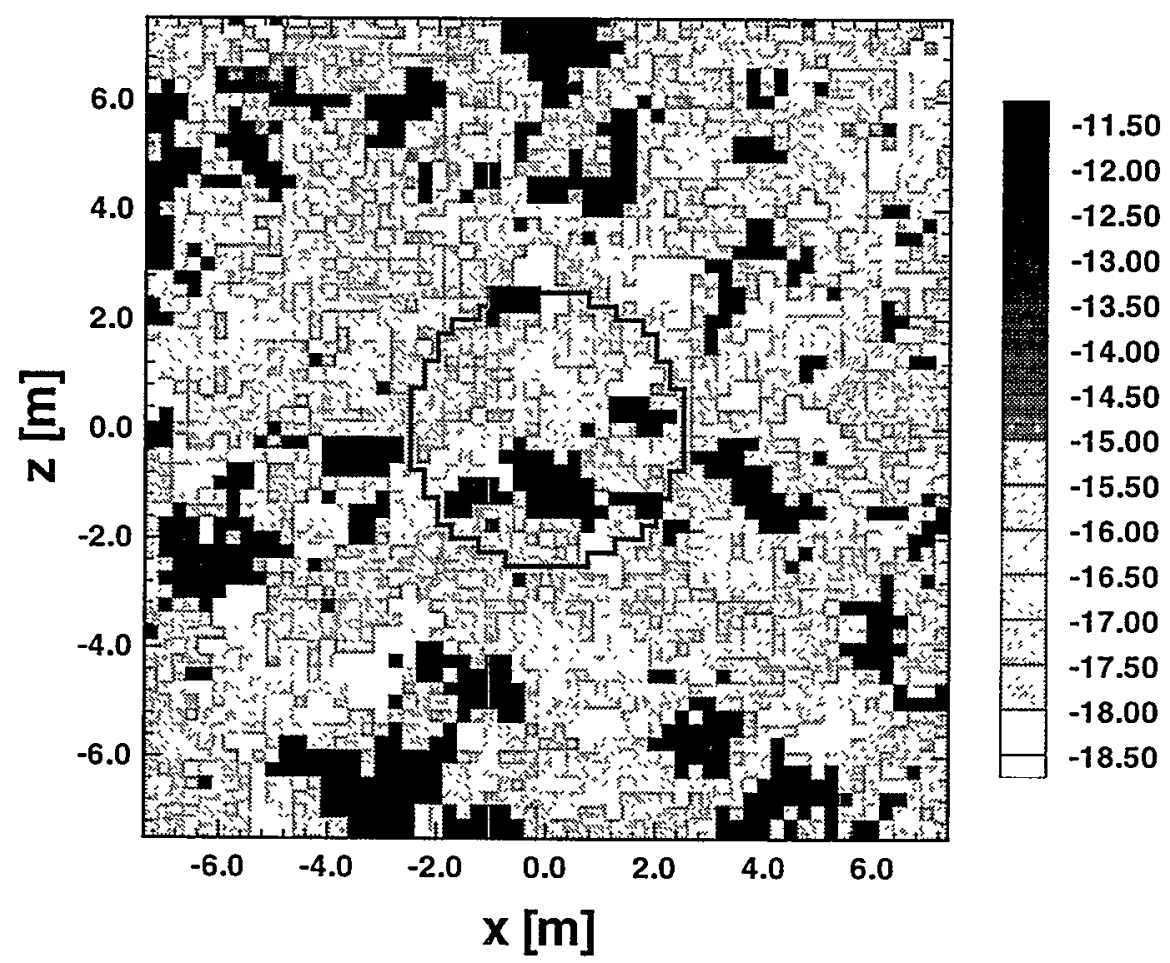

Figure 9 Saturated permeability distribution in the XZ_2 plane (in $\log _{10} \mathrm{~m}^{2}$ ) 
If not otherwise indicated in the respective sections of this report, all simulation are obtained using the two-dimensional permeability fields presented in Figures 7, 8 and 9. However, for the simulation of infiltration pulses (see below), we were also interested in permeability fields comprising continuous high permeability areas that cut through the entire model area. Through-going vertical fractures or faults may act as conduits for episodic, rapid flow of water through the unsaturated zone (e.g. Nitao \& Buscheck, 1991; Nitao et al., 1992; Zimmerman et al., 1996; Fairley \& Sonnenthal, in progress; Altman et al., in press). We manually adjusted the random permeability fields shown above by replacing individual low-permeable matrix elements with high-permeable fracture elements (threshold value $\mathrm{k}=10^{-14} \mathrm{~m}^{2}$ ). Figure 10 shows the "new" distribution of saturated permeability in the $\mathrm{YZ}$ - plane, featuring a through-going fracture area at about $\mathrm{y} \sim 7 \mathrm{~m}$ to $8 \mathrm{~m}$. Figure 11 depicts the "new" permeability distribution in the $\mathrm{XZ} \_1$ plane. Here, a continuous fracture area was generated which connects the top boundary of the model area with the tunnel in the center. The properties assigned to the "new" elements represent average parameters of the fracture ensemble as listed in Table 1 (i.e. $\mathrm{k}_{\mathrm{f}}=10^{-12} \mathrm{~m}^{2}, \theta_{\mathrm{f}}=0.1 \%, 1 / \alpha_{\mathrm{f}}=$ $1681 \mathrm{~Pa}, \theta_{\mathrm{f}}=1.33, \mathrm{~S}_{\mathrm{r}, \mathrm{f}}=0.2$ ).

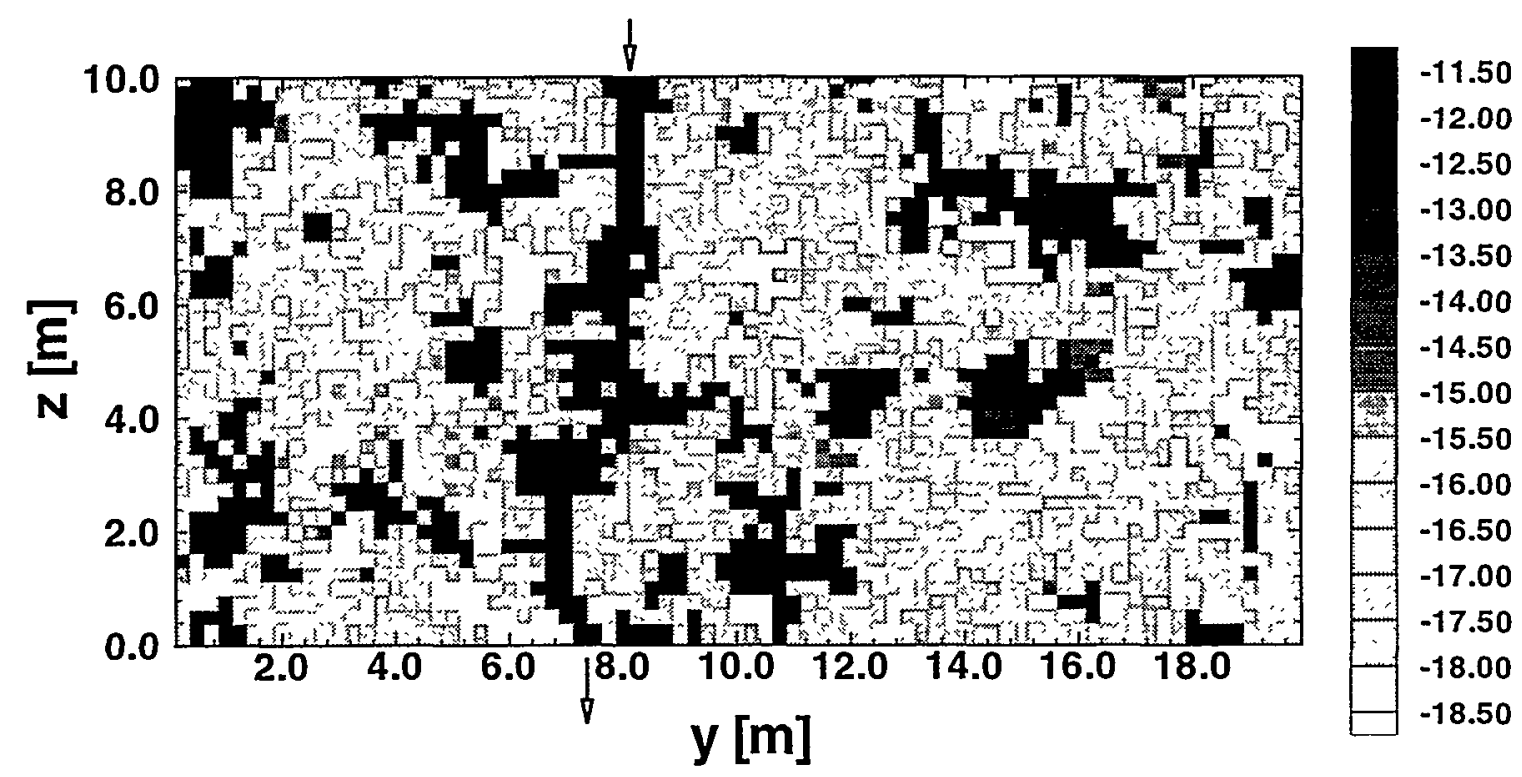

Figure 10 Saturated permeability distribution in the $\mathrm{YZ}$ plane featuring a continuous fracture area from the top to the bottom of the model area (in $\log _{10} \mathrm{~m}^{2}$ ). Arrows delineate the continuous fracture. 


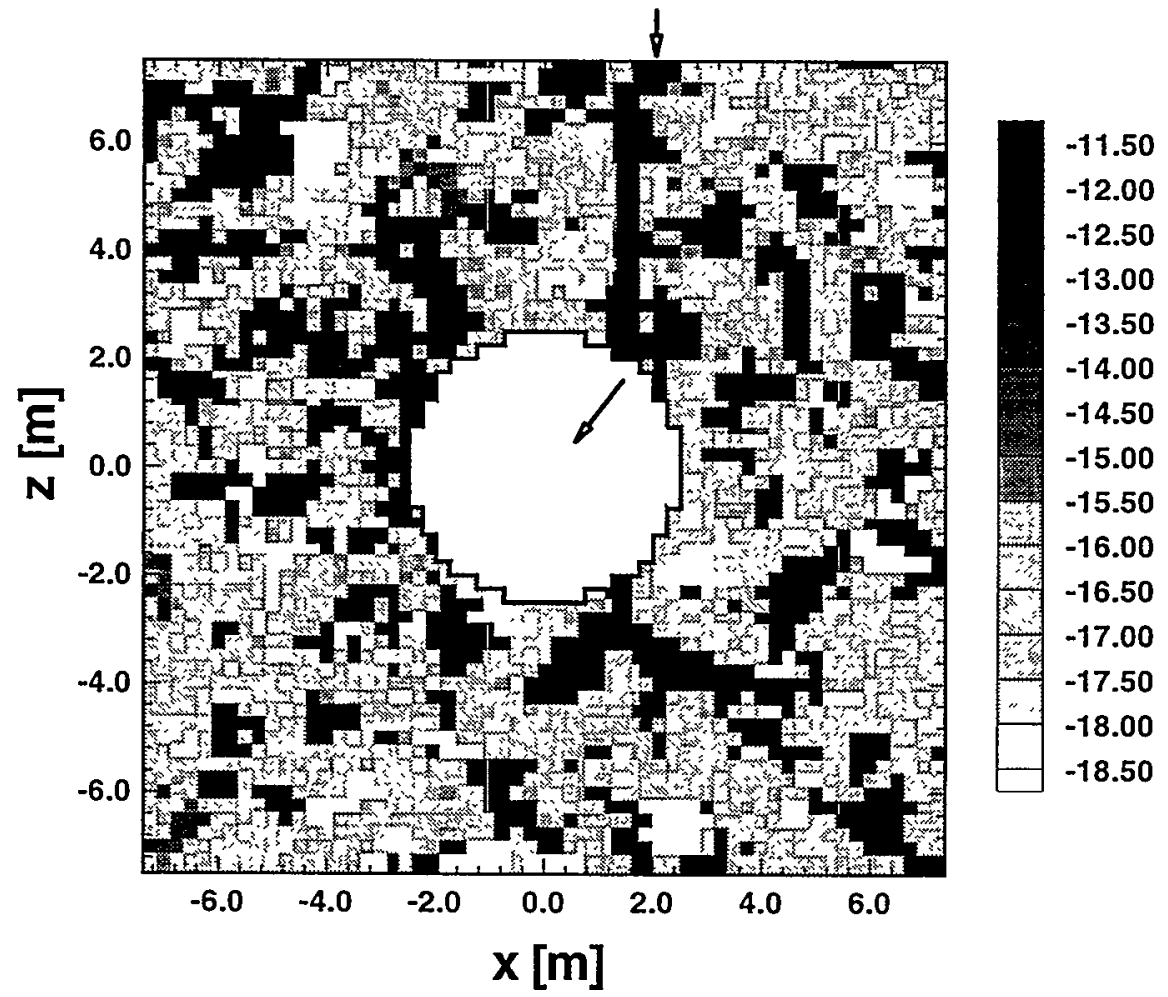

Figure 11 Saturated permeability distribution in the XZ_1 plane featuring a continuous fracture area from the top of the model area to the tunnel (in $\log _{10} \mathrm{~m}^{2}$ ). Arrows delineate the continuous fracture. 


\subsection{Simulation Scenarios}

Four simulation scenarios have been considered in this study to investigate the flow phenomena in the vicinity of the drift.

\section{Scenario 1: Steady-State Flow without Drift Impact}

This drift-scale simulation evaluates the steady-state flow field in the vicinity of the drift before the drift has actually been excavated. The boundary conditions represent a small infiltration rate typical of a "dry" period without strong rainfall events. This gives rise to an almost "static" flow field, where the fractures are essentially non-conductive because of their very low water saturations. The results of Scenario 1 serve as the initial condition for Scenario 2 and Scenario 3.

\section{Scenario 2: Infiltration Pulse without Drift Impact}

Starting with Scenario 1, the impact of a localized infiltration pulse, applied at a high permeability "fracture" area on the top boundary, is simulated. This is possible if a continuous large permeability flow path connects the ground surface with the TSw - unit. In the case of strong rain events, the infiltrated water can follow the large permeability path, creating episodic, rapid flow through the formation (see Figures 21 and 22 below). However, the pulse propagation might be strongly retarded or even completely stopped because of matrix imbibition. In our case, we assume a rain event that is sufficiently long so that the infiltration pulse actually arrives at the TSw - unit. Again, we study the flow field in the vicinity of the drift before the drift is excavated.

\section{Scenario 3: Drift Simulation with Ventilation}

Simulations are performed to simulate the impact of the drift on the flow regime within the first 50 years after the drift has been excavated, but without the presence of waste canisters. Therefore, thermal effects are not considered. Due to the ventilation that takes place in the drift over that time period, the relative humidity in the tunnel is below $100 \%$ and incoming water evaporates at the surface of the drift. This creates a strong capillary gradient towards the drift. The results of these simulations can help to understand the magnitude and variation of incoming fluxes, and can eventually be compared with measurements performed in the ESF; in particular, with the infra-red images taken to map inflow variations on the tunnel walls. The simulations start with the initial condition calculated in Scenario 1. A constant net infiltration is assumed without considering infiltration pulses.

\section{Scenario 4: Long-Term Drift Simulation with Steady-State and Pulse Infiltrations}

This simulation studies the magnitude and variation of fluxes towards the drift after the repository is closed and sealed. Since the long-term behavior is studied after the nuclear waste has already cooled off, there is no thermal effect on the flow field. The relative humidity in the drift returns to $100 \%$ (by definition, for the system in equilibrium), and the open void acts as a capillary barrier. Both steady-state runs and infiltration pulses are considered. 


\subsection{Boundary Conditions}

Before the drift is excavated, the model domains considered in our study represent an undisturbed part of the Topopah Springs hydrogeologic unit, with the capillary pressure being macroscopically uniform within this unit. As the macroscopic pressure gradient is zero, gravity is the only driving force for water flux. For the initial simulation in Scenario 1, we apply a uniform capillary pressure value of $-0.583 \mathrm{MPa}$ at the upper and lower model boundaries. This value corresponds to a saturation of 0.9 for matrix blocks with a saturated permeability of $5 \times 10^{-18} \mathrm{~m}^{2}$ (which is the geometric mean of the rock matrix permeabilities). Field observations and simulations performed with the Site-Scale Model have shown that the matrix rock in the TSw - unit has saturations in the range of 0.8 to 0.95 . An alternative boundary condition would be to specify the inflow/outflow rate, and obtain the boundary capillary pressures and saturations as model results. However, we felt that the measured and/or simulated saturation values are more reliable than the rather diverse information about the percolation flux through the mountain. The left and right boundaries are closed in all simulation runs.

For the infiltration pulse run (Scenario 2) the boundary conditions are essentially the same as in the initial run, except that at specified locations along the upper boundary (i.e. at through-going high permeability features) a high inflow rate is imposed instead of assigning a capillary pressure value. The crucial point here is that we have to assume a certain pulse size as well as the temporal and spatial distribution of pulses. Different studies on the mountain scale have come up with very different results regarding fast vertical flow paths, due to their strong dependence on model assumptions, hydrogeologic properties and precipitation characteristics. In light of this large uncertainty we performed a number of runs with different flow rates and pulse duration.

The other simulation runs (Scenarios 3 and 4) study the impact of the drift on the flow field. The first drift scenario focuses on the early time situation when the drift has just been excavated, with the tunnel being open and ventilated. Then, the relative humidity in the drift is low and formation water evaporates at the surface. The evaporation and transfer of moisture at the free surface is a complicated process which depends on factors such as relative humidity, temperature gradient, wind velocity in the drift and surface roughness, the latter two defining the thickness of the laminar boundary layer involved and the magnitude of the effective vapor diffusion coefficient at the drift wall [Finsterle \& Pruess, 1995]. A very detailed simulation scale would be needed to model these processes explicitly. Instead, we apply the reduced humidity as an equivalent capillary suction boundary condition at the drift wall, and calculate the flux under this suction. This simulation procedure actually "models" a water flux from the formation into the drift; however, this water is not really dripping into the open space of the drift, because it evaporates in a thin boundary layer at the drift wall. The equivalent capillary suction is calculated using Kelvin's equation [Edlefsen \& Anderson, 1943]

$$
P_{\text {cap }}=\ln \left(h_{R}\right) \rho \frac{R(T+273.15)}{M}
$$

with $h_{R}$ being relative humidity, $\rho$ the liquid density, $R$ the universal gas constant, $T$ the temperature (in degrees centigrade) and $M$ the molecular weight of water. We assume a constant temperature of $18^{\circ} \mathrm{C}$ in the drift, but the results would essentially be the same for temperatures up 
to $\sim 30^{\circ} \mathrm{C}$. Applying a value of $50 \%$ relative humidity, we obtain an equivalent capillary suction of $-93.1 \mathrm{MPa}$ at the drift wall. To study the sensitivity of the results, we also simulated relative humidity values of $75 \%$ and $95 \%$. However, we obtained very similar behavior for all these cases, and only the $50 \%$ humidity runs will be presented in this report.

Due to their different orientation relative to the drift axis, the $\mathrm{YZ}$ plane and the $\mathrm{XZ}$ planes are handled differently with respect to the drift boundary. The YZ plane is parallel to the drift axis, and we assume that the model area is located on the top of the tunnel, with the drift wall forming the lower boundary of the domain. The XZ planes are perpendicular to the drift axis. Here we assume that the tunnel is located in the center of the model area, forming a circular void with a $2.5 \mathrm{~m}$ radius. The other boundary conditions are the same as in the initial run.

The second drift scenario (Scenario 4) is used to study the long-term behavior next to the drift, when the tunnel has been sealed, the waste has cooled off and the relative humidity has returned to $100 \%$. In that case, the drift boundary is simply modeled by a zero capillary suction. In the first run, the other boundary conditions are set equal to those of the initial steady-state simulation. Then, additionally, we study the effect of episodic rapid water flow; i.e. we check if a strong infiltration pulse injected at the upper boundary is able to reach and break the capillary barrier and enter the tunnel cavity.

Figure 12 and Figure 13 give a schematic description of the boundary conditions applied for the initial simulation (Scenario 1) and the drift simulations (Scenario 2 and 4), respectively.
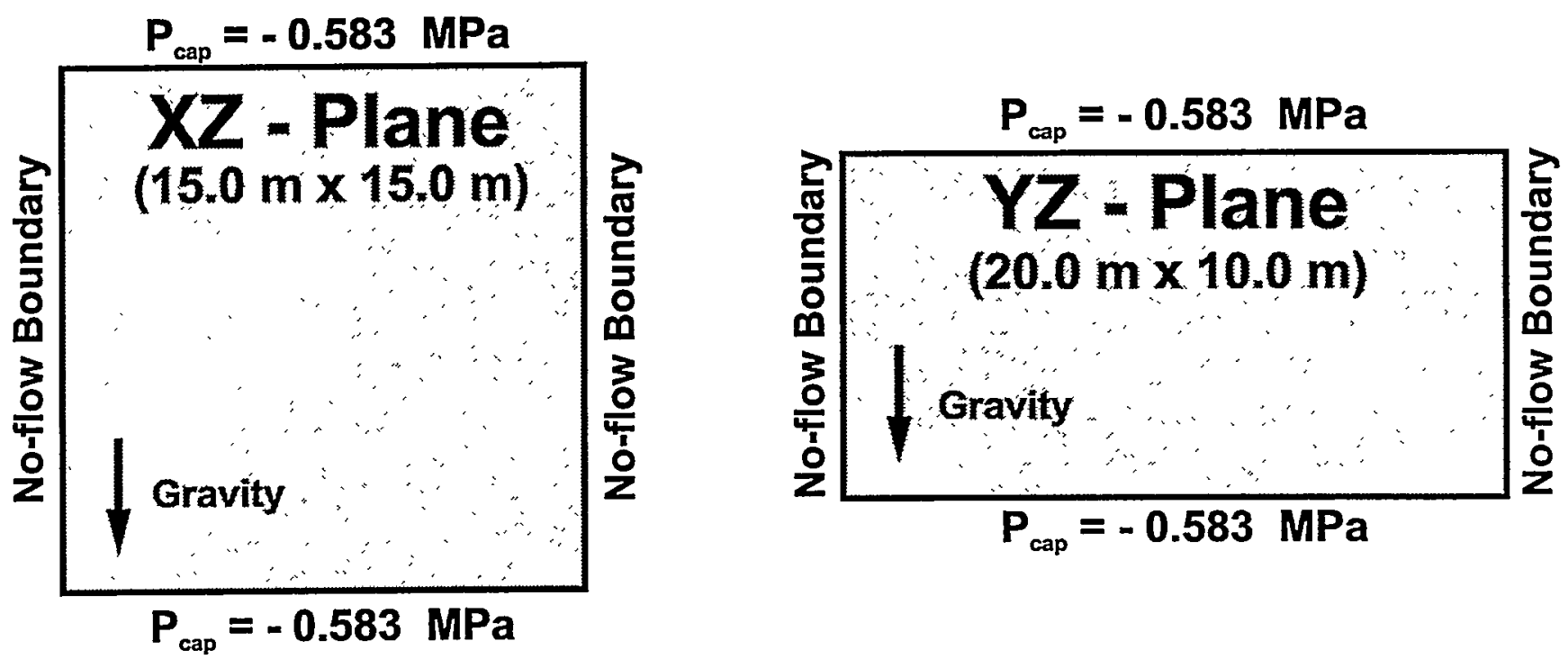

Figure 12 Schematic illustration of the model area and the boundary conditions for the initial simulation runs 

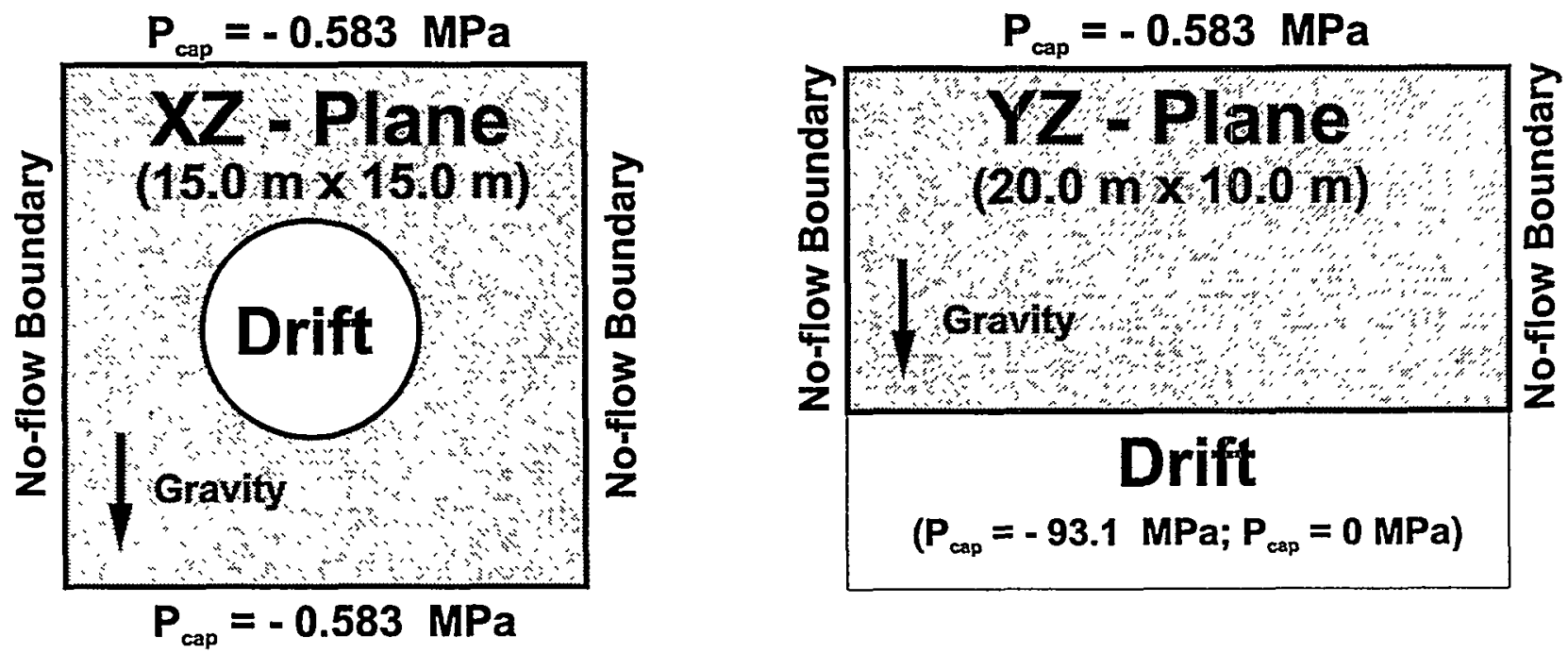

Figure 13 Schematic illustration of the model area and the boundary conditions for the drift simulation runs

\subsection{Discretization}

Different finite difference discretizations have been used to study the sensitivity of the model results. For the (pre-drift) initial runs a relatively coarse discretization was sufficient, and each $(0.25 \mathrm{~m} \mathrm{x} 0.25 \mathrm{~m})$ square cell of the permeability field with a single set of property values was represented by only one finite difference grid element. For the drift runs, however, a much finer temporal and spatial discretization was needed in the vicinity of the drift, due to the strong capillary suction enforced at the drift walls. Therefore, a locally refined grid was used. The cells adjacent to the drift wall are represented by 5 grid elements each, with the distances from the drift wall chosen to be $0.001 \mathrm{~m}, 0.005 \mathrm{~m}, 0.02 \mathrm{~m}, 0.07 \mathrm{~m}$ and $0.154 \mathrm{~m}$ (Figure 14).

In the $\mathrm{XZ}$ planes, the circular shape of the tunnel was approximated by simply eliminating the inner square elements whose centers are within $\mathrm{R}=2.5 \mathrm{~m}$ (Figure 14). One could think of more sophisticated discretizations to better model the geometry of the tunnel; however, all of them would involve spatial interpolation to represent the underlying rectangular structure of the permeability field. In light of the focus of our study, an exact description of the heterogeneity field is more important than an exact representation of the tunnel geometry. We checked the accuracy of our discretization approach for a homogeneous field, comparing two-dimensional simulation runs with a 1-D radially symmetric calculation, and found a good agreement between the two solutions. 

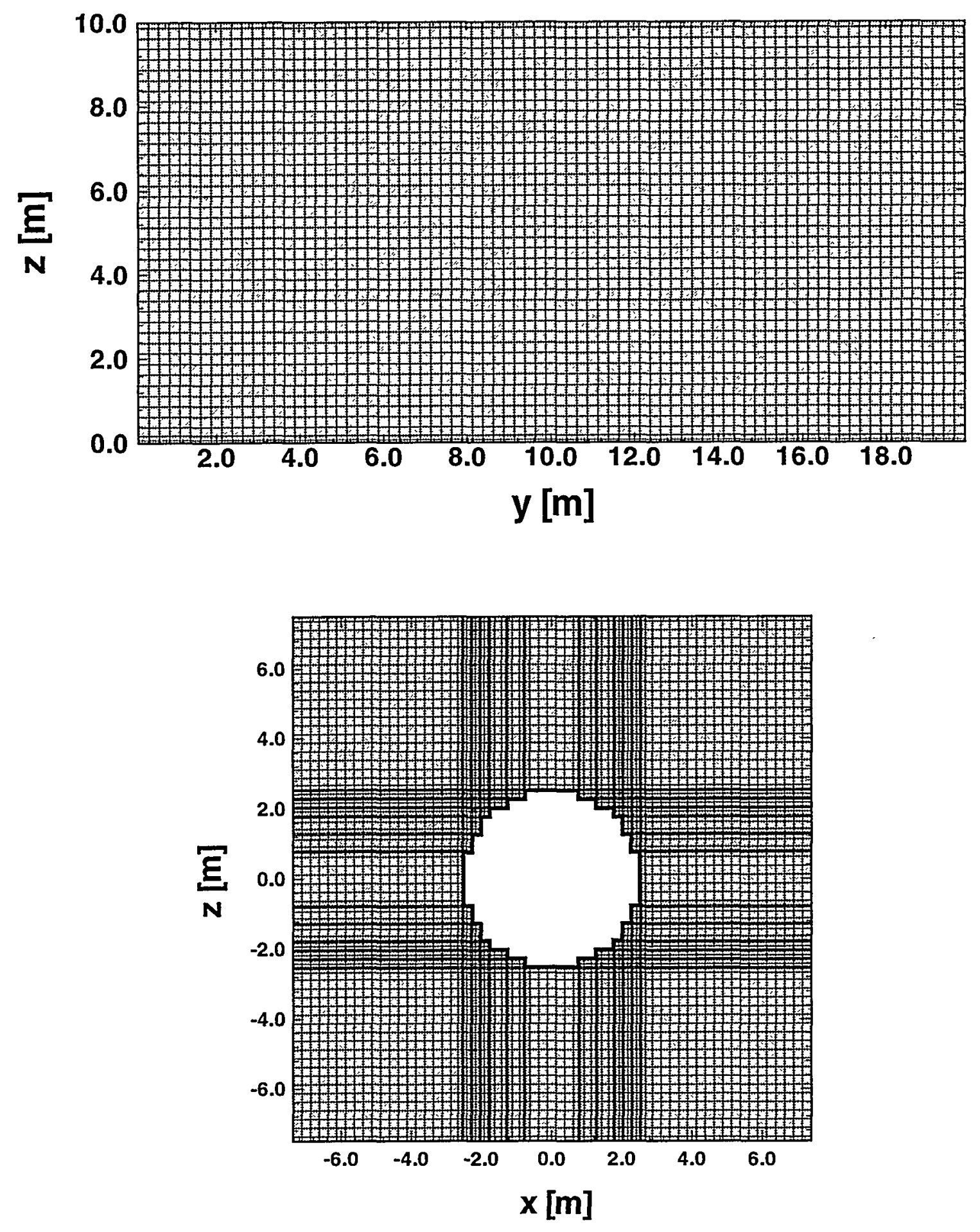

Figure 14 Finite difference grids used for the drift simulation runs in the YZ plane (above) and the XZ plane (below) 


\section{Simulation Results}

\subsection{Steady-State Flow without Drift Impact (Scenario 1)}

The results presented in this section simulate the drift scale flow characteristics for steady-state boundary conditions, representing the long-term situation in the vicinity of the drift before the drift is actually excavated. These simulations are important for understanding the magnitude and variation of flow rates and travel times at the present state. They also serve as initial conditions for the drift simulation runs presented in the following sections.

Two-dimensional numerical simulations were performed for the three cross-sections XZ_1, $\mathrm{XZ} \_2$, and $\mathrm{YZ}$ of the three-dimensional heterogeneity field. As already mentioned, we applied a uniform capillary pressure boundary condition at the top and the bottom of the model area, with a value of $\mathrm{P}_{\text {cap }}=-0.583 \mathrm{MPa}$ corresponding to an average saturation of 0.9 in the low permeable "rock matrix" areas. Then, the vertical flux through the model area is a calculated result rather than an input parameter. Since the upper and lower boundaries are kept at the same capillary pressure, the regional pressure gradient is zero, and gravity is the only driving force for flux. Of course, the heterogeneity of the permeability field gives rise to local variations of capillary pressure, saturation and fluxes. Examples of results are presented for the $\mathrm{YZ}$ plane of the model area. Figure 15 gives a schematic picture of the distribution of high permeability and low permeability areas, with the threshold permeability chosen as $10^{-14} \mathrm{~m}^{2}$. Figure 16 shows the water saturation and Figure 17

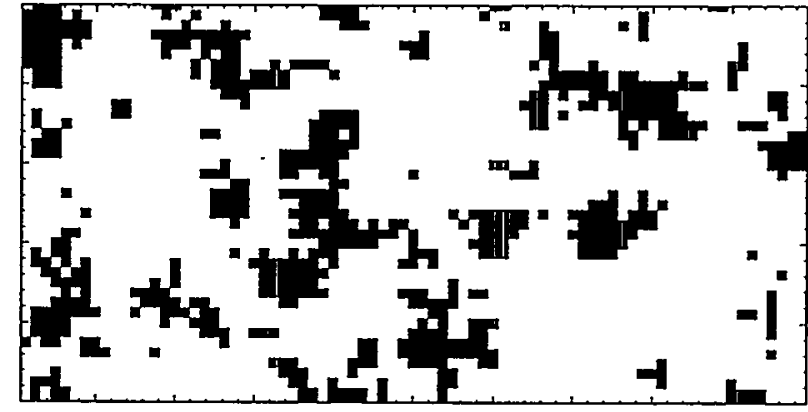

Figure 15 "Fracture" (black) and "matrix" areas (white) in the $\mathrm{YZ}$ plane. Compare to Figure 7. shows the magnitude of fluxes.

Comparison of Figure 15 and 17 indicates that the flow predominantly occurs in the low permeability areas of the model domain. These areas, which represent the rock matrix in the stochastic continuum approach, are associated with high air entry values and thus maintain high water saturations in the range of 0.9 . The highly permeable "fracture" areas on the other hand have very low saturation values, close to the residual saturation; they are essentially dry and do not conduct significant amounts of water. These two facts together, i.e. small saturated "matrix" permeability and low "fracture" saturation, give rise to a very small percolation flux of $0.018 \mathrm{~mm} / \mathrm{yr}$ through the model domain; the flow field represents almost "static" conditions. Recent hydrological studies estimate net infiltration fluxes for the Yucca Mountain Site ranging from 0 to $14 \mathrm{~mm} / \mathrm{yr}$ (Flint et al., in review), and the average percolation flux at the potential repository horizon in the $\mathrm{TSw}$ - unit is often expected to be in the range of $0.1 \mathrm{~mm} / \mathrm{yr}$ to $5 \mathrm{~mm} / \mathrm{yr}$ (e.g. Wittwer et al., 1995). The very small percolation flux displayed in our initial simulation runs represents the flow field in a "dry" period assuming steady-state conditions, with almost nonconductive fractures. If the dynamics of the system were accounted for by including the effect of episodic infiltration 
pulses, one would end up with higher average infiltration rates, depending on the temporal distribution of rain events and the spatial distribution of fast flow paths in the mountain. This is discussed in Section 6.2 below.

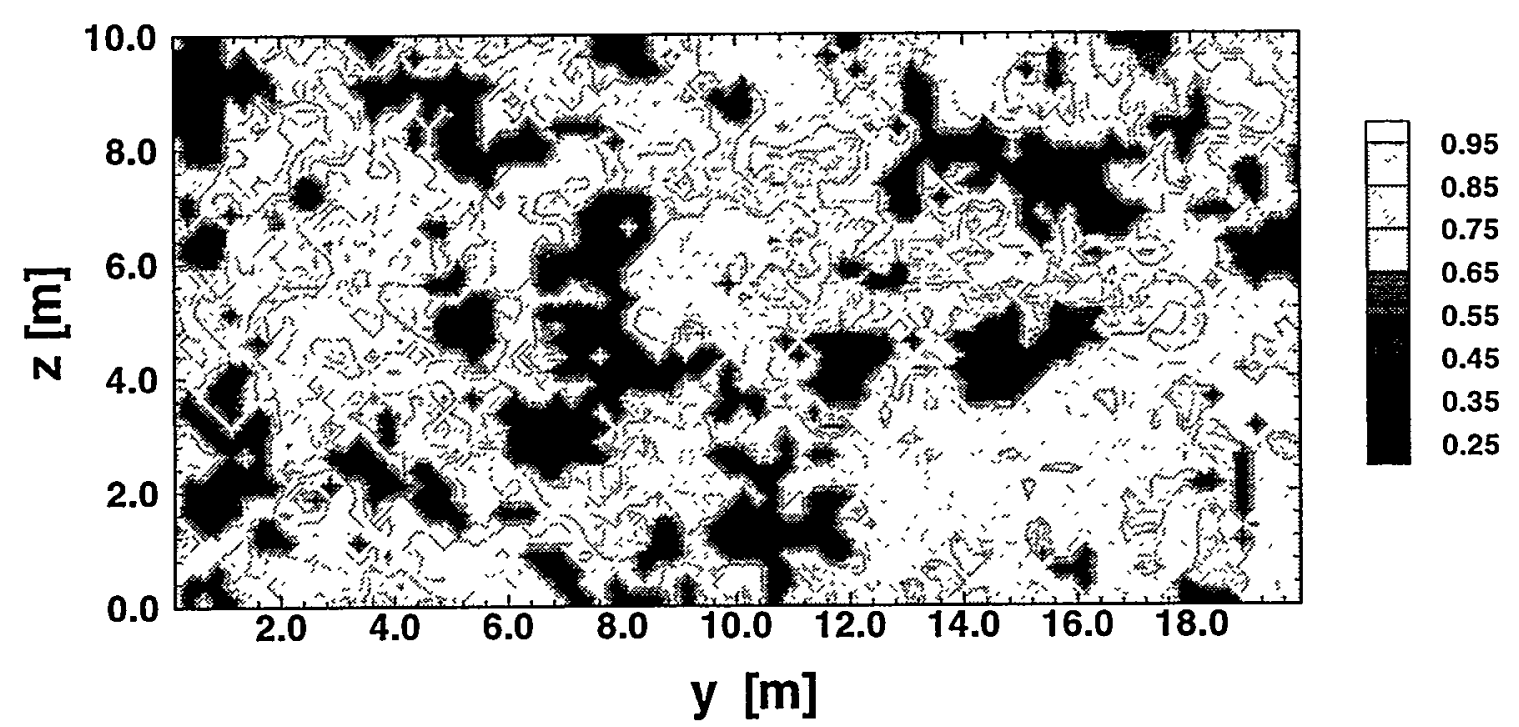

Figure 16 Liquid saturation distribution in the $\mathrm{YZ}$ plane

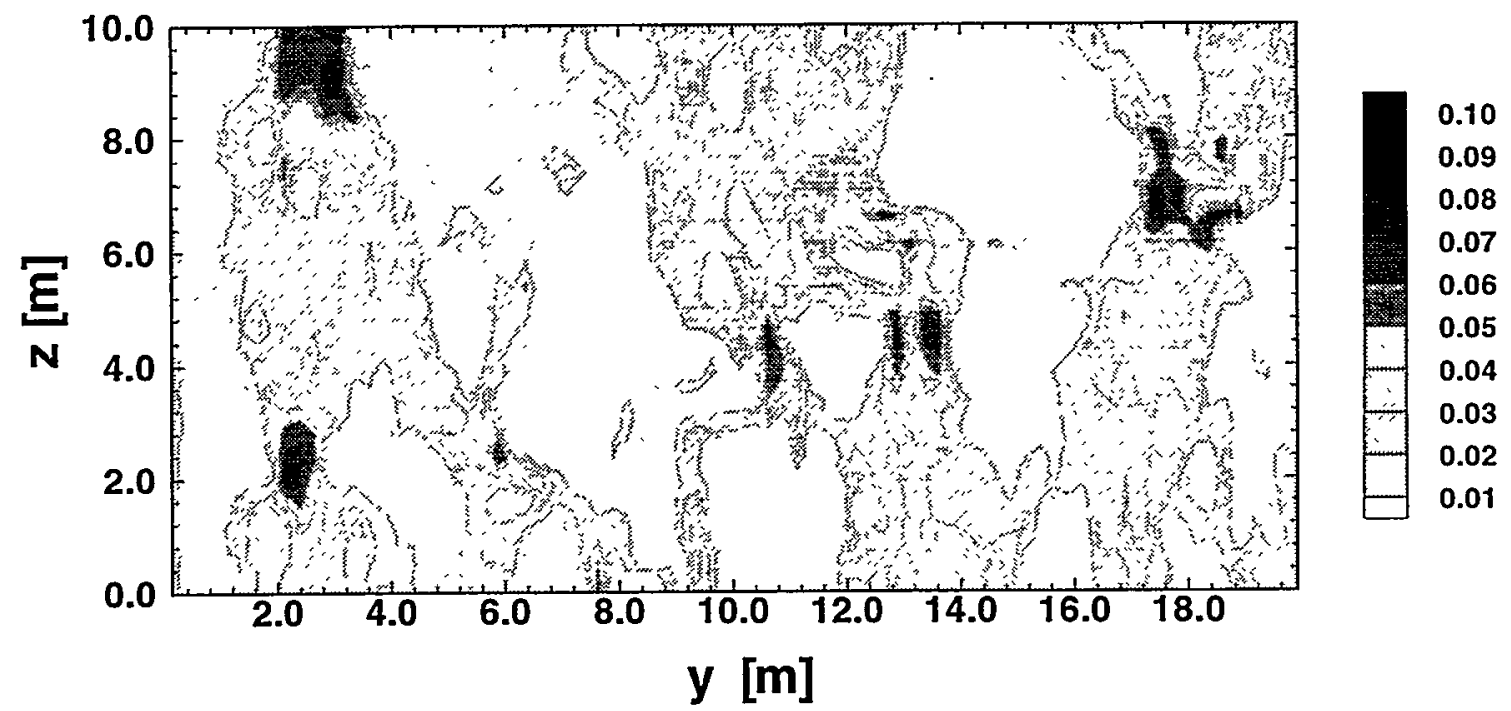

Figure 17 Magnitude of flux in the $\mathrm{YZ}$ plane (in $\mathrm{mm} / \mathrm{yr}$ )

Table 3 lists some flow results calculated for the entire model domain from the initial simulation runs. Values are given for the $\mathrm{YZ}$ plane as well as for the two $\mathrm{XZ}$ planes. In Table 4 we identify "fracture" flow properties and "matrix" flow properties by choosing a threshold permeability of $10^{-14} \mathrm{~m}^{2}$ to distinguish between high-permeable "fracture" areas and low-permeable "matrix" areas. In both tables, the so called "mean" permeability denotes the geometric mean of the 
respective permeability fields. Note that all simulations presented in this section have been performed on the three original permeability fields as shown in Figures 7, 8 and 9, i.e. in permeability fields without through-going high-permeability features. However, additional simulations have shown that the effect of through-going fracture areas is almost negligible at low infiltration rates. This is because the flow mainly occurs in the matrix, while high permeability features are essentially nonconductive.

As can be seen from the tables, the percolation fluxes for all three cross sections were found to be in the same range. The actual value of percolation depends mostly on the volumetric proportion of the fracture areas and the matrix areas, respectively. The more fracture areas included in the model area (e.g. in cross section XZ_1), the smaller is the percolation flux. This is due to the fact that the water flow is predominantly conducted through the matrix. In our simulations $93 \%$ to $97 \%$ of the total flux through the model area takes place in the matrix. The ratio of fast flow versus average flow is relatively small; the maximum flux in all cases is only 4 to 6 times higher than the average percolation flux. This is due to the fact that the variation of the matrix permeability around its mean value is not very large. However, one should keep in mind that the entire domain is strongly heterogeneous with respect to the permeability differences between the fracture ensemble and the matrix ensemble.

Table 3: Flow results calculated for the entire domain

\begin{tabular}{|c|c|c|c|c|}
\hline $\begin{array}{c}\text { Cross } \\
\text { Section } \\
\end{array}$ & Permeability & $\begin{array}{l}\text { Percolation } \\
\text { Flux over mov } \\
\text { Domain } \\
\text { (mim/yr) }\end{array}$ & 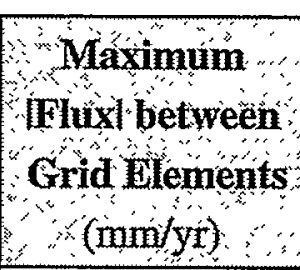 & $\begin{array}{l}\text { Minimum } \\
\text { Oluxibetween } \\
\text { Grid Elements } \\
(\text { mim } / y)\end{array}$ \\
\hline $\begin{array}{l}\mathrm{XZ} \\
\therefore \mathrm{XZ} T\end{array}$ & $\begin{array}{l}0.58 \times 10^{-16} \\
0.14 \times 10^{-15} \\
0.41 \times 10^{-16}\end{array}$ & $\begin{array}{l}0.018 \\
0.014 \\
0.021\end{array}$ & $\begin{array}{l}0.083 \\
0.076 \\
0.116\end{array}$ & $\begin{array}{l}0.0002 \\
0.0005 \\
0.0005\end{array}$ \\
\hline
\end{tabular}

Table 4: Flow results of the "matrix" and the "fracture" areas

\begin{tabular}{|c|c|c|c|c|c|c|}
\hline$\because \because \because \cdots$ & \multicolumn{3}{|c|}{ Datrix } & \multicolumn{3}{|c|}{ Eractíne } \\
\hline $\begin{array}{l}\text { Cross } \\
\text { Section } \\
\end{array}$ & $\mid \begin{array}{l}\text { Volume } \\
\\
(\%)\end{array}$ & $\begin{array}{c}\text { Mean } \\
\text { Perman } \\
\left(\mathrm{m}^{2}\right)\end{array}$ & $\begin{array}{l}\text { Percolat } \\
\text { Hux } \\
\text { (o) }\end{array}$ & Volume & $\begin{array}{l}\text { Mean } \\
\text { Permo } \\
(\mathrm{m})\end{array}$ & $\begin{array}{l}\text { Pexcolat } \\
\text { Fiux } \\
(\%)\end{array}$ \\
\hline$y$ & 79 & $0.49 \times 10^{-17}$ & 97 & 21 & $0.70 \times 10^{-12}$ & 3 \\
\hline $\mathrm{XZ}$ & 72 & $0.54 \times 10^{-17}$ & 93 & 28 & $0.55 \times 10^{-12}$ & 7 \\
\hline$=X Z_{2} 2$ & 82 & $0.50 \times 10^{-17}$ & 97 & 18 & $0.64 \times 10^{-12}$ & 3 \\
\hline
\end{tabular}




\section{Sensitivity Analysis}

Simulations were performed for the $\mathrm{YZ}$ plane to study the sensitivity of the percolation fluxes with respect to different model parameters. In each simulation only one parameter was changed while all other properties and boundary conditions remained the same as in the original run.

In Case 1, the matrix permeabilities were increased by one order of magnitude. This may be justified by arguing that the $0.25 \mathrm{~m} \times 0.25 \mathrm{~m}$ cells may contain microfractures so that the mean permeability of these cells could be much higher than the value for the matrix only.

- In Case 2, a different correlation function was chosen for the relation between the permeability and the air entry value $1 / \alpha$ of the van-Genuchten capillary pressure function. This was done such that the air entry value associated with the mean fracture permeability was increased by a factor of five, while the air entry value associated with the mean matrix permeability was kept constant. All other values were interpolated using the given reference data and the usual square-root correlation function.

- In Case 3, the pore size distribution coefficient used in the van-Genuchten formulation was increased (2.0 instead of 1.33 as originally chosen), representing more uniform pore sizes.

Table 5 lists some flow results for these additional runs.

Table 5: Flow results for additional simulation runs

\begin{tabular}{|c|c|c|c|c|c|}
\hline $\begin{array}{r}\text { Case } \\
\vdots \\
\vdots \\
\end{array}$ & $\begin{array}{l}\text { Percolation } \\
\text { Flux } \\
\text { (mm/yr) }\end{array}$ & $\begin{array}{l}\text { Maximum } \\
\text { [Flux] } \\
(\text { min/yr) }\end{array}$ & 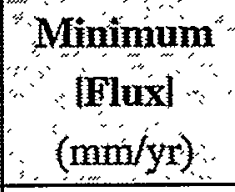 & $\begin{array}{l}\text { Flux } \\
\text { in Matrix } \\
(\%)\end{array}$ & $\begin{array}{l}\text { Fux } \\
\text { in Fractures } \\
(\%)\end{array}$ \\
\hline 1 & 0.157 & 0.949 & 0.0001 & 99 & 1 \\
\hline 2 & 0.042 & 0.121 & 0.0076 & 74 & 26 \\
\hline 3 & 0.072 & 0.581 & 0.0 & 100 & 0 \\
\hline referen & 0.018 & 0.083 & 0.0002 & 97 & 3 \\
\hline
\end{tabular}

In all three cases, the percolation rates are increased significantly compared to the original run. In Case 1 this is simply due to the higher matrix permeabilities. Note that a similar increase in the fracture permeabilities would not have any effect under the present assumption of constant net infiltration without infiltration pulses. In Case 2 the fractures are able to maintain slightly larger saturations due to higher air entry values. This gives rise to higher relative permeabilities, and allows $26 \%$ of the percolation flux to occur through the fractures. The increase of the pore size distribution coefficient in Case 3 has two counteracting effects. First, the relative permeability function is less steep; i.e. the relative permeabilities maintain higher values for given water saturations. Secondly, the capillary pressure function changes such that the saturation values associated with a given capillary pressure decrease. For the capillary pressure values obtained in our simulation runs (i.e. $\mathrm{P}_{\text {cap }} \sim-0.583 \mathrm{MPa}$ ), this effect is not significant in low permeability features, but quite significant in high permeability features. The combination of these counteracting effects makes the matrix blocks more permeable as compared to the reference case. The fractures, however, become completely dry and essentially impermeable. 
The above preliminary results show that the percolation fluxes are sensitive to the model parameters, both with respect to the actual flux rate and to the relative distribution of the fluxes between the matrix and the fracture areas. However, the qualitative characteristics of the unsaturated flow are not significantly affected. Under the assumption of steady-state conditions, the fractures have very low saturations, with the flow rates being several orders of magnitude lower than the flow rates under saturated conditions (i.e. infiltration pulses). This gives rise to a very small percolation flux through the model area, with the simulated fluxes ranging from 0.014 $\mathrm{mm} / \mathrm{yr}$ to $0.157 \mathrm{~mm} / \mathrm{yr}$. For such a small percolation flux the average time needed for a contaminant to travel the $10 \mathrm{~m}$ distance from the top to the bottom of the model area would be more than 50000 years, assuming a porosity of $14 \%$ for the matrix areas and $0.1 \%$ for the fracture areas (the reference case parameters). The ratio between fast flow and average flow is quite small; it is a result of the relatively small heterogeneity of the matrix ensemble.

Another set of simulations was performed for the $\mathrm{YZ}$ plane to study the sensitivity of the percolation fluxes with regard to the upper and lower boundary condition. As was already mentioned in Section 5.2, a uniform capillary pressure boundary condition of $-0.583 \mathrm{MPa}$ was applied for the reference case, corresponding to an average saturation of 0.9 in the rock matrix. If smaller capillary suction values were imposed at the boundaries, the saturations in the domain would be higher, and the overall percolation flux would increase. To study this dependency we simulated two additional cases with modified upper and lower boundary conditions, choosing capillary pressure values of $-0.028 \mathrm{MPa}$ and $-0.168 \mathrm{MPa}$. For matrix blocks with the mean saturated permeability of $5 \times 10^{-18} \mathrm{~m}^{2}$, these values correspond to saturations of 0.9975 and 0.975 , respectively. A fully saturated case was also studied to estimate the maximum possible percolation flux through the domain for comparison. Results of these runs are summarized in Table 6.

Table 6: Flow results for additional simulation runs

\begin{tabular}{|c|c|c|c|c|c|}
\hline 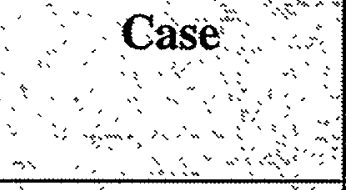 & $\begin{array}{l}\text { Percolation } \\
\text { Flux } \\
\text { (mmitys) }\end{array}$ & $\begin{array}{l}\text { Maximum } \\
\text { (mom } / y)\end{array}$ & $\begin{array}{l}\text { Minimum } \\
\text { (min/y) }\end{array}$ & $\begin{array}{l}\text { Tux } \\
\text { Matrx } \\
\text { (\%) }\end{array}$ & $\begin{array}{l}\text { Flux } \\
\text { in Fractures } \\
(\%)^{\circ}\end{array}$ \\
\hline fully saturated & 3.88 & 197.0 & 0.0 & 40 & 60 \\
\hline $\mathrm{P}_{\mathrm{cap}}=-0.028 \mathrm{MPa}$ & 1.02 & 9.11 & 0.004 & 58 & 42 \\
\hline $\mathrm{P}_{\mathrm{cap}}=-0.168 \mathrm{MPa}$ & 0.129 & 0.557 & 0.004 & 88 & 12 \\
\hline $\begin{array}{l}\mathrm{P}_{\mathrm{eap}}=0.583 \mathrm{MP} \\
\text { (reference case) }\end{array}$ & 0.018 & 0.083 & 0.0002 & 97 & 3 \\
\hline
\end{tabular}

It can be seen from Table 6, that smaller boundary capillary suction values give rise to an increase in percolation flux, with the maximum flux given as $3.88 \mathrm{~mm} / \mathrm{yr}$ for the fully saturated case. This increase is mostly due to increased fluxes in the fracture areas of the model domain; the percentage of flux occurring in the fractures rises from $3 \%$ in the reference case up to $60 \%$ in the fully saturated case. Thus, for high capillary suction values as in the reference case, the percolation flux is mainly determined by the properties of the rock matrix (since the high permeability features have low saturations and are essentially non-conductive). However, with decreasing 
capillary suction values imposed at the upper and lower boundaries, the fracture conductivity increases due to higher saturations, and the properties of the fracture network become more and more significant for the percolation flux. In the cases studied, the upper limit of the percolation flux is essentially determined by the geometry of the fracture network. As the permeability field does not contain a through-going fracture conduit from the top to the bottom, the fast flow in the fractures is blocked by low permeability matrix zones, giving rise to localized ponding effects. If a continuous fracture area existed in the domain, the maximum percolation flux would be orders of magnitudes higher than the values given in Table 6.

\subsection{Infiltration Pulse without Drift Impact (Scenario 2)}

As discussed above, at a low infiltration rate, flow occurs mainly through the matrix areas while high permeability features have low saturations. However, during a strong rainfall event throughgoing connected vertical fractures or faults may act as conduits for episodic, rapid flow of water through the unsaturated area of Yucca Mountain (cf. Figures 20, 21, and 22). As the wetting front moves in the fast conduit, significant amounts of water may be imbibed into the neighboring matrix, and the pulse propagation can be strongly retarded or even completely stopped, depending on the size of the infiltration pulse. However, observation of localized occurrences of ${ }^{36} \mathrm{CL}$ in the ESF indicates that rapid flow through the mountain into the $\mathrm{TSw}$ - unit is actually possible.

In this section we study the effects of an infiltration pulse that has arrived at the inflow boundary of the drift scale model domain by assuming a localized pulse of given size and duration, and follow its propagation through the flow field. We are interested in the propagation velocity of the pulse, the effect of heterogeneity on the pulse propagation, the amount of water imbibed into the matrix, and the possibility of water dripping into the drift under $100 \%$ humidity conditions in the tunnel. The latter is considered in Section 6.4, Scenario 4.

A number of recent investigations have focused on fast transient gravity-driven flux in throughgoing fracture or fault areas at Yucca Mountain and studied the feasibility of infiltration water penetrating the repository level (e.g. Nitao \& Buscheck, 1991; Nitao et al., 1992; Zimmerman et al., 1996; Fairley \& Sonnenthal, in progress; Altman et al., in press). Generally it was found that two necessary conditions must be met for a pulse to arrive at the ESF level: the presence of large permeability (fracture) pathways from the surface to depth, and a sufficiently large pulse size. However, very different boundary conditions were used in the above mentioned works, giving strongly varying pulse volumes at the fracture entrance. For example, Nitao \& Buscheck (1991), Nitao et al. (1992) and Zimmerman et al. (1996) assumed a ponded situation at the top boundary which gives rise to very large infiltration rates. On the other hand, Fairley \& Sonnenthal (in progress) prescribed fluxes at the top boundary (fracture entrance), using much smaller values. These studies therefore give rather different results, in particular with respect to the magnitude and temporal distribution of flux arriving at the repository level. Both parameters are a necessary input for our simulation runs.

In light of this uncertainty, we decided to study pulse sizes covering a wide range from $28 \mathrm{~mm} / \mathrm{yr}$ to $28000 \mathrm{~mm} / \mathrm{yr}$, injected in a fracture area at the top of the model domain. The latter value is similar to maximum pulses studied by Wang \& Narasimhan (1986) and Fairley \& Sonnenthal (in 
progress), and is smaller than expected when using ponded boundary conditions as in Nitao \& Buscheck (1991), Nitao et al. (1992) and Zimmerman et al. (1996). Fairley \& Sonnenthal (in progress) show in a simple geometrical analysis that strong rainfall events (e.g. $2 \mathrm{~cm} / \mathrm{hr}$ for $1 \mathrm{hr}$ precipitation) at Yucca Mountain can indeed generate localized pulses of the given maximum value with one week duration at the entrance to a fault area, assuming that the rain is captured in a basin, then saturates the alluvium layer and eventually enters the fault area. However, since our model domain is located at the ESF - level, which is several hundred meters below the ground surface, the pulse characteristics may be very different from that at higher elevations. The pulse magnitude is expected to be smaller, and its duration may be longer, due to the retarding effect of matrix imbibition and the impact of lateral flow at the PTn - horizon. In the present study continuous injection is applied at different rates and its effect is studied for different injection time periods.

\section{Sensitivity Analysis}

The propagation of an infiltration pulse in unsaturated fractured porous rock has a complex nonlinear behavior, due to the different time scales involved with rapidly transient fracture flow on the one hand and slow imbibition into the adjoining matrix on the other. Nitao \& Buscheck (1991) distinguish three characteristic time periods for the movement of a liquid front in a fracture which is bounded on two sides by matrix blocks of limited width. During period I, flow in the fracture is only weakly influenced by matrix imbibition. In period II, matrix imbibition retards fracture flow, with the matrix diffusive strength decreasing while the matrix saturations slowly increases. Finally, in period III, the imbibition front in the matrix reaches the lateral boundary (e.g. half-width of the block), and eventually stabilizes to a steady-state condition. Whether all three of these periods are actually relevant for a given pulse depends on a variety of parameters, such as the pulse volume and duration, the geometry of the system, the material properties, and the initial saturation. Therefore, before simulating more complex heterogeneous flow systems, we decided to study the sensitivity of some of these parameters for a simplified fracture-matrix system which features similar properties and dimensions. Results of our sensitivity analysis are given in the following.

Figure 18 shows the schematics of the flow domain, which extends $10 \mathrm{~m}$ in the vertical direction. It also depicts the finite difference discretization chosen for the TOUGH2 simulation runs. A vertical fracture area of $0.25 \mathrm{~m}$ width and $0.1 \%$ porosity is located in the center; the adjoining matrix area has a width of $2.5 \mathrm{~m}$. If not otherwise indicated, the properties of fracture and matrix are given by average parameter values of the respective ensembles presented in Section 3 . On the upper boundary, matrix blocks receive a steady-state infiltration rate as in Scenario 1, while infiltration pulses of different sizes are injected into the fracture area. The left and right boundaries are closed. The simulation starts from equilibrium, with the initial matrix saturation equal to 0.9 and the fracture essentially non-conducting. Note that the fracture - matrix interface was discretized with very small element dimensions in the $\mathrm{x}$ - direction to ensure an accurate approximation of the matrix diffusive strength.

Table 7 gives a list of the simulation runs performed in the sensitivity analysis, and presents a summary of the results. The first four runs denote the different infiltration fluxes, chosen as 
$28000 \mathrm{~mm} / \mathrm{yr}, 2800 \mathrm{~mm} / \mathrm{yr}, 280 \mathrm{~mm} / \mathrm{yr}$ and 28 $\mathrm{mm} / \mathrm{yr}$. The actual volumetric flow rates injected into the fracture area are quite small; they range from $0.8 \mathrm{liter} / \mathrm{hr}$ for Case 1 to $0.0008 \mathrm{liter} / \mathrm{hr}$ for Case 4 (calculated for a fracture area of $0.25 \mathrm{~m}$ width and $1 \mathrm{~m}$ depth). All these injection rates are smaller than the saturated capacity of the fracture area; i.e. the saturations in the fracture are smaller than 1 . For comparison purposes, an additional run was performed assuming a ponded boundary condition at the top (with an infiltration flux of 74700 $\mathrm{mm} / \mathrm{yr}$ ).

All other runs are performed with an infiltration flux of $28000 \mathrm{~mm} / \mathrm{yr}$, while different material properties are changed from the original data set. These cases are used to study the influence of matrix and fracture saturated permeabilities (Case 1A, 1B and $1 C$ ), of initial matrix saturation (Case $1 \mathrm{D}$ and $1 \mathrm{E}$ ), of van Genuchten parameters $1 / \alpha$ and $\beta$ (Case $1 F$, $1 \mathrm{G}, 1 \mathrm{H})$, and of a reduced interface area between fracture and matrix areas (Case 1I), as a result of channelized flow within the fracture plane.

For each case, we ran the simulations until the wetting front arrived at the lower boundary, and measured the travel time needed for that arrival to occur (Column 4 of Table 7). The arrival of the wetting front is defined by measuring saturation changes in the outflow fracture element, and checking if the saturation increases by a (somewhat arbitrarily chosen) few percent from the maximum change. For comparison purposes, we performed the same procedure for a single fracture without adjoining matrix blocks, while assuming the same properties and boundary conditions as before (Column 5). The ratio of the respective travel times gives an indication of how much the front propagation is retarded by imbibition into the matrix (Column 6).

Another interesting number is the ratio of the total amount of imbibed water versus the total amount of infiltrated water. This ratio is time-dependent because (1) the imbibition rate changes with the increase of saturation in the matrix and (2) the amount of imbibed water depends on the front propagation, as imbibition from the fractures into the matrix takes place only along such locations where the infiltration pulse has already passed. We decided to calculate the percentage of imbibed water for the time period from the start of the simulation until the wetting front arrives at the lower boundary (Column 3). Alternatively, we calculated the imbibition ratio for the time period needed to inject a given pulse volume of 9.6 liter. It turned out, however, that the characteristics reflected in the calculated imbibition ratios were similar for the two methods; therefore, only the results of the first method are presented here. 
Table 7: Pulse test simulation runs

\begin{tabular}{|c|c|c|c|c|c|c|}
\hline Case & {$\left[\begin{array}{l}\text { Description } \\
\text { (ortogat vatues itatio) }\end{array}\right.$} & $\begin{array}{l}\text { Imbibed } \\
\text { Water } \\
\text { Total Infil } \\
\text { tration } \\
\text { Iod }\end{array}$ & $\begin{array}{l}\text { Travel } \\
\text { Time } \\
\text { Fracture } \\
\text { with Matrix } \\
\text { [days] }\end{array}$ & $\begin{array}{l}\text { Trave } \\
\text { Time } \\
\text { Tracture } \\
\text { only } \\
\text { [days] }\end{array}$ & $\begin{array}{l}\text { Travel } \\
\text { Time Ratio } \\
\\
\end{array}$ & $\begin{array}{r}\text { Satuation } \\
\text { at } \\
\text { Tracture } \\
\text { Inlet } \\
\end{array}$ \\
\hline 1 & $\begin{array}{c}\text { Infiltration flux } \\
28000 \mathrm{~mm} / \mathrm{yr}\end{array}$ & 85.3 & 0.49 & 0.08 & 6.13 & 0.96 \\
\hline 2 & $\begin{array}{c}\text { Infiltration flux } \\
2800 \mathrm{~mm} / \mathrm{yr} \\
\end{array}$ & 97.3 & 17.50 & 0.62 & 28.14 & 0.82 \\
\hline 3 & $\begin{array}{l}\text { Infiltration flux } \\
280 \mathrm{~mm} / \mathrm{yr}\end{array}$ & 99.1 & 239.40 & 4.36 & 54.91 & 0.69 \\
\hline 4 & $\begin{array}{c}\text { Infiltration flux } \\
28 \mathrm{~mm} / \mathrm{yr}\end{array}$ & 98.1 & $585.90 *$ & 29.15 & 20.10 & 0.57 \\
\hline 5 & $\begin{array}{c}\text { Ponded Condition } \\
(74700 \mathrm{~mm} / \mathrm{yr})\end{array}$ & 73.9 & 0.12 & 0.03 & 4.29 & 1.00 \\
\hline $1 A$ & $\begin{array}{l}\text { Matrix Permeability } \\
5 \times 10^{-17} \mathrm{~m}^{2}\left(5 \times 10^{-18}\right)\end{array}$ & 98.4 & 4.50 & 0.08 & 56.25 & 0.96 \\
\hline $1 \mathrm{~B}$ & $\begin{array}{l}\text { Matrix Permeability } \\
5 \times 10^{-19} \mathrm{~m}^{2}\left(5 \times 10^{-18}\right)\end{array}$ & 39.4 & 0.13 & 0.08 & 1.63 & 0.96 \\
\hline $1 \mathrm{C}$ & $\begin{array}{|cc|}\text { Fracture Perm. } \\
10^{-11} \mathrm{~m}^{2} & \left(10^{-12}\right) \\
\end{array}$ & 60.3 & 0.14 & 0.06 & 2.30 & 0.60 \\
\hline 1D & $\begin{array}{c}\text { Initial Matrix Sat. } \\
0.95(0.9)\end{array}$ & $\frac{10.4}{70.4}$ & 0.24 & 0.08 & 3.00 & 0.96 \\
\hline 1E & $\begin{array}{c}\text { Initial Matrix Sat. } \\
0.8(0.9)\end{array}$ & 94.1 & 1.24 & 0.08 & 15.50 & 0.96 \\
\hline $\mathbf{T F}$ & $\begin{array}{c}\text { Pore Size Distrib. } \\
2.0 \quad(1.33)\end{array}$ & 93.7 & 0.95 & 0.08 & 11.88 & 0.80 \\
\hline $1 G$ & $\begin{array}{c}1 / \alpha-\text { Fracture } \\
7222 \mathrm{~Pa}(1681 \mathrm{~Pa})\end{array}$ & 84.2 & 0.39 & 0.08 & 4.88 & 0.96 \\
\hline 1H & $\begin{array}{c}1 / \alpha-\text { Matrix } \\
0.38 \mathrm{MPa}(0.75 \mathrm{MPa})\end{array}$ & 75.0 & 0.29 & 0.08 & 3.63 & 0.96 \\
\hline ii & $\begin{array}{c}\text { Interface Area } \\
\text { reduced to } 10 \%\end{array}$ & $\frac{60.3}{60.350}$ & D. & 0.08 & $\frac{2.38}{2.38}$ & 0.96 \\
\hline
\end{tabular}

* At this time, the lateral imbibition front in the matrix has already reached the two closed side boundaries. 
As evident from Table 7, the single most important factor in determining the impact of matrix imbibition on the pulse propagation is the volume of the infiltration pulse. As the infiltration rate decreases, the liquid front travel times increase significantly. This is true for the runs considering the complete fracture and matrix system as well as the runs simulating only the fracture area. However, the ratio of the travel times increases as well, indicating that the impact of matrix imbibition is more significant in the low infiltration cases. Case 4 is an exception from this trend; here the time period considered is long so that the imbibition front in the matrix actually reaches the closed lateral boundaries on the two sides of the flow domain, and the system eventually stabilizes to a steady-state condition. Checking the amount of water being imbibed into the matrix, the calculated numbers are quite high in all cases, ranging from $73.9 \%$ up to $99.1 \%$. This is somewhat surprising, since the model area has only a $10 \mathrm{~m}$ vertical extension.

Other parameters considered also affect the propagation of pulses. The matrix permeability directly influences the imbibition rate into the matrix pores. A higher fracture permeability gives rise to a smaller saturation in the fracture area (because the saturated flow capacity is much higher than the infiltration rate), and creates a higher capillary pressure in the fracture. Thus the capillary pressure gradient at the fracture - matrix interface decreases, giving rise to reduced matrix imbibition. The initial matrix saturation and the air entry pressures also affect the magnitude of the capillary gradient. The pore size distribution coefficient influences both the relative permeability function and the capillary pressure function. Here, the dominating effect of changing $\beta$ is the increase of relative permeability in the matrix, giving rise to a higher imbibition rate.

It is evident from this study that infiltration pulses lose significant amounts of water through imbibition into the matrix. The front travel times and fluxes appear to be dependent on all the studied parameters. Also, the dependence on some of the parameters is both non-linear (e.g. relative permeability on saturation) and time varying (e.g. saturation change with time). Further studies are being planned to investigate the implication and significance of these results.

\section{Infiltration Pulse for the Heterogeneous Flow System}

Initially, our simulation runs considering pulse infiltration involved the heterogeneous permeability fields as presented in Figures 7,8 and 9. However, none of these fields feature a throughgoing fracture area from the top to the bottom of the model area. It turned out that infiltration pulses injected in top fracture areas are almost completely stopped as soon as a barrier formed by a low permeable matrix area is reached. Even if the infiltration continues for a long time period, inducing a pressure build-up with ponded conditions in the fracture, the retarding effect of the barrier is still too strong to allow for a rapid propagation of a pulse. Thus, the existence of connected fractures is a necessary condition for fast gravity-driven flux at Yucca Mountain. Therefore, in a second set of simulations, we used the modified permeability field as presented in Figure 10 which comprises a continuous high permeability fracture area cutting through the entire model domain. Figure 19 gives a schematic "black and white" picture of this permeability field, with a threshold permeability of $10^{-14} \mathrm{~m}^{2}$. used to distinguish between fracture and matrix areas. 
We studied the same range of infiltration fluxes as in the previous section, namely $28000 \mathrm{~mm} / \mathrm{yr}, 2800 \mathrm{~mm} / \mathrm{yr}, 280 \mathrm{~mm} / \mathrm{yr}$ and $28 \mathrm{~mm} / \mathrm{yr}$. Injected into a $1 \mathrm{~m}$ wide fracture area at the top of the model area, the actual flow rates range from 3.2 liter/hr for Case 1 to $0.0032 \mathrm{liter} / \mathrm{hr}$ for Case 4 . The simulation runs start with the equilibrated initial condition for a steady-state infiltration (Scenario 1). Example results are presented for Case 1 with $28000 \mathrm{~mm} / \mathrm{yr}$ in Figure 20, showing the changes in flux magnitude compared to the initial situation for time steps 1 hour and 4 hours after infiltration start. Note that only the center portion of the model area is shown in these figures, extending from $x=4 \mathrm{~m}$ to

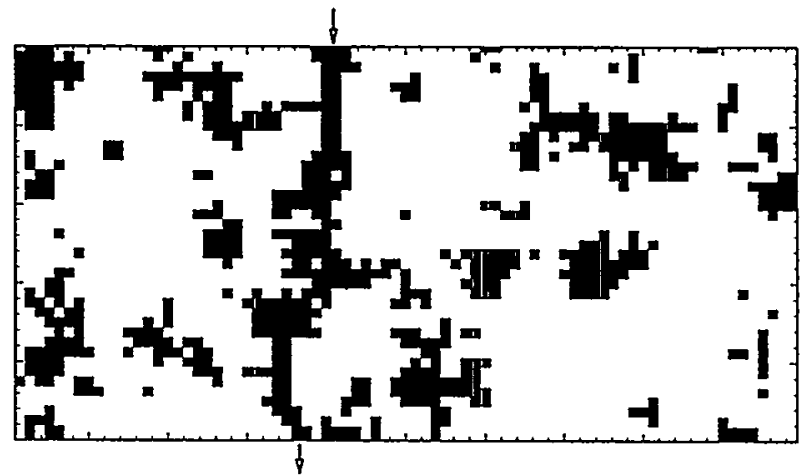

Figure 19 "Fracture" (black) and "matrix" areas (white) in the YZ plane. Arrows delineate the through-going fracture. Compare to Figure 10. $x=12 \mathrm{~m}$. Also note that the fluxes are given in a logarithmic scale. It is evident, that at a high infiltration flux, fast vertical flow is possible when a continuous pathway exists. The wetting front arrives at the lower boundary after about 3.8 hours. Part of the infiltrated water is being imbibed into the matrix, as can be seen from the increase of fluxes in the adjoining matrix blocks. The flux in the connected fracture area is mainly vertical, while flux in the matrix is mainly perpendicular to the fractures, induced by the capillary suction gradient.

\section{1 hour}

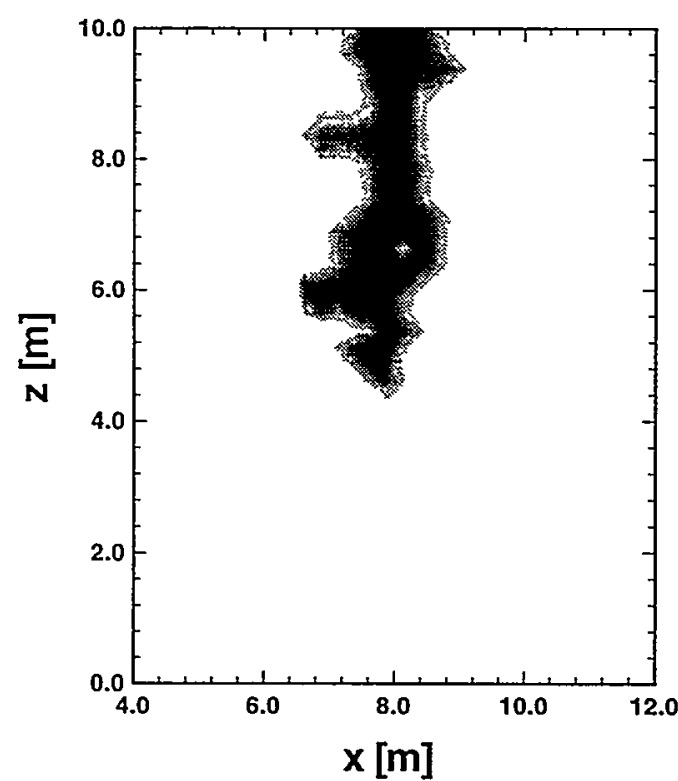

\section{4 hours}

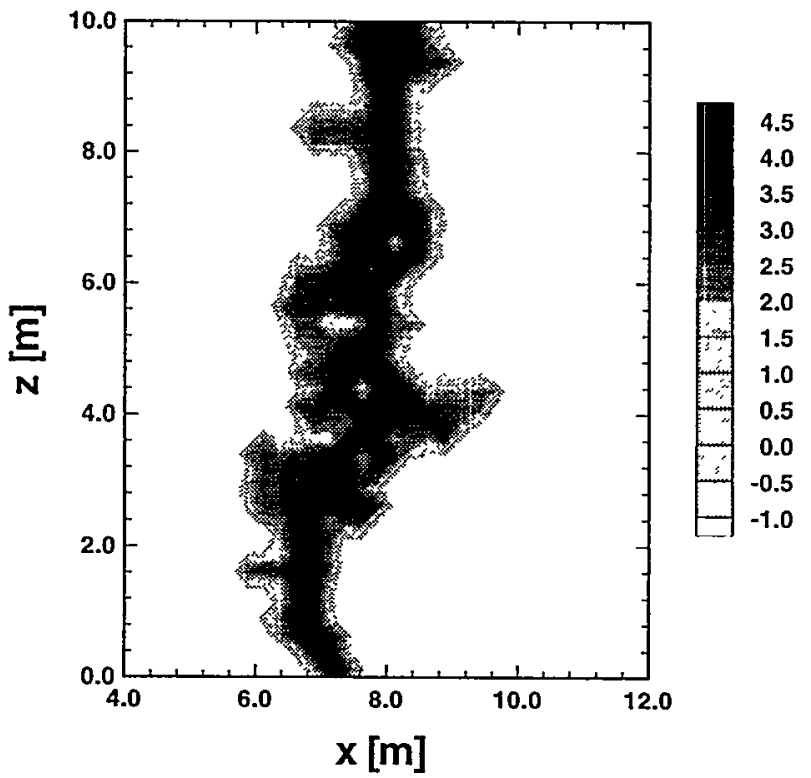

Figure 20 Increase of flux magnitude compared to initial simulation in the $\mathrm{YZ}$ - plane for a $28000 \mathrm{~mm} / \mathrm{yr}$ pulse (in $\log _{10} \mathrm{~mm} / \mathrm{yr}$ ). 
Our model results indicate that the pulse propagation is mostly influenced by the large contrast in fracture and matrix flow properties; the heterogeneity within each ensemble seems less important. This is mainly due to the strongly dynamic nature of the pulse flow and the very short time scale involved in Case 1; the time period considered is simply not long enough to induce a significant response in the matrix. As a consequence, the results obtained for all cases with the heterogeneous field feature similar characteristics as the simplified system in the previous section. However, for lower infiltration rates as in Case 4, the propagation of the front is much slower, and larger parts of the matrix are affected if the infiltration is sustained over a long enough period. Then, the heterogeneity within the matrix ensemble may have a greater impact. It should be mentioned at this point that the discretization used in these pulse runs could not be as refined at the fracture-matrix interface as in the sensitivity study in the previous section. Therefore the approximation of the capillary suction gradient is less accurate, leading to underestimated imbibition rates and an overestimated pulse propagation velocity.

Additional simulations were performed with a modified boundary condition at the top. In all previous calculations it was assumed that a localized pulse reaches the model area, as a result of a fast continuous pathway connecting the surface with the ESF. As this procedure might already prejudice our results, we studied, in a more theoretical manner, the case when the infiltration pulse is spread over the entire width of the upper model boundary. We assumed the pulse volumes to be consistent with the other cases; i.e. flow rates ranging from $3.2 \mathrm{liter} / \mathrm{hr}$ to 0.0032 liter/hr were injected over the entire $20 \mathrm{~m}$ cross section. (Note that the respective infiltration fluxes range from $1400 \mathrm{~mm} / \mathrm{yr}$ to $1.4 \mathrm{~mm} / \mathrm{yr}$ ). To allow the water to freely enter the flow domain according to the local unsaturated permeability and pressure gradient, an additional layer of elements was added on the top of the model with a large horizontal flow capacity, and a uniform infiltration rate was introduced into each element. In a natural system, one could consider this additional layer to represent a homogeneous unit above fractured porous rock, with a relatively high horizontal permeability allowing for a non-uniform infiltration into the underlying formation.

Figures 21 and 22 show results obtained with the new boundary condition and an injection rate of $3.2 \mathrm{liter} / \mathrm{hr}$ which corresponds to Case 1 . The figures give the increase in flux magnitude compared to the initial situation for time steps 2 hours and 16 hours after the infiltration starts. Two characteristic time periods can be distinguished: In the beginning, the infiltrated water saturates all fracture areas which intersect the top boundary, and the infiltrating water is almost uniformly distributed among them. In later stages, however, only the through-going fracture area acts as a conduit for rapid vertical flux; the liquid front reaches the bottom boundary after approximately 15 hours. The propagation in non-continuous fractures stops at matrix "barriers", and positive pressures build up there. Eventually, the infiltration into these non-connected fractures significantly decreases, because an equilibrated state has been reached, and the majority of the pulse is focused to the entrance of the connected fracture area. Compared to the pulse propagation of the previous cases where a localized infiltration is applied only at the continuous fracture, the distributed pulse here leads to a vertical flow delay, because in early periods less water is injected into the connected fracture. However, after this initial delay, the pulse propagation is similar to that in the previous simulations. 


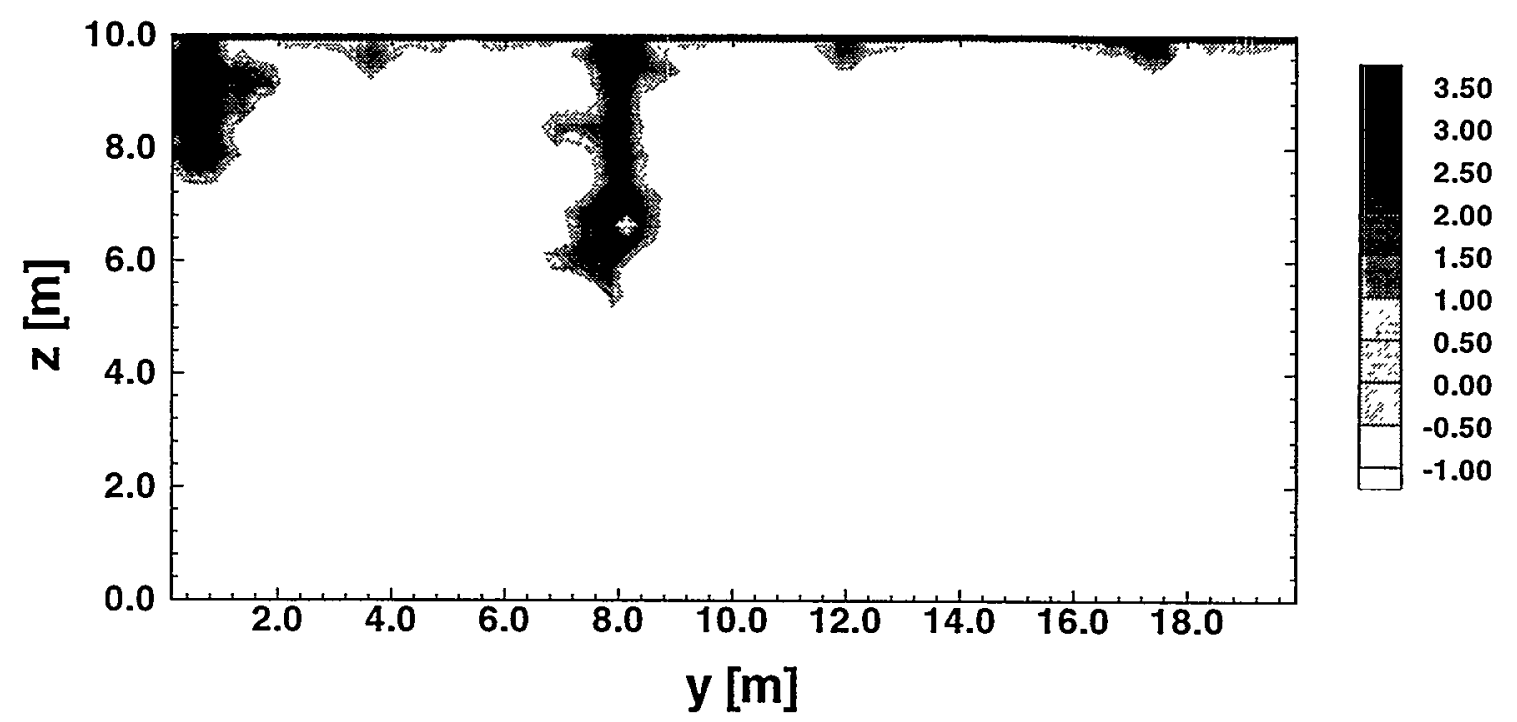

Figure 21 Increase of magnitude of flux compared to initial simulation in the $\mathrm{YZ}$ - plane after 2 hours for a $28000 \mathrm{~mm} / \mathrm{yr}$ pulse (in $\log _{10} \mathrm{~mm} / \mathrm{yr}$ ).

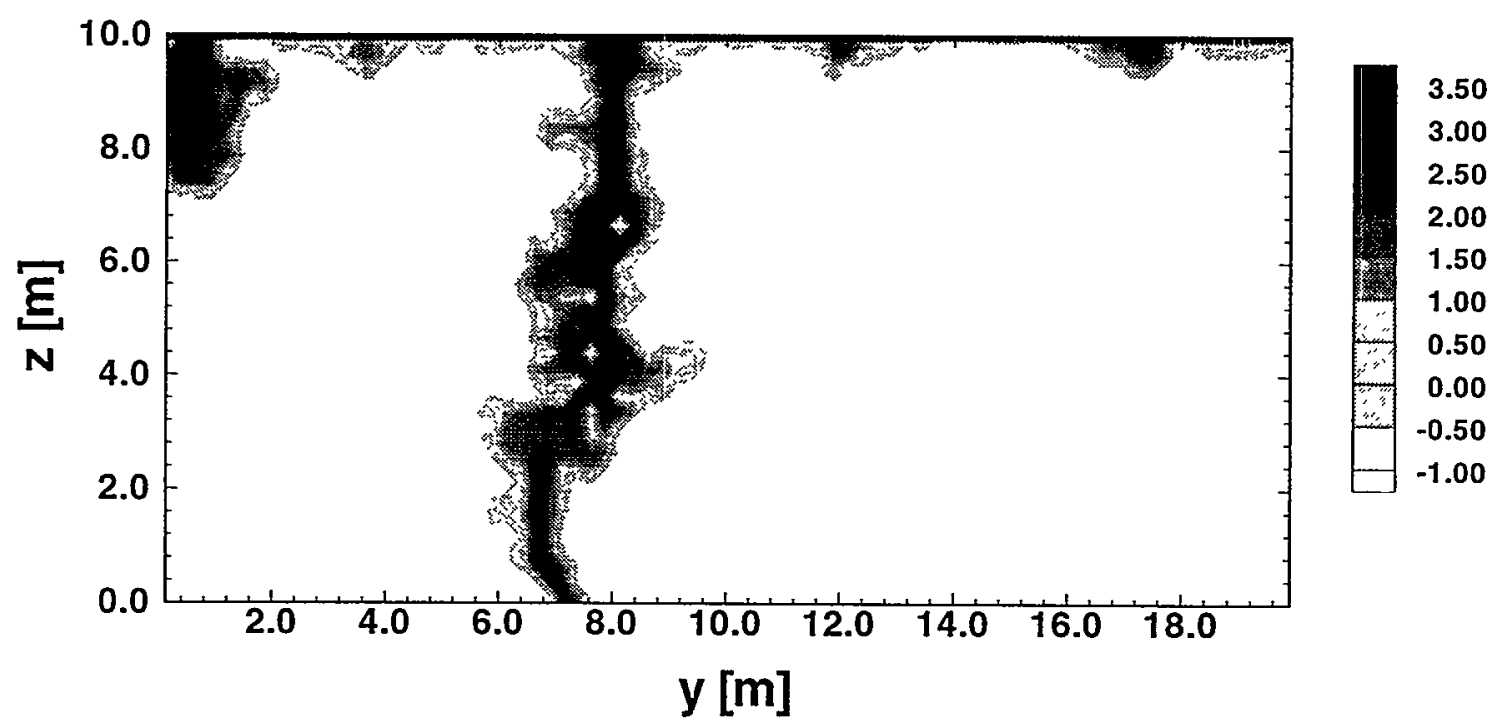

Figure 22 Increase of magnitude of flux compared to initial simulation in the YZ - plane after 16 hours for a $28000 \mathrm{~mm} / \mathrm{yr}$ pulse (in $\log _{10} \mathrm{~mm} / \mathrm{yr}$ ). 


\subsection{Drift Simulation with Ventilation (Scenario 3)}

The objective in this section is to investigate the magnitude and variation of water movement towards the drift under ventilated conditions in the ESF. Eventually, it may be possible to correlate the simulated fluxes towards the drift with the infra-red images of evaporation-induced temperature changes observed on the drift wall. Qualitatively, this can help to understand the permeability heterogeneity on a local scale; quantitatively, it may lead to better estimates of formation properties such as rock permeabilities, porosities etc.

The impact of the drift is modeled by applying a strong capillary suction at the tunnel walls, representing the evaporation of formation water at the surface. As was explained in Section 5.2, the equivalent capillary suction value can be calculated using Kelvin's law given in equation (3). The simulation runs start with the equilibrated initial condition for a steady-state infiltration. Then the equivalent suction boundary condition $P_{\text {cap }}=-93.1 \mathrm{MPa}$ is instantly applied at the drift wall while the upper and lower boundary conditions remain unchanged. Examples of results are shown for the $\mathrm{XZ} \_1$ plane. For comparison purposes, the spatial distribution of "fracture" areas $\left(\mathrm{k} \geq 10^{-14} \mathrm{~m}^{2}\right)$ and "matrix" areas $\left(\mathrm{k}<10^{-14} \mathrm{~m}^{2}\right)$ is depicted in Figure 23. Figures 24,26 and 28 give the spatial distribution of flux in the model area for a series of three time steps, chosen to be 1 day, 1 year and 10 years after imposing the drift wall boundary condition. Figures 25, 27 and 29 show the changes in saturation compared to the initial situation for the same time steps.

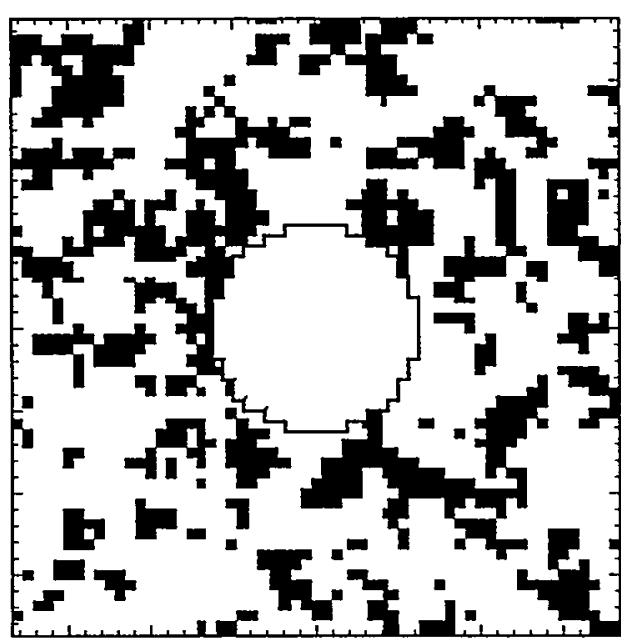

Figure 23 "Fracture" (black) and "matrix" areas (white) in the XZ_1 plane. Compare to Figure 8.

As can be seen from Figure 24, the capillary pressure boundary on the drift wall enforces an immediate response in the adjoining blocks, with the flux rate towards the tunnel being several orders of magnitude higher than the average flux. (Note that the fluxes are given in a logarithmic scale.) This induces a change of water content in the formation; the system slowly desaturates. However, the depth of the affected area is very small for the first time step, and it propagates very slowly, as can be seen in Figures 27 and 29 . After one year, an area of approximately $2 \mathrm{~m}$ from the drift wall appears to be affected; after 10 years, the penetration has almost reached the upper and lower model boundaries. However, a steady-state situation has not yet been achieved, and our simulations show that the system would need at least 10000 years to equilibrate, due to the small permeabilities in the formation. 


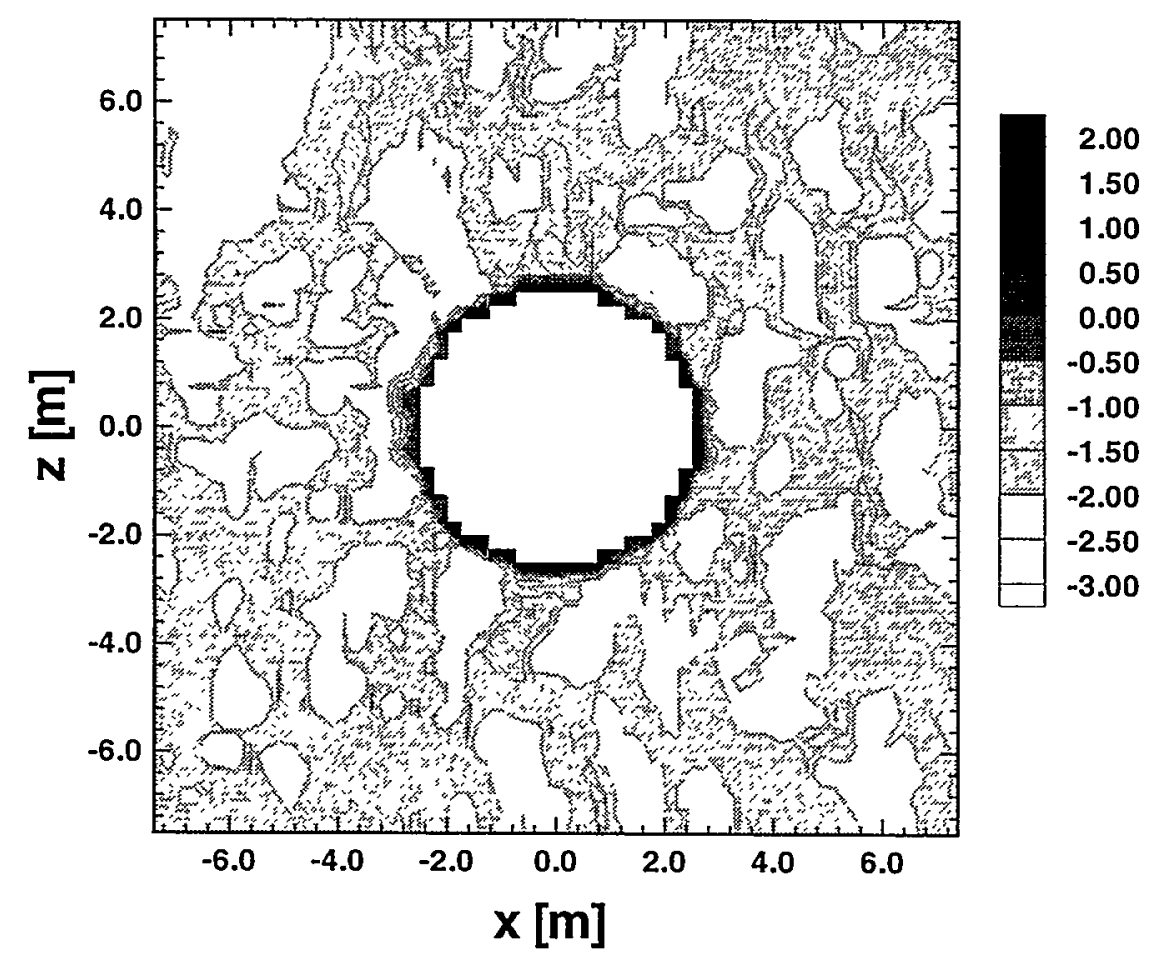

Figure 24 Magnitude of flux in the $\mathrm{XZ}_{-} 1$ plane after 1 day (in $\log _{10} \mathrm{~mm} / \mathrm{yr}$ )

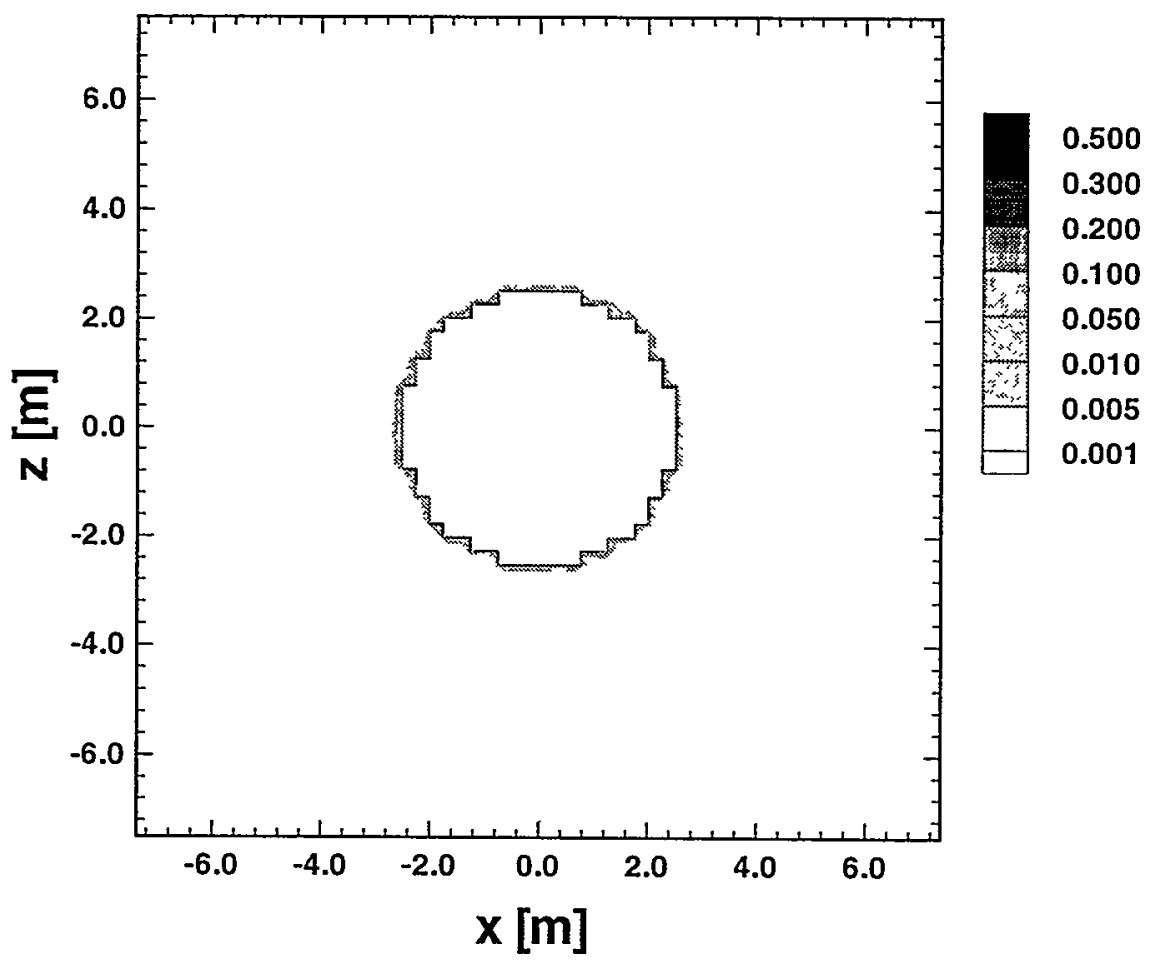

Figure 25 Decrease in saturation compared to initial situation in the XZ_1 plane after 1 day 


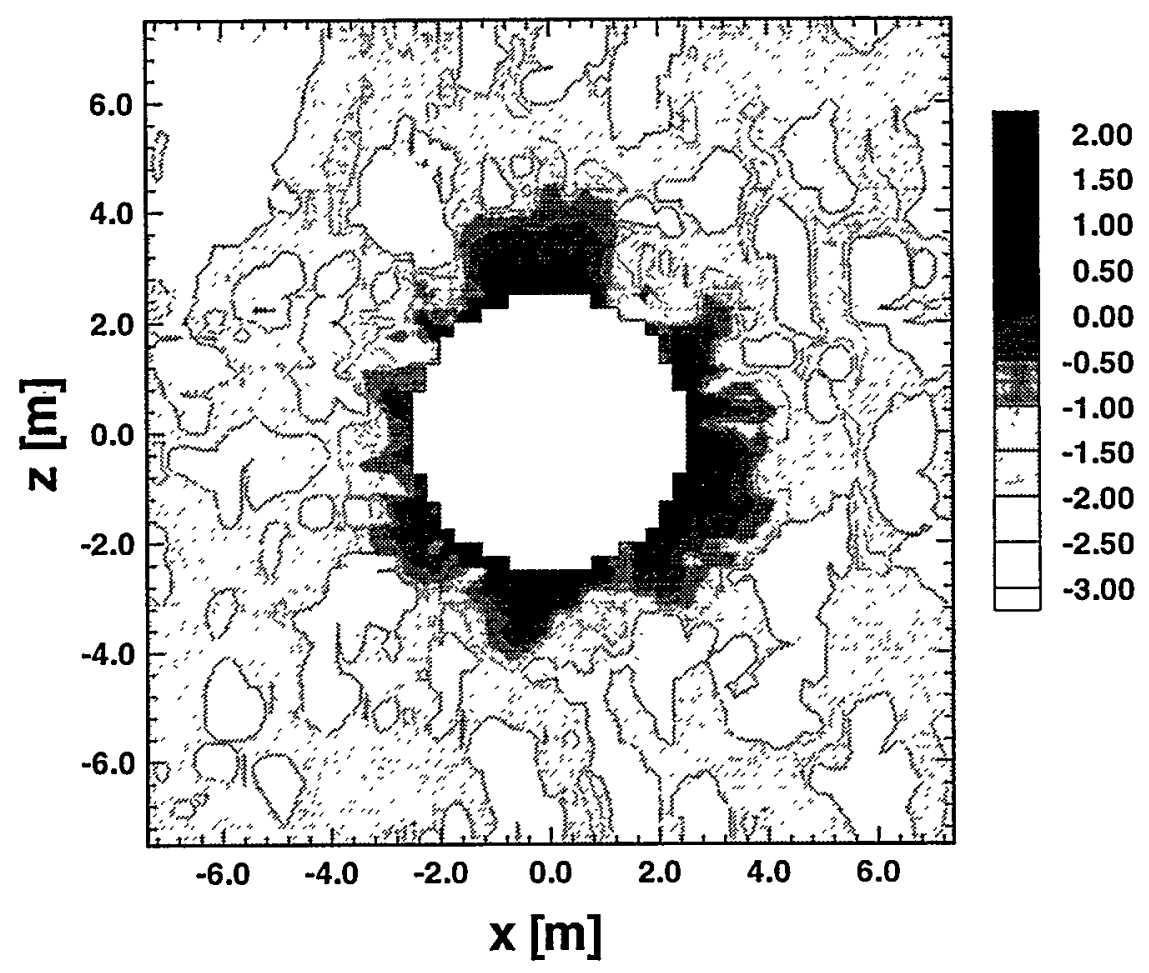

Figure 26 Magnitude of flux in the $X Z$ _1 plane after 1 year (in $\log _{10} \mathrm{~mm} / \mathrm{yr}$ )

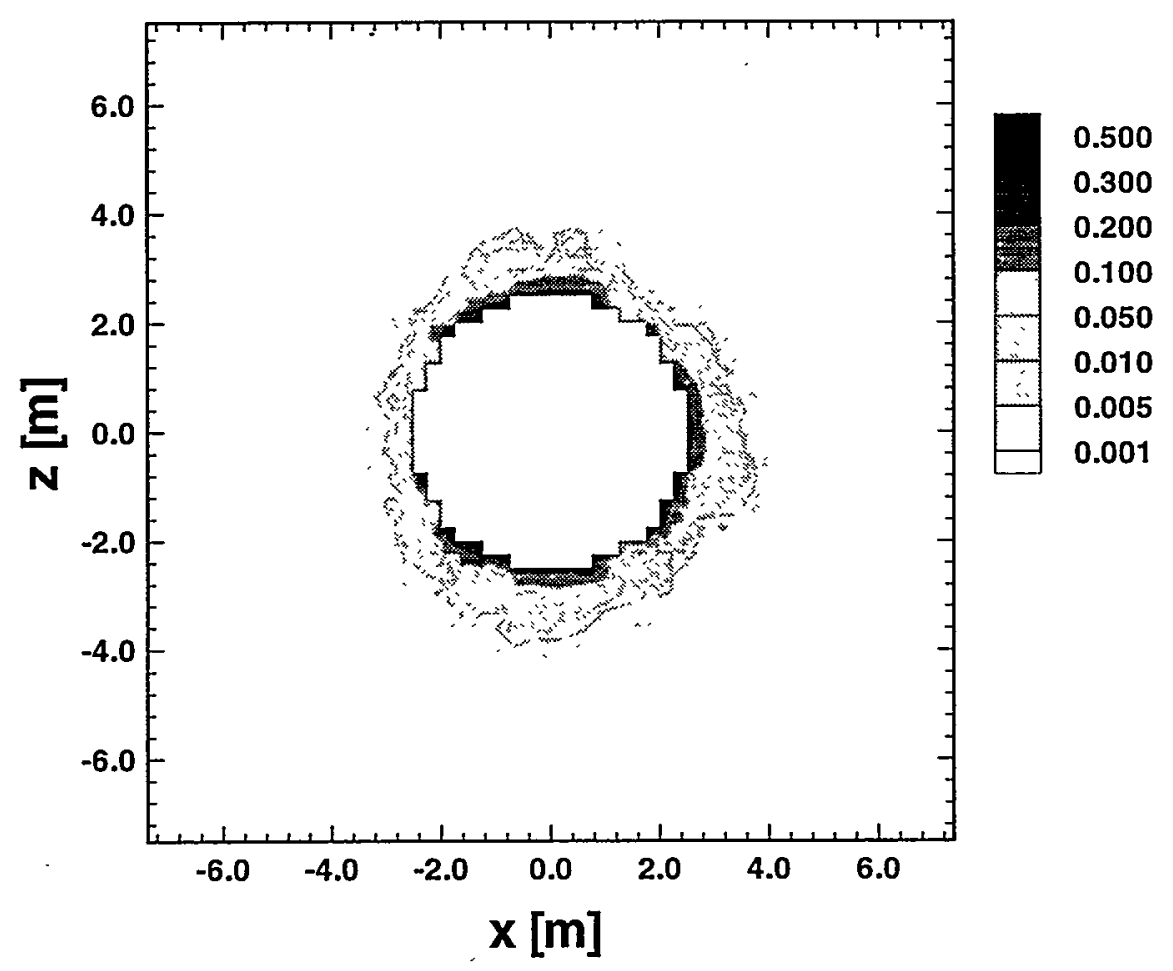

Figure 27 Decrease in saturation compared to initial situation in the $\mathrm{XZ} \_1$ plane after 1 year 


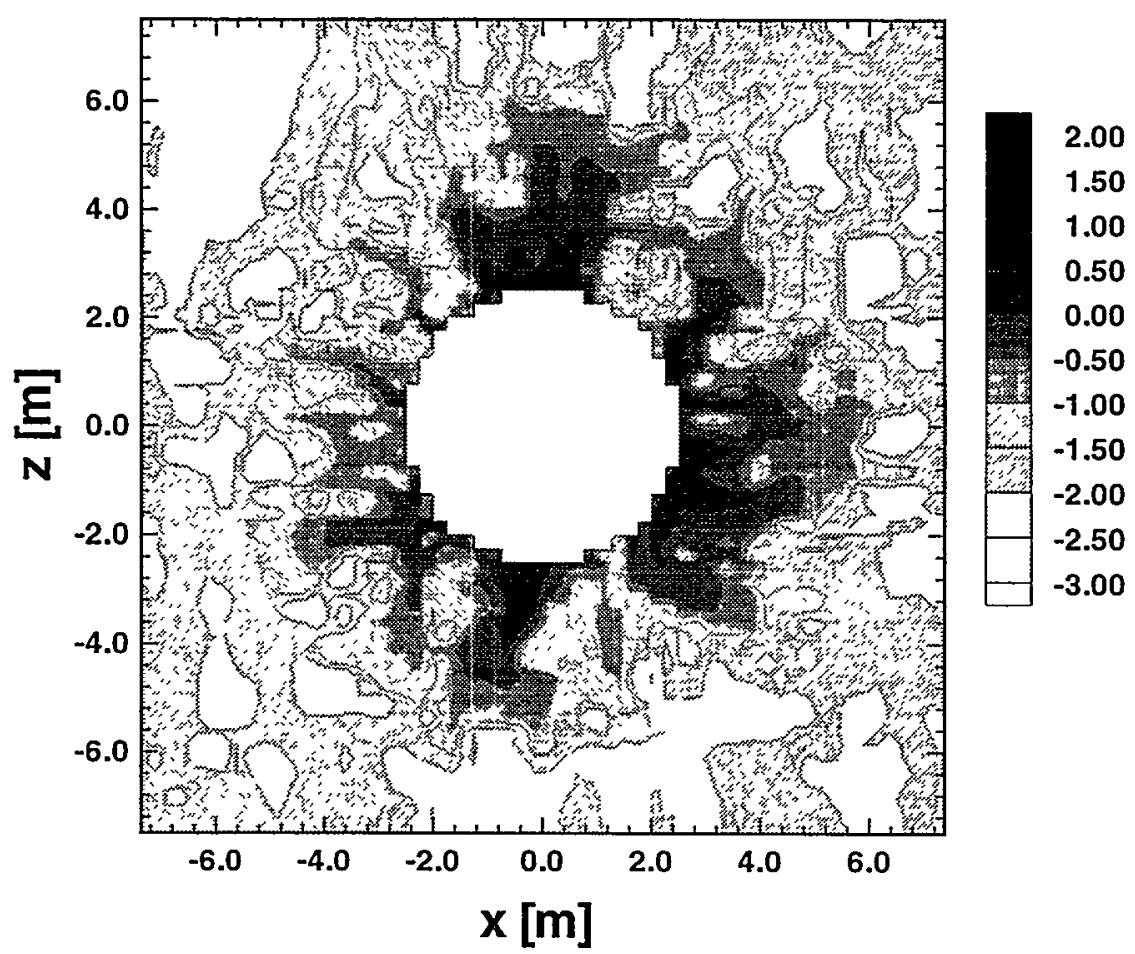

Figure 28 Magnitude of flux in the XZ_1 plane after 10 years (in $\log _{10} \mathrm{~mm} / \mathrm{yr}$ )

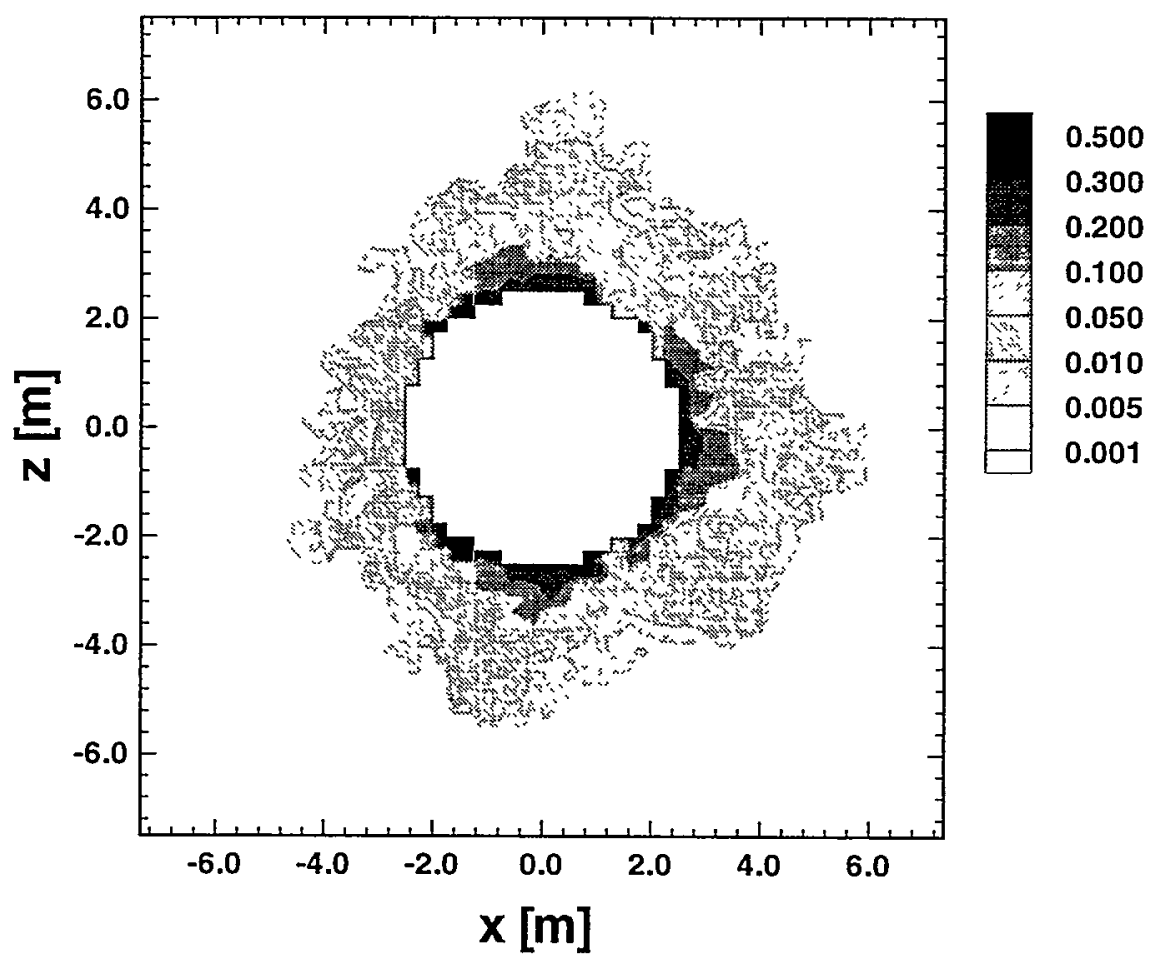

Figure 29 Decrease in saturation compared to initial situation in the $\mathrm{XZ}_{-} 1$ plane after 10 years 
Comparison with Figure 23 indicates that the drift evaporation mainly involves the "matrix" portion of the model area. Since the constant upper and lower boundary conditions represent a steady-state net infiltration into the system, the "fracture" areas have very low initial saturation values. Thus the strong suction towards the drift reduces the water content in the fractures only minimally. This, however, would totally change if an infiltration pulse of large rate was considered, or if the simulation started with "wet" conditions in the fractures near the drift. The latter could be a reasonable initial condition right after drift drilling when the drift walls are sprayed with water as part of the drilling process. This aspect was not studied in this report and needs further investigation.

Figure 30 depicts the spatial distribution of inflow along the ceiling and the side walls of the drift. The $0^{\circ}$ angle denotes the top of the circular tunnel; positive angles represent the upper right wall, negative angles represent the upper left wall. Remember that these fluxes do not refer to actual liquid flow into the drift; they rather give the amount of incoming formation water evaporating at the drift surface. Also note the different scales of the vertical axis chosen for the three time steps given. The maximum flux values presented on the vertical axis are $200 \mathrm{~mm} / \mathrm{yr}$ at 1 day, 10 $\mathrm{mm} / \mathrm{yr}$ at 1 year and $5 \mathrm{~mm} / \mathrm{yr}$ at 10 years. All time steps show a strong spatial variability of the flux. It turns out that higher flux values coincide with matrix areas adjacent to the drift; the smaller values coincide with fracture areas. The question of how well this behavior matches the actual temperature changes observed in the ESF needs further investigation. The sequence of figures in Figure 30 indicates how rapidly the evaporation rate at the drift wall decreases with time as the flow regime desaturates. For example, the average fluxes are $86.2 \mathrm{~mm} / \mathrm{yr}$ at 1 day, 2.9 $\mathrm{mm} / \mathrm{yr}$ at 1 year and $0.7 \mathrm{~mm} / \mathrm{yr}$ at 10 years. All these values are relatively small, but still much higher than the percolation flux for the steady-state system, which is $0.014 \mathrm{~mm} / \mathrm{yr}$. Despite the differences in magnitude of fluxes, the spatial distribution around the drift wall is similar for all time steps. 

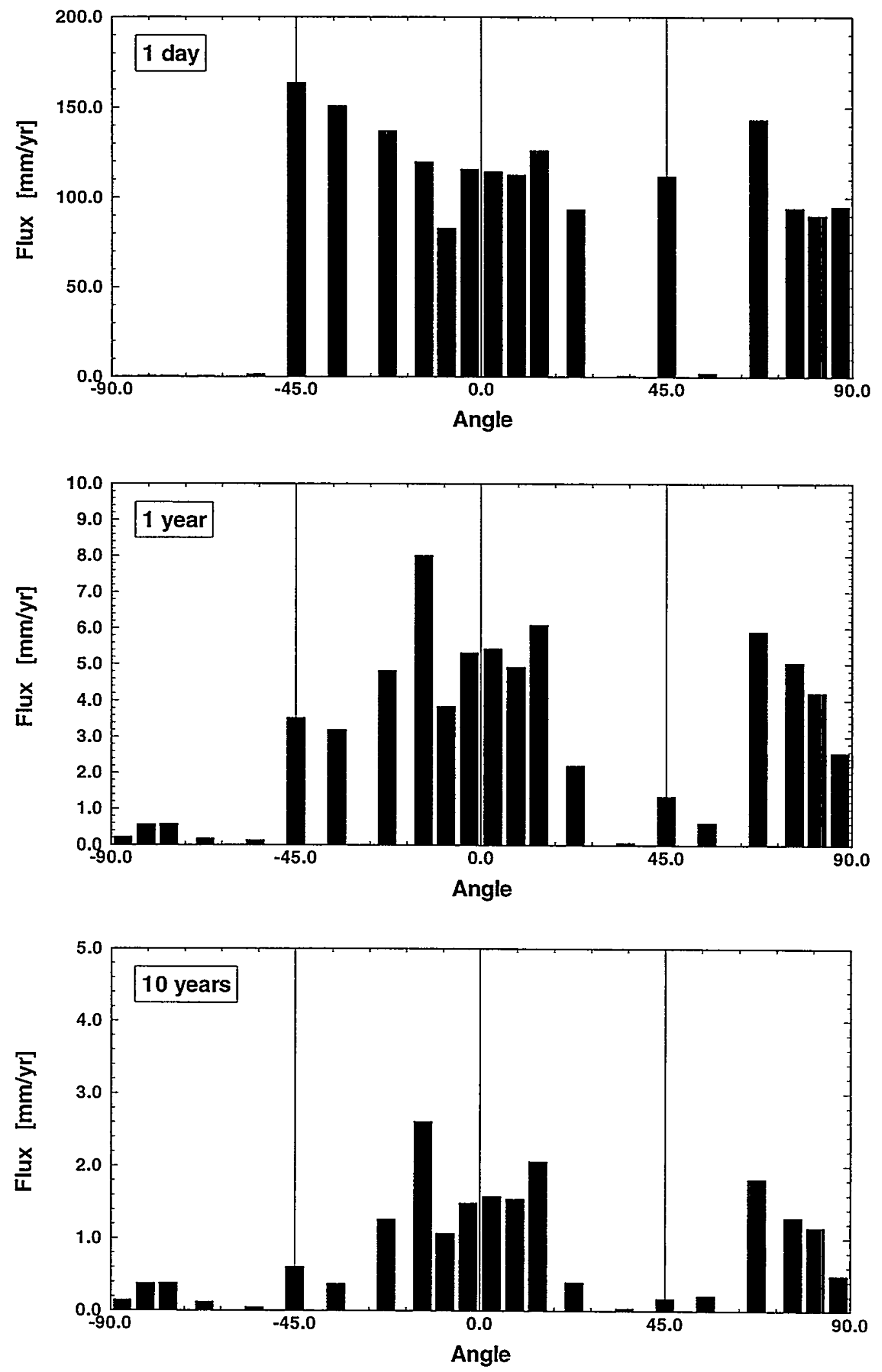

Figure 30 Spatial distribution of fluxes along the ceiling and side walls of the drift for the $\mathrm{XZ} \_1$ plane 
Figure 31 depicts the average rate of water evaporating at the drift wall as a function of time, over the first year after the drift has been drilled. Though only the case of $X Z \_1$ was presented in detail above, here the results for all three cross sections XZ_1, XZ_2, and YZ are included. The temporal distribution of the inflow / evaporation rate is quite similar for the different permeability fields of these cross sections. All curves start with relatively high fluxes in the beginning, and decrease rapidly with time. It should be mentioned at this point that similar simulations have been performed with different relative humidity levels in the tunnel. The results, however, proved to be quite insensitive to the actual values of relative humidity, as long as the equivalent capillary pressure induced by surface evaporation was large enough to overcome the capillary suction in the formation (which is the situation in our cases with relative humidity up to $\sim 99 \%$ ).

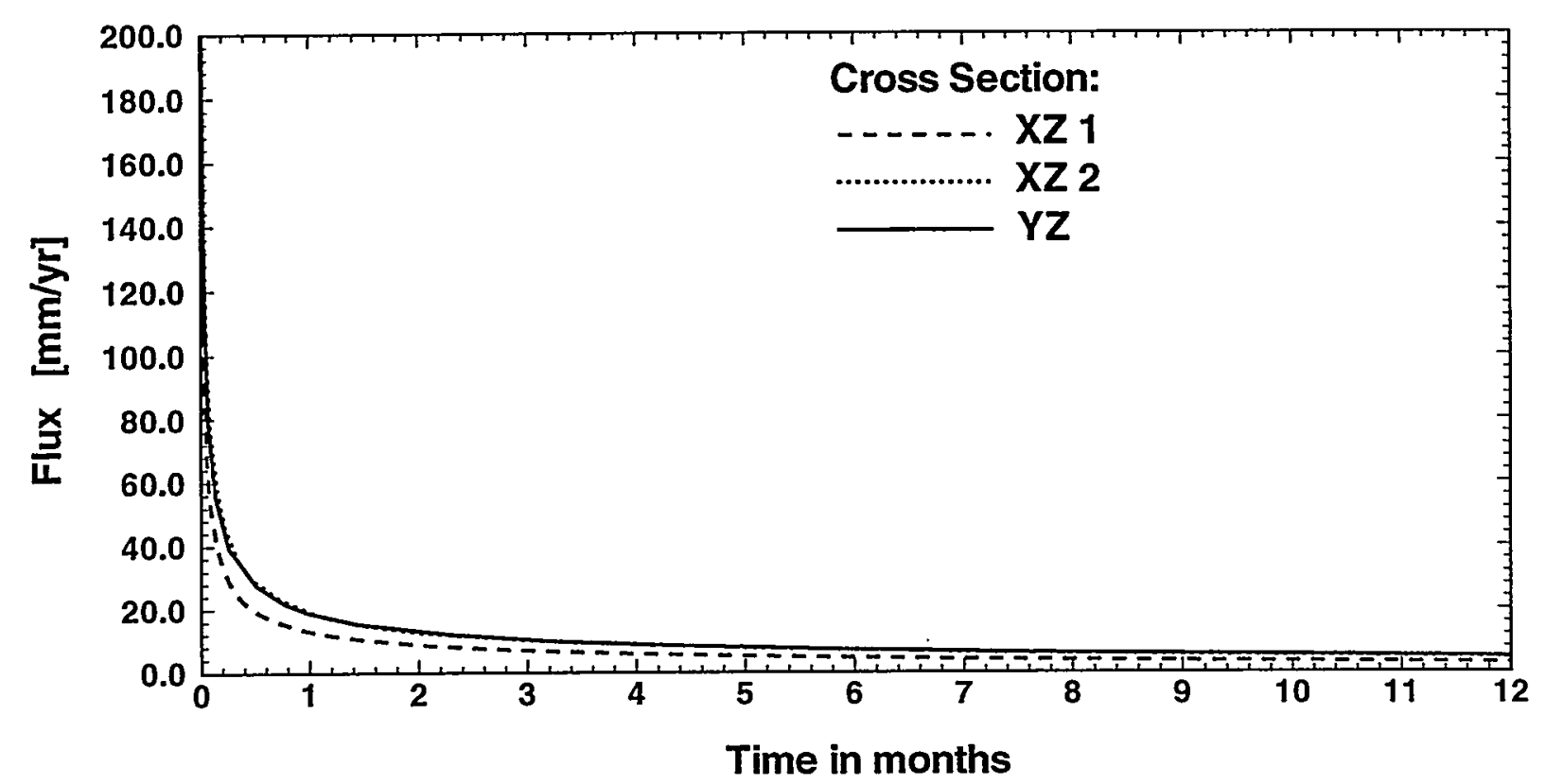

Figure 31 Fluxes at the drift wall as a function of time 


\subsection{Long-Term Drift Simulation with Steady-State and Pulse Infiltrations (Scenario 4)}

For the PA, it is useful to understand the long-term behavior of the flow field in the drift vicinity. It is assumed that the repository has been closed and sealed, the waste canisters have already cooled off and the relative humidity in the drift has returned to $100 \%$. In particular, the question is whether percolating water will bypass the tunnel, or whether it can drip into the tunnel under certain conditions. We addressed this topic by studying both the steady-state situation (with a constant net infiltration) and transient infiltration pulses. Examples of these simulations will be presented for the XZ_1 plane.

A necessary condition for water entering the drift is a positive pressure in the formation adjoining the drift walls (i.e. local ponded condition); only then it is possible to overcome the capillary barrier formed by the $\mathrm{P}_{\text {cap }}=0$ boundary condition which represents the $100 \%$ relative humidity in the tunnel (Equation 3). For the steady-state case, no dripping into the tunnel could be observed. The infiltration rate is too small to allow for ponded conditions at any location in the model area; the percolating water always finds a continuous (low-permeable) pathway around the drift. However, this changes when a large infiltration pulse propagates towards the drift in a continuous fracture feature. We studied this scenario using the modified permeability field shown in Figure 11 which comprises a connected fracture area from the top of the model area to the tunnel. Figure 32 shows the spatial distribution of fracture and matrix areas in a schematic "black and white" presentation, using a threshold permeability value of $10^{-14} \mathrm{~m}^{2}$.

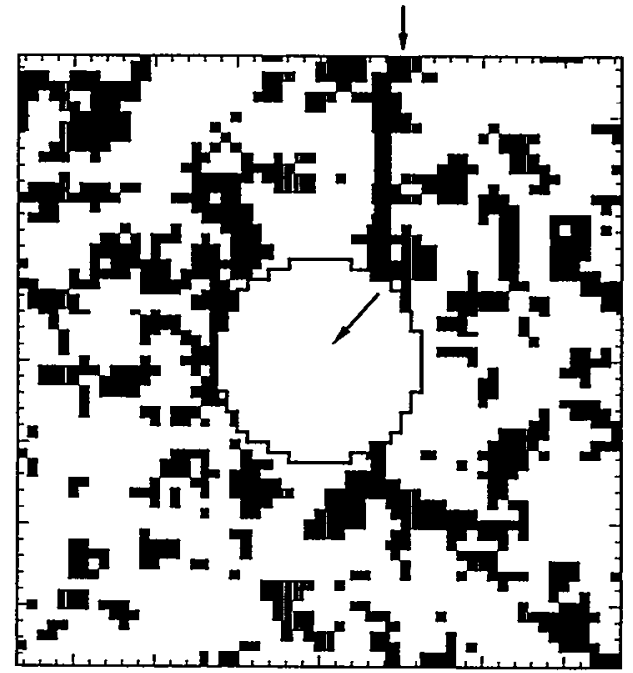

Figure 32 "Fracture" (black) and "matrix" areas (white) in the $X Z \_1$ plane. Arrows delineate the throughgoing fracture. Compare to Figure 11.

We studied the same range of infiltration fluxes as in Section 6.3, namely $28000 \mathrm{~mm} / \mathrm{yr}, 2800$ $\mathrm{mm} / \mathrm{yr}, 280 \mathrm{~mm} / \mathrm{yr}$ and $28 \mathrm{~mm} / \mathrm{yr}$. The water is injected into a $0.5 \mathrm{~m}$ wide fracture area at the top of the model area, which gives flow rates ranging from $1.6 \mathrm{liter} / \mathrm{hr}$ for Case 1 to $0.0016 \mathrm{liter} / \mathrm{hr}$ for Case 4. It turned out that in the first three cases water actually drips into the tunnel. Figures 33, 34 and 35 depict the changes in flux magnitude compared to the initial situation for these cases, showing the flow field immediately after water first enters the tunnel. No dripping was seen in case of the $28 \mathrm{~mm} / \mathrm{yr}$ infiltration, even for a very long pulse duration. Instead, water of the pulse travels downwards around the drift. Figure 36 shows the flow field for that case after 10000 days of infiltration. Note that all figures depict only the upper right part of the model area. Also note the different scales used for the contouring. 
Different characteristic time periods can be distinguished for the pulse. In the first period, the wetting front moves rapidly in the connected fracture area until it hits the drift. The saturation is still smaller than 1 , and the drift acts as a capillary barrier. Then, since the fracture area is not connected all the way down, the front propagation is blocked, and the saturation increases locally. If the pulse sustains through this second period with limited matrix imbibition, the fracture area eventually becomes fully saturated and positive pressures build up. At this time, water starts dripping into the tunnel (period $\mathrm{II}$ ). The dripping will stop at the end of the pulse period when the fracture desaturates through water imbibing into the neighboring low permeability areas.

For pulses of $28000 \mathrm{~mm} / \mathrm{yr}, 2800 \mathrm{~mm} / \mathrm{yr}$ and $280 \mathrm{~mm} / \mathrm{yr}$, we obtained all three characteristic periods mentioned above in our simulation runs (including dripping into the tunnel), provided that the pulse duration was long enough. At present, when results are still preliminary, we do not provide exact numbers for the minimum pulse size and duration because of the possible inaccuracies due to the relatively coarse discretization at the fracture-matrix interfaces. However, the general pattern observed should be valid; the range of time periods appears to be similar to the range of pulse travel times given in Table 7, i.e. in the order of several hours in Case 1, several days in Case 2 and a few hundred days in Case 3. Generally, the smaller the infiltration rates, the longer is the time period before water starts dripping into the tunnel. This is evident from Figures 33,34 and 35, when comparing the different sizes of the matrix area affected by the pulse. Also the ratio of the dripping time (i.e. the beginning of period III) versus the time when the liquid front first arrives at the tunnel (i.e. the beginning of period II) increases with smaller infiltration volume. In these cases, it takes longer to saturate the fracture area because of (a) the slower pulse propagation and (b) the stronger effect of matrix imbibition.

For the case with $28 \mathrm{~mm} / \mathrm{yr}$ infiltration, the effect of matrix imbibition is so strong that no water drips into the tunnel at any time. Still, the pulse moves rapidly towards the drift (period I), and the water saturation increases in the fracture area adjoining the drift walls (period $\mathrm{M}$ ). However, the system never reaches a fully saturated condition, even if the pulse is sustained for a very long time period. As a consequence, the infiltrated water bypasses around the tunnel (Figure 36).

An interesting observation is that the location where the water actually enters the tunnel varies for the different cases, as indicated by the arrows in Figures 33, 34 and 35. For the high pulse volume of $28000 \mathrm{~mm} / \mathrm{yr}$, the infiltration front drips into the tunnel where it first hits the drift wall. If the infiltration continues, it also enters the tunnel at other, more downstream locations. For the $2800 \mathrm{~mm} / \mathrm{yr}$ and $280 \mathrm{~mm} / \mathrm{yr}$ infiltration cases, water bypasses part of the tunnel wall, and drips into the drift at the location where the fracture pathway is blocked by a low permeability area. Apparently, in the first case the flux rate is so high that a positive pressure is already induced by the lateral diversion of the flow when the front first hits the tunnel without the need of blocked flow due to a low permeability area. In the other cases, positive pressures can only build up when the front reaches the end of the connected fracture pathway. 


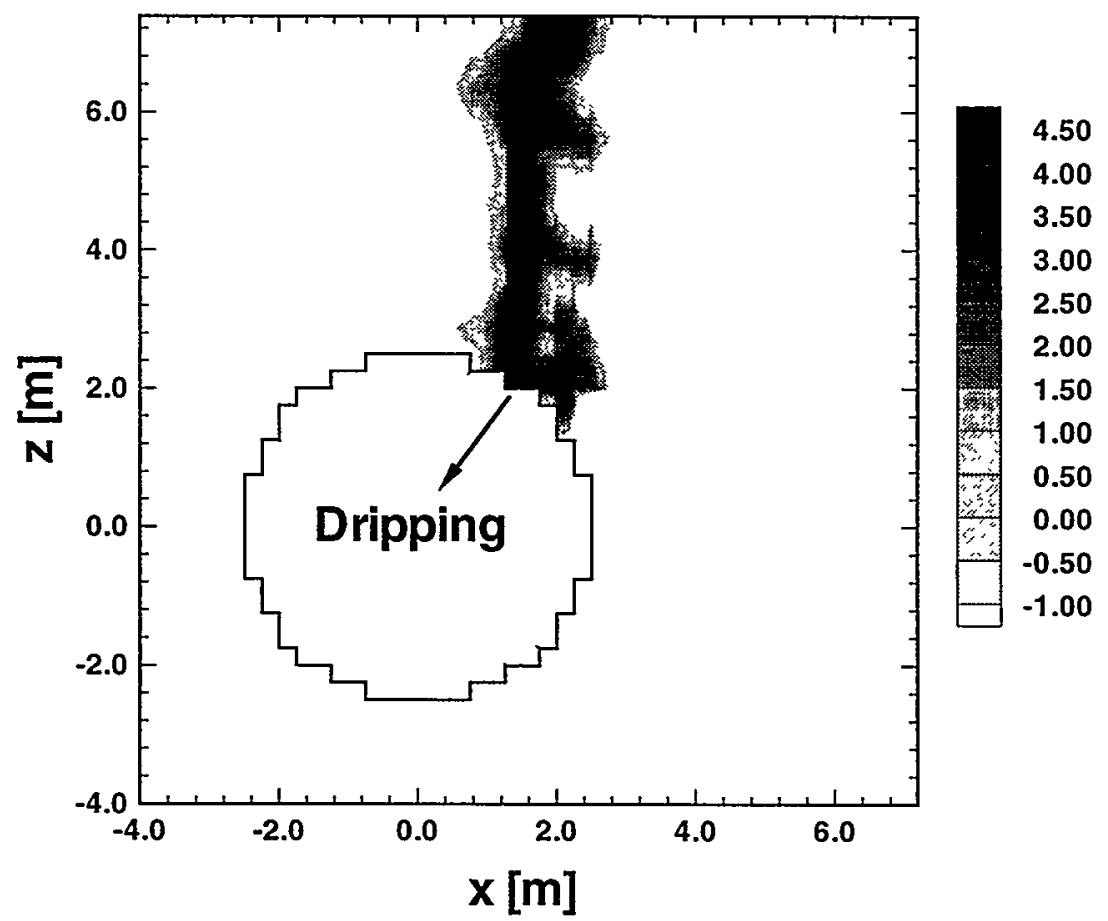

Figure 33 Increase of flux magnitude compared to initial situation in the $\mathrm{XZ} \_1$ plane for a $28000 \mathrm{~mm} / \mathrm{yr}$ pulse immediately after dripping starts (in $\log _{10} \mathrm{~mm} / \mathrm{yr}$ )

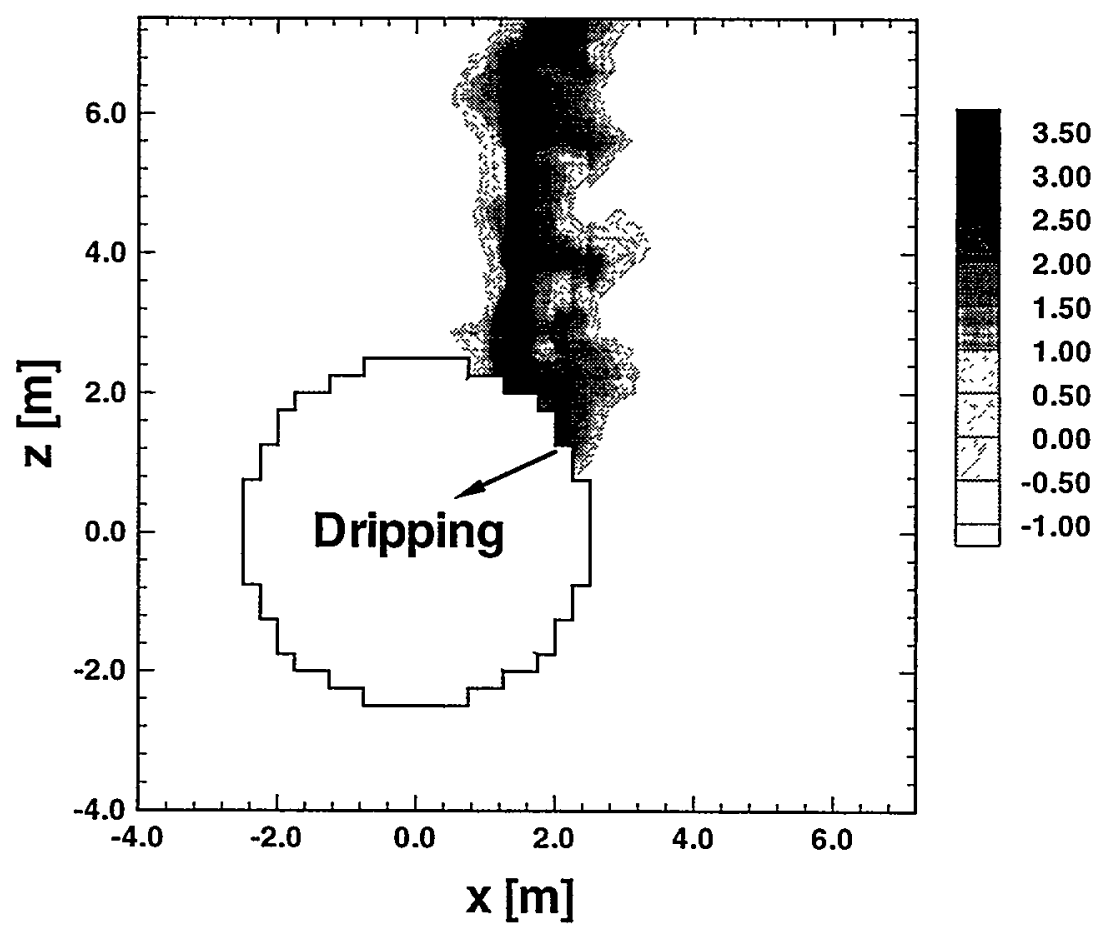

Figure 34 Increase of flux magnitude compared to initial situation in the $\mathrm{XZ}_{-} 1$ plane for a $2800 \mathrm{~mm} / \mathrm{yr}$ pulse immediately after dripping starts (in $\log _{10} \mathrm{~mm} / \mathrm{yr}$ ) 


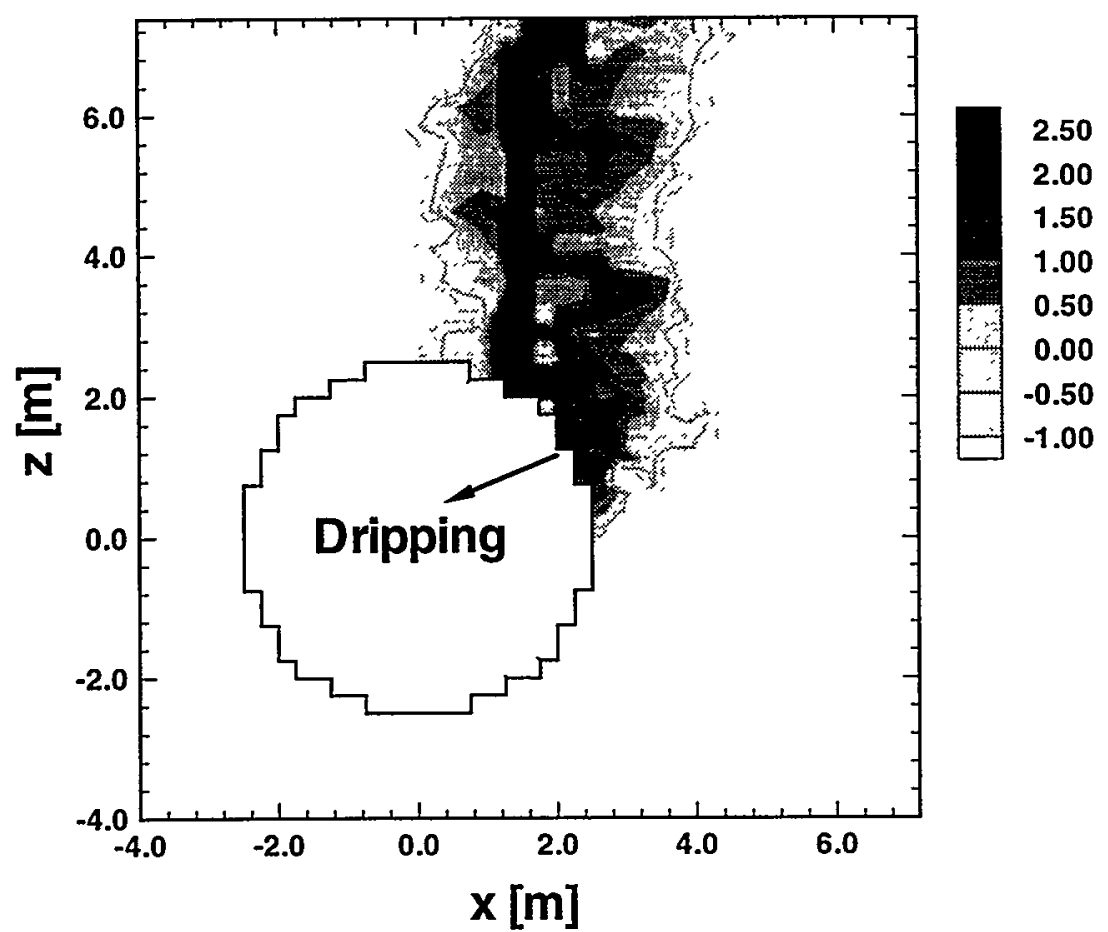

Figure 35 Increase of flux magnitude compared to initial situation in the $\mathrm{XZ}_{-} 1$ plane for a $280 \mathrm{~mm} / \mathrm{yr}$ pulse immediately after dripping starts (in $\log _{10} \mathrm{~mm} / \mathrm{yr}$ )

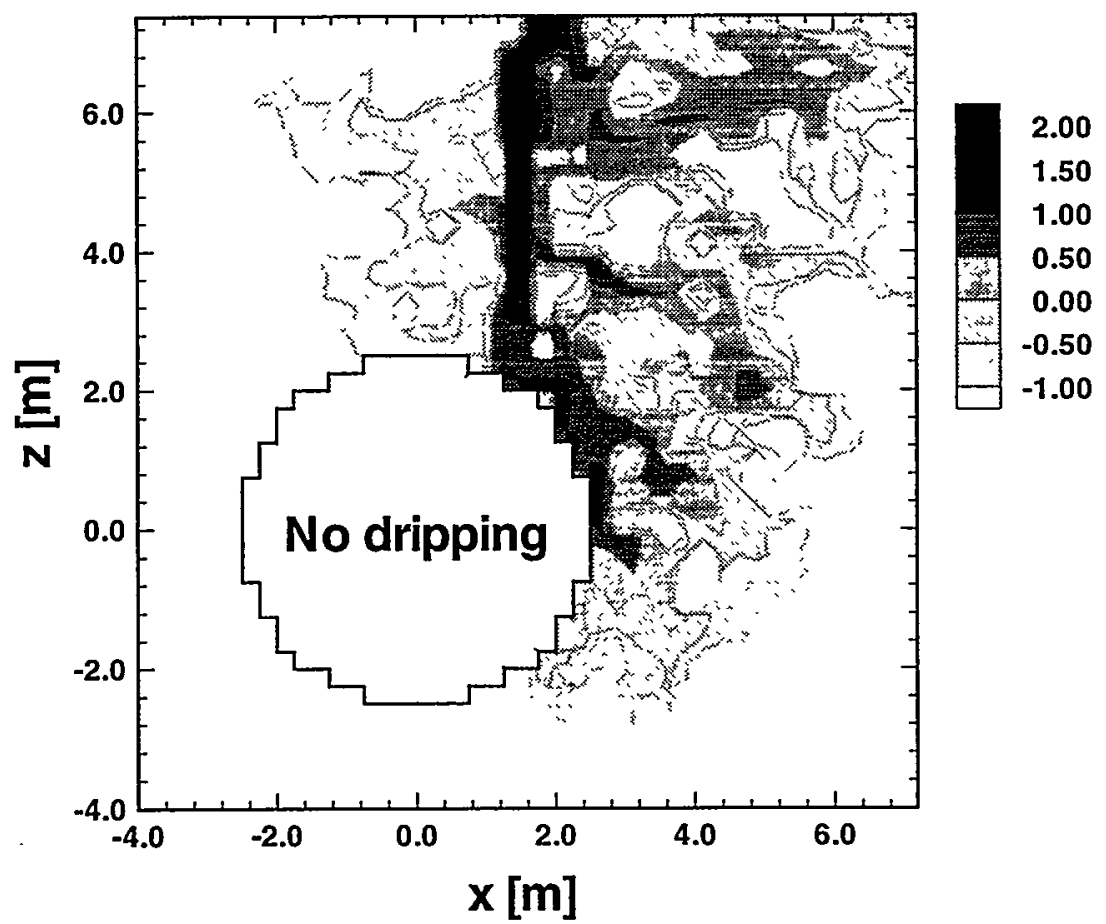

Figure 36 Increase of flux magnitude compared to initial situation in the $\mathrm{XZ}_{-} 1$ plane for a $28 \mathrm{~mm} / \mathrm{yr}$ pulse after 10000 days (in $\log _{10} \mathrm{~mm} / \mathrm{yr}$ ) 
Summary and Discussion

Based on the Stochastic Continuum Model of the fracture-porous medium, we have generated a three-dimensional block with a heterogeneous distribution of permeabilities representing the portion of the Topopah Spring welded unit just above the drift level. Model parameters are obtained by reviewing results of recent experiments in the ESF and by reviewing the development of the LBNL/USGS Site-Scale Model. Vertical cross sections are taken from the block along the axis of the drift and normal to it. Flow under gravity through the flow domain is simulated for the condition before the construction of the drift, considering steady-state net infiltration (Scenario 1) as well as episodic pulse infiltration (Scenario 2). Other simulations involved the condition after the drift emplacement, assuming two different scenarios. First, we studied the early-stage behavior for a ventilated drift without the presence of waste canisters, imposing a steady-state net infiltration (Scenario 3). Secondly, we studied the long-term behavior after the drift is closed and sealed, and the waste canisters have cooled off, both for constant net infiltration and episodic pulse infiltration (Scenario 4). Below we present discussions of a number of issues that emerge from a study of our simulation results.

\subsection{Flow Variations and Variation of Inflows into the Drift}

Results of our preliminary modeling studies show a strong variation of fluid fluxes through the medium, the variation being as large as several orders of magnitude for cases with steady-state net infiltration (Scenario 1: Tables 3, 5 and 6; Figure 17). This implies that the age of water at different parts of the flow domain can be very different.

The emplacement of the drift imposes an equivalent suction pressure at the boundary of the flow domain where it is intercepted by the drift (Scenario 3). With a relative humidity of $50 \%$ in the drift, the equivalent suction pressure corresponds to $-93.1 \mathrm{MPa}$ (Equation 3). This value is very large compared to the suction pressures in the rock medium. Inflow rates into the drift are calculated which show strong variations along the drift walls (Figure 30). These inflows evaporate and cause a local temperature drop that can be measured by infra-red cameras, thus affording a possible direct comparison between our modeling results and field observation. Additional simulation runs have been performed with other relative humidity levels in the drift. However, the results are not very sensitive to the actual value of relative humidity, provided that it is larger than or comparable in magnitude with the capillary suction in the formation.

\subsection{Infiltration Flux and Pulse Infiltration}

The average infiltration flux through the flow domain in our calculations turns out to be very small, ranging from $0.014 \mathrm{~mm} / \mathrm{yr}$ to $0.021 \mathrm{~mm} / \mathrm{yr}$ for the reference cases with steady-state net infiltration (Scenario 1), which corresponds to the low end of the range used in mountain scale model. Given the matrix permeability that we assumed for our model taken from the best estimates from a number of experiments and modeling studies, an infiltration flux much higher than the above given range would give rise to matrix saturations very close or equal to 1 . However, 
the calculated percolation flux is sensitive to the assumed value of the matrix permeability. In a sensitivity study (Table 5) we showed that if the matrix permeability is increased by a factor of 10 , the infiltration flux is also increased by about a factor of 10 . There may be a good reason for larger matrix permeability values to be used in our model. The grid element used in our calculation is of dimension $25 \mathrm{~cm}$. If the matrix permeability of $5 \times 10^{-18} \mathrm{~m}^{2}$ is measured on samples much smaller than this, then the grid element in our calculation is large enough to contain both the matrix and small fractures which would then increase the permeability on the $25 \mathrm{~cm}$ scale.

In all steady-state reference cases, the flow predominantly occurs through the low permeability matrix areas. Saturation values in the fractures are very close to the residual saturation, and high permeability features are essentially non-conductive. However, even for a fully saturated case, when fracture areas are conductive, the maximum percolation flux through the system is limited to $3.81 \mathrm{~mm} / \mathrm{yr}$. This is mainly a result of the geometry of the fracture network, i.e. the cases studied did not feature a through-going fracture area from the top to the bottom. Then, fast flow in the fractures is blocked by low permeability matrix areas, thus limiting the total infiltration rate.

A very different picture emerges if through-going high permeability features exist which allow for episodic, rapid water flow through the domain (Scenario 2). We studied cases in which the infiltration is composed of a large infiltration pulse for a limited time period and a low rate for the rest of the year, so that the average over the year remains at small values in the range of a few $\mathrm{mm} / \mathrm{yr}$ or lower. We show in Figures 21 and 22 that when such a large flow is imposed on the upper boundary of the flow domain, the flow will seek out the large permeability flow path, rather than avoiding it because of its low capillary pressure as in the low infiltration case. Thus, if a connected large permeability flow path exists, it will allow a large flow through the system, largely bypassing the matrix. The portion of the flow that imbibes into the matrix will still leave it in an unsaturated condition. This behavior is illustrated by Figure 20.

\subsection{Flow into a Sealed Drift and Impact of Pulse Infiltration}

When the drift is closed and sealed, and the waste canisters have cooled off, the relative humidity in the drift comes into equilibrium with the moisture in the rock (Scenario 4). Then the humidity in the drift is $100 \%$, by definition. Equation 3 indicates that the drift boundary represents a zero capillary suction condition, so that there will be no flow from the rock into the drift. Basically, the flow in the rock under gravity will circle around the drift, leaving the drift at $100 \%$ humidity without inflow of water.

However, the situation changes when there is a strong pulse infiltration of a short duration. As is explained above, the flow will seek a connected large permeability flow path. If the drift intercepts the flow path and there is no alternative large permeability flow path leading it away from the drift, the saturation will build up to 1 at the drift wall and water will drip into the tunnel (Figures 33 to 35). As the magnitude of the infiltration pulse decreases the saturation build-up at the drift is less likely to reach 1 , and flow will circle around the drift (Figure 36). Note that phenomena like local ponding can not be studied on larger scales. 
Both this result and the discussion in the previous subsection point to the critical role played by infiltration pulses at Yucca Mountain. Within our model, it is no longer reasonable to only consider an average infiltration over the site, but a careful study of historical and projected future infiltration pulses and their sizes and frequency is important. Potentially, the hydrogeologic system at Yucca Mountain is not of steady state nature; it may be a dynamic and cyclic system.

\subsection{Sensitivity Studies}

In this report, the results of a number of sensitivity studies have been presented (Tables 5, 6 and 7). Though a systematic sensitivity investigation is not yet done, one can already see that some of the conclusions are highly sensitive to a variety of parameters. For example, in the steady-state case the percolation flux is directly affected by the matrix permeability. More careful field determination of the representative matrix permeability is important. Also the appropriate permeability value to be used for a calculational grid element, based on permeability measurements on samples very different in size than the grid element, needs to be determined. The percolation flux is also sensitive to van Genuchten parameters, $1 / \alpha$ and $\beta$. A "not unreasonable" change of these parameters may change the percolation flux by a factor of two or more. The percolation flux is also sensitive to the boundary conditions. A higher overall saturation in the model domain (i.e. smaller value of capillary suction at the boundaries) can give rise to an increase in percolation fluxes by one or two orders of magnitude.

The existence of transient fast flow paths along high permeability features is sensitive to infiltration pulse size and duration. If the pulse is small, the flow along such features can be strongly retarded or completely stopped because of matrix imbibition. Even if the pulse is sufficiently large, it still requires sufficient duration in order to penetrate through the unsaturated system for a significant distance. Thus pulse characteristics as well as fracture and matrix parameters are important data for PA.

\subsection{Discussion of the Stochastic Continuum Model Used}

The simulations presented in this study are based on the Stochastic Continuum Model (SCM), using a number of different scenarios and conditions. The Stochastic Continuum Model is different from the Effective Continuum Model (ECM) or the Double Porosity/Permeability Model (DKM). Both the ECM and DKM are intrinsically homogeneous, meaning that the properties in one model grid block are averaged over a large number of fractures and matrix blocks. Many of the phenomena described in the results above related to fast paths and flow variations in discrete features are not captured in these models. (It is however possible to impose special features, such as a discrete fault zone, into the ECM or the DKM.) The SCM, on the other hand, is intrinsically a heterogeneous model, which allows to represent the spatial variation of hydraulic permeabilities on the scale of single fracture zones or matrix blocks. The high permeability fracture zones are made distinct from the matrix by imposing a long range correlation structure in specified directions. In the present preliminary modeling studies, we have not yet explored the full flexibility of the model by adjusting the correlation structure and performing conditioning to specific field observations. However, the results presented in this report have demonstrated that 
the SCM is a good alternative model potentially capable of describing heterogeneous flow and transport variations at Yucca Mountain on the drift scale.

\section{$8 \quad$ Future Studies}

As already referred to in our presentation on the preliminary modeling results and in our discussions of their implications, a number of studies are suggested for the coming year:

1. Systematic evaluation of the effects of episodic pulse infiltration

2. Sensitivity analysis of the SCM

a. conditioning to observed fractures and other ESF data

b. dependence on correlation lengths

c. dependence on multiple realizations

3. Continue to monitor the most recent and dependable field data, including calibration results from the Site-Scale Model, in order to update input parameters.

4. Continue to include the most recent findings of laboratory scale studies and mountain scale studies to improve input for drift scale modeling.

5. Study of dependence on numerical grid size and weighting schemes

\section{Recommendations for Performance Assessment}

Based on insights obtained by examining the results of the many simulations at the drift scale using the Stochastic Continuum Model, we suggest the following issues or elements which should be included or addressed in the performance assessment (PA) of the potential repository at Yucca Mountain:

1. Take into account in PA the spatial heterogeneity for flow and transport processes, in particular for the Topopah Springs welded tuff at the potential repository level. For example, the inflows at the drift walls are different from location to location, with the largest inflow area having a flow rate several times the average. Thus, it is important to predict not only the average flow, but also the flow variation, which can be expressed, for example, as the ratio of maximum flow to average. Often the "extreme" values are associated with unusual field observations or even with performance measures.

2. Quantify pulse and episodic infiltration in PA, rather than simply assuming an average infiltration rate. Large infiltration pulses have been shown in this and other studies to mainly go through connected fractures. If such fast paths along connected high permeability features extend 100's of meters from the ground surface to the repository horizon, then episodic large infiltration may allow the infiltrated water to flow to the repository horizon with large velocity, leading to travel times much shorter than average. However, whether an infiltration pulse injected at the ground surface will actually arrive at the repository horizon without being retained by matrix imbibition, depends on a variety of parameters (e.g. pulse volume and duration, imbibition rate, fracture permeability, fracture connectivity etc.) of which some are not very well constrained at the present stage. Therefore, determination of these properties and 
further studies of episodic pulse flow phenomena should receive high priority in PA. This may lead to conclusions different from those obtained using an average infiltration rate when flow predominantly occurs through the matrix.

3. The above two points lead to the need of identifying connected high permeability features (fractures or faults) and estimating the spatial density of these features (e.g. the number of vertically connected features, longer than a certain length, per volume of rock). This is an important input for PA, and can only be obtained by field observations involving areal surveys. It is also recommended that PA includes sensitivity studies on the presence of connected features and on their density or average spatial separation.

4. The heterogeneity of the fractured porous rock gives rise to local areas of high or low saturations and hence low or high capillary suction. For example, we have seen in our studies that fast flow in high permeability features may be blocked by low permeability matrix zones, giving rise to a localized increase in saturation and even local ponding. Further, our results show that local ponding near a sealed drift makes it more likely for water to enter the drift (assuming that the waste canisters have already cooled off, and the relative humidity in the drift returns to $100 \%$ ). Thus, the degree of heterogeneity and its spatial correlation length should be studied further especially with regard to their impact on the canister environment.

5. Our calculations show the sensitivity of flow and transport results on parameters such as matrix and fracture permeabilities and van Genuchten parameters. Obtaining representative values of these parameters for model grid blocks with size different from samples (or scales on which measurements were made) is a challenge to PA.

\section{Quality Assurance Status of Data and Software Used in this Report}

The rock properties and geologic data used in the model simulations are in part not qualified. The simulation code TOUGH2 is qualified under a Quality Assurance Program. The geostatistical library GSLIB is in the process of being qualified.

\section{Acknowledgments}

This work was supported by the U.S. Department of Energy, Office of Civilian Radioactive Waste Management, Yucca Mountain Project, through U.S. Department of Energy Contract Number DE-AC03-76SF00098. Review and comments of C. Doughty and J. Fairley from Berkeley Laboratory and of S.J. Altman and S.A. McKenna from Sandia National Laboratory are gratefully acknowledged. We are particularly grateful to K. Pruess and S. Finsterle for making TOUGH2 available to the authors and providing guidance in the use of this code. 


\section{References}

Altman, S.J., B.W. Arnold, C.K. Ho, S.A. McKenna, R.W. Barnard, G.E. Barr, R.R. Eaton, in press. Flow Calculations for Yucca Mountain Groundwater Travel Time (GWTT-95), Sandia National Laboratories, Albuquerque, NM.

Altman, S.J., B.W. Arnold, C.K. Ho, S.A. McKenna, R.W. Barnard, G.E. Barr, R.R. Eaton, in press. Flow Calculations for Yucca Mountain Groundwater Travel Time (GWTT-95), Sandia National Laboratories, Albuquerque, NM.

Bodvarsson, G.S., T.M. Bandurraga (editors), in progress. Development and Calibration of the Three-Dimensional Site-Scale Unsaturated Zone Model of Yucca Mountain, Yucca Mountain Project Milestone.

Deutsch, C.V., A.G. Journel, 1992. GSLIB - Geostatistical Software Library and User's Guide, Oxford University Press, New York Oxford.

Edlefsen, N.E., A.B.C. Anderson, 1943. Thermodynamics of soil moisture, Hilgardia, 15, 31298.

Endo, H.K., J.C.S. Long, C.R. Wilson, P.A. Witherspoon, 1984. A model for investigating mechanical transport in fracture networks, Water Resour. Res., 20, 1390-1400.

Fairley J., E. Sonnenthal, in progress. Preliminary conceptual models of flow pathways based on ${ }^{36} \mathrm{CL}$ and other environmental isotopes, Chapter 10 in Development and Calibration of the Three-Dimensional Site-Scale Unsaturated Zone Model of Yucca Mountain, Bodvarsson \& Bandurraga (editors), Yucca Mountain Project Milestone.

Finsterle, S., K. Pruess, 1995. Solving the estimation-identification problem in two-phase modeling, Water Resour. Res., 31, 913-924.

Flint, A.L., J.A. Hevesi, L.E. Flint, in review. Conceptual and numerical model of infiltration for the Yucca Mountain area, Nevada, U.S. Geological Survey Water Resources Investigation Report 96-xxxx, U.S. Geological Survey, Denver, CO.

Gerke, H.H., M.T. van Genuchten, 1993. A dual-porosity model for simulating the preferential movement of water and solutes in structured porous media, Water Resour. Res., 29, 305-319.

Gómez-Hérnández, J.J., R.M. Srivastasva, 1990. ISIM3D: An ANSI-C three dimensional multiple indicator conditional simulation program, Computers and Geosciences, 16(4), 395-440.

Leverett, M.C., 1941. Capillary behavior in porous solids, AIME Trans., Vol. 142.

Mitchell, A., Memorandum, 1996. Borehole Videos from the Exploratory Studies Facility Thermal Testing Facility (TTF) - Thermomechanical Alcove (TMA), LA-EES-13-LV-05-96021, dated May 21.

Mualem, Y., 1978. A new model for predicting the hydraulic conductivity of unsaturated porous media, Water Resour. Res., 12, 513-522. 
Nitao, J.J., T.A. Buscheck, 1991. Infiltration of a liquid front in an unsaturated fractured porous medium, Water Resour. Res., 27, 2099-2112.

Nitao, J.J, T.A. Buscheck, D.A. Chesnut, 1992. The implications of episodic non-equilibrium fracture-matrix flow on site suitability and total system performance, Proceedings of the Third High-Level Radioactive Waste Management Conference, Las Vegas, NV, 279-296.

Pruess, K., TOUGH user's guide, 1987. Lawrence Berkeley Laboratory report LBL-20700, Berkeley, CA.

Pruess, K., J.S.Y. Wang, Y.W. Tsang, 1990. On the thermohydrologic conditions near high-level nuclear wastes emplaced in partially saturated fractured tuff, part 2 . Effective continuum approximation, Water Resourc. Res., 26, 1249-1261.

Pruess, K., 1991. TOUGH2 - A general-purpose numerical simulator for multiphase fluid and heat flow, Lawrence Berkeley Laboratory report LBL-29400, Berkeley, CA.

Schwartz, F.W., L. Smith, 1988. A continuum approach for modeling mass transport in fractured media, Water Resour. Res., 24, 1360-1372.

Tsang, Y.W., C.F. Tsang, F.V. Hale, B. Dverstorp, in print. Tracer transport in a stochastic continuum model of fractured media, Water Resour. Res.

Tsang, Y.W., J. S. Y. Wang, B. Freifeld, P. Cook, R. Suárez-Rivera, T. Tokunaga, 1996. Letter report on hydrological characterization of the single heater test area in the ESF, Level 4 milestone for WBS 1.2.3.14.2, YMP.

Van Genuchten, M.T., 1980. A closed-form equation for predicting the hydraulic conductivity of unsaturated soil, Soil Sci. Soc. Am. J., 892-898.

Wang, J.S.Y., T.N. Narasimhan, 1986. Hydrologic properties governing partially saturated fluid flow in fractured welded units and porous non-welded units at Yucca Mountain, Rep. SAND85-7114, Sandia National Laboratory, Albuquerque, NM.

Wilson, M.L., J.H. Gauthier, R.W. Barnard, G.E. Barr, H.A. Dockery, E. Dunn, R.R. Eaton, D.C. Guerin, N. Lu, M.J. Martinez, R. Nilson, C.A. Rautman, T.H. Robey, B. Ross, E.E. Ryder, A.R. Schenker, A.J. Shannon, L.H. Skinner, W.G. Halsey, J. Gansemer, L.C. Lewis, A.D. Lamont, I.R. Triay, A. Meijer, D.E. Morris, 1994. Total system performance assessment for Yucca Mountain - SNL second iteration (TSPA-1993), Rep. SAND93-2675, Sandia National Laboratories, Albuquerque, NM.

Wittwer, C., G. Chen, G.S. Bodvarsson, M. Chornack, A. Flint, L. Flint, E. Kwicklis, R. Spengler, 1995. Preliminary development of the LBL/USGS three-dimensional site-scale model of Yucca Mountain, Nevada, Lawrence Berkeley Laboratory report LBL-37356, Berkeley, CA.

Zimmerman, R.W., T. Hadgu, A. Niemi, J. Wan, G.S. Bodvarsson, 1996. Summary report of LBNL work on modeling fluid flow in unsaturated fractured rocks at Yucca Mountain, Nevada, Yucca Mountain Project Milestone 3GLS101MM. 